\title{
Review Article \\ Functionalized Activated Carbon Derived from Biomass for Photocatalysis Applications Perspective
}

\author{
Samira Bagheri, Nurhidayatullaili Muhd Julkapli, and Sharifah Bee Abd Hamid \\ Nanotechnology \& Catalysis Research Centre (NANOCAT), University of Malaya, IPS Building, 50603 Kuala Lumpur, Malaysia \\ Correspondence should be addressed to Nurhidayatullaili Muhd Julkapli; nurhidayatullaili@um.edu.my
}

Received 20 March 2014; Revised 7 July 2014; Accepted 8 July 2014

Academic Editor: Jimmy C. Yu

Copyright ( 2015 Samira Bagheri et al. This is an open access article distributed under the Creative Commons Attribution License, which permits unrestricted use, distribution, and reproduction in any medium, provided the original work is properly cited.

\begin{abstract}
This review highlighted the developments of safe, effective, economic, and environmental friendly catalytic technologies to transform lignocellulosic biomass into the activated carbon (AC). In the photocatalysis applications, this AC can further be used as a support material. The limits of AC productions raised by energy assumption and product selectivity have been uplifted to develop sustainable carbon of the synthesis process, where catalytic conversion is accounted. The catalytic treatment corresponding to mild condition provided a bulk, mesoporous, and nanostructure AC materials. These characteristics of AC materials are necessary for the low energy and efficient photocatalytic system. Due to the excellent oxidizing characteristics, cheapness, and long-term stability, semiconductor materials have been used immensely in photocatalytic reactors. However, in practical, such conductors lead to problems with the separation steps and loss of photocatalytic activity. Therefore, proper attention has been given to develop supported semiconductor catalysts and certain matrixes of carbon materials such as carbon nanotubes, carbon microspheres, carbon nanofibers, carbon black, and activated carbons have been recently considered and reported. AC has been reported as a potential support in photocatalytic systems because it improves the transfer rate of the interface charge and lowers the recombination rate of holes and electrons.
\end{abstract}

\section{Introduction}

Increasing environmental problems and the need for competitive and cost-effective products are becoming two major principles in modern material research [1-4]. Former developed routes to get a periodic porous carbon network were successful, but they did not take into account any criteria of sustainability [5-7]. For the last 20 years, countless laboratories of research institution have done some indepth researches on the conversion of biomass to carbon based materials without using the catalysts $[5,8,9]$. Studies of such researches have covered many model carbon material compounds, for example, methanol, lignin, glucose, cellulose, and some real biomass compounds [10-12]. As prosperous demonstrations were accumulated, kinetics, thermodynamics, and detailed reaction mechanism have created a solid base for subsequent researches [13-15]. However, in order to enhance the selectivity of carbon material manufactures, immense activation energy is necessary for the reaction without the use of catalyst. The excessive cost of tools and operations has undoubtedly become the biggest hindrance to the formulation of this technology [15].

Hence, the main problem of carbon synthesis under sustainable conditions was currently revisited and executed by several terms, where catalytic treatment of biomass through either heterogeneous or homogeneous catalytic approach corresponding in mild condition provided a bulk, mesoporous, and nanostructure carbon materials [16-18]. Catalytic effects of homogeneous catalyst, especially ionic liquid on the biomass conversion, have been established by many of the open literature. The main characteristics of this catalytic technique are to have a conversion system with minimal energy to confirm the high yield of carbon materials [18-20]. If we compare homogeneous catalysts with heterogeneous catalysts, heterogeneous catalysts have the advantages of being highly selective, recyclable, and environmentally friendly $[19,21]$. Heterogeneous catalysts have the advantages of being highly selective; therefore, heterogeneous catalyst with the ample range of solid acid, ion exchange resin, metal oxide, and zeolite has become a research hotspot in this 
field [21]. Both techniques have been explored substantially, with the need for creating cheap and sustainable ways to obtain chemicals and carbon from raw materials other than natural gas or crude oil that could lead to a reexploration of this area. In addition, the implementation of low-priced pathway to recycle the products of farmed biomass would furthermore represent a way to sequester particular amount of $\mathrm{CO}_{2}$ creating a material advantaged at the same time $[22,23]$.

This paper will not debate on the preparation of the catalyst, but instead it would focus primarily on the use of the catalyst to bring out carbon based materials through the conversion process of biomass, which can be additionally used as a photocatalyst.

Various published papers and examined articles have indicated the theory and environmental supplication of heterogeneous photocatalysis by the employment of semiconductors $[24,25]$. One of the biggest drawbacks of using these semiconductors is the power necessity because of the utilization of ultraviolet light [26]. However, upgrading the photocatalytic reactors may upgrade reaction rate and hence downgrade the time of residence and minimize consumption of energy per unit of volume being treated. It is accepted that this might be accomplished by depositing the photocatalyst on a high surface product that will particularly absorb the polluted molecules and will fixate them around the photocatalyst [26-28]. Lamentably, active absorption of pollutant lowers the diffusion rate into semiconductor powder, which may thus hinder the activeness of the photocatalyst. Such drawback has assisted various researchers to find any worthy initiative of semiconductor for the operation of some particular pollutants or try to formulate the latest techniques of deposition $[29,30]$. The $\mathrm{pH}$ of the solution, the support, and the kind of pollutant play a significant role in the accomplishment of photocatalytic process.

Various efforts have announced utilization of activated carbon (AC) as a platform for the semiconductor but it has been cautioned that effective absorption of pollutants into the absorbent area may hinder diffusion into the catalyst and thus may affect the entire process [31,32]. AC acts as a brace for the titanium oxide $\left(\mathrm{TiO}_{2}\right)$ which could give tremendous results over the other mediums [32]. These consist its potential to swiftly absorb pollutants and also its high absorption ability because of its surface area and porosity [31]. As indicated, medium pores AC will make easier the diffusion of pollutants and product discharging from the surface $[32,33]$. Furthermore, high ability to absorb fluid of AC may reduce the penetration of ultraviolet lights into small areas, and it may cause confining of pollutants within the pores without getting able to diffuse into the outer surface for further reaction with the $\mathrm{OH}$ radical of pollutants [34-36]. Additionally, some types of pollutants, for example, phenol, may go through polymerization on the AC's carbon surface, which causes unchangeable absorption $[37,38]$. The general processes involved in semiconductor particles upon bandgap excitation are illustrated in Figure 1.

\section{Activated Carbon}

2.1. Properties of Carbon Materials. Carbon materials technology has made extraordinary progress in current years because of its diversity of physicochemical properties, such as tunable porosity, lightweight, exciting electronic properties, electrical conductivity, chemical and thermal balancing, and the potential to acquire an immense range of morphologies [40-43]. Hence, carbon materials have found a large number of applications in different domains, varying from environmental science [44], absorbent [45], drug delivery [46], catalyst [44], electrode materials [47], stationary phase in the chromatography system [48], energy storage [49], and many others according to its structure, morphology, and chemical properties (Figure 2).

However, for some particular applications, functionalization is essential at controllable size and shape [48, 49]. Nevertheless, the production of such materials usually requires very harsh conditions and has several limits such as extreme temperature of the carbonization process in the first steps up to $>800^{\circ} \mathrm{C}$ and followed by chemical or physical activation to transform carbon materials into activated carbon [4349]. Furthermore, it is significantly important here to explore economical and sustainable ways to get carbon materials from raw materials other than crude oil or natural gas which leads to a reexploration of this field (Table 1; Figure 3 ).

2.2. Conventional Conversion of Biomass to Carbon. The use of biomass extracted products or biomass is becoming vitally significant for the enhancement of effective and environmentally friendly technology and together it solves the issues of agricultural and forestry waste use [5-9]. Different synthetic methods, such as carbonization [56], high-voltagearc electricity [57], laser ablation [58], or hydrothermal carbonization [56], have been disclosed for the preparation of carbonaceous, amorphous, crystalline carbon materials or porous with different sizes, chemical composition, and shape of the biomass feedstocks [56-59].

Moreover, the application of a low-priced pathway to recycle by-products of biomass formed would furthermore represent a way to separate significant amount of $\mathrm{CO}_{2}$ and at the same time a material advantage would also be created.

Biomass conversion is very significant, yet, working with this complex biomass feedstock is challenging, and approaches based on the creation of simpler and more six balanced intermediate derivatives, known as platform molecules, have been shown to be active for efficient biomass conversion into chemicals and fuels [55], catalytic routes consisting deoxygenation, and reaction combined with $-\mathrm{C}-$ C- coupling processes [57]. Biomass conversion to carbon materials through catalytic approach normally begins with hydrolysis of dehydration and cellulose chains $[57,59]$ and is divided into monomer's soluble products that come from the hydrolysis of cellulose [58], condensation or polymerization of the soluble products, aromatization of the polymers hence formed, and growth of the nuclei so created by linkage and diffusion of species from the solution to the nucleus surface 


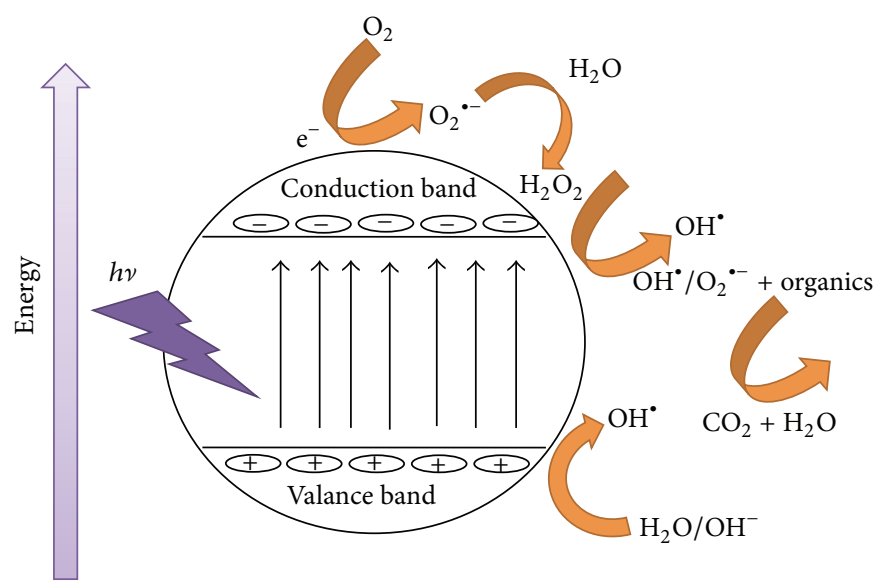

Figure 1: Processes involved in semiconductor particles upon bandgap excitation [39].

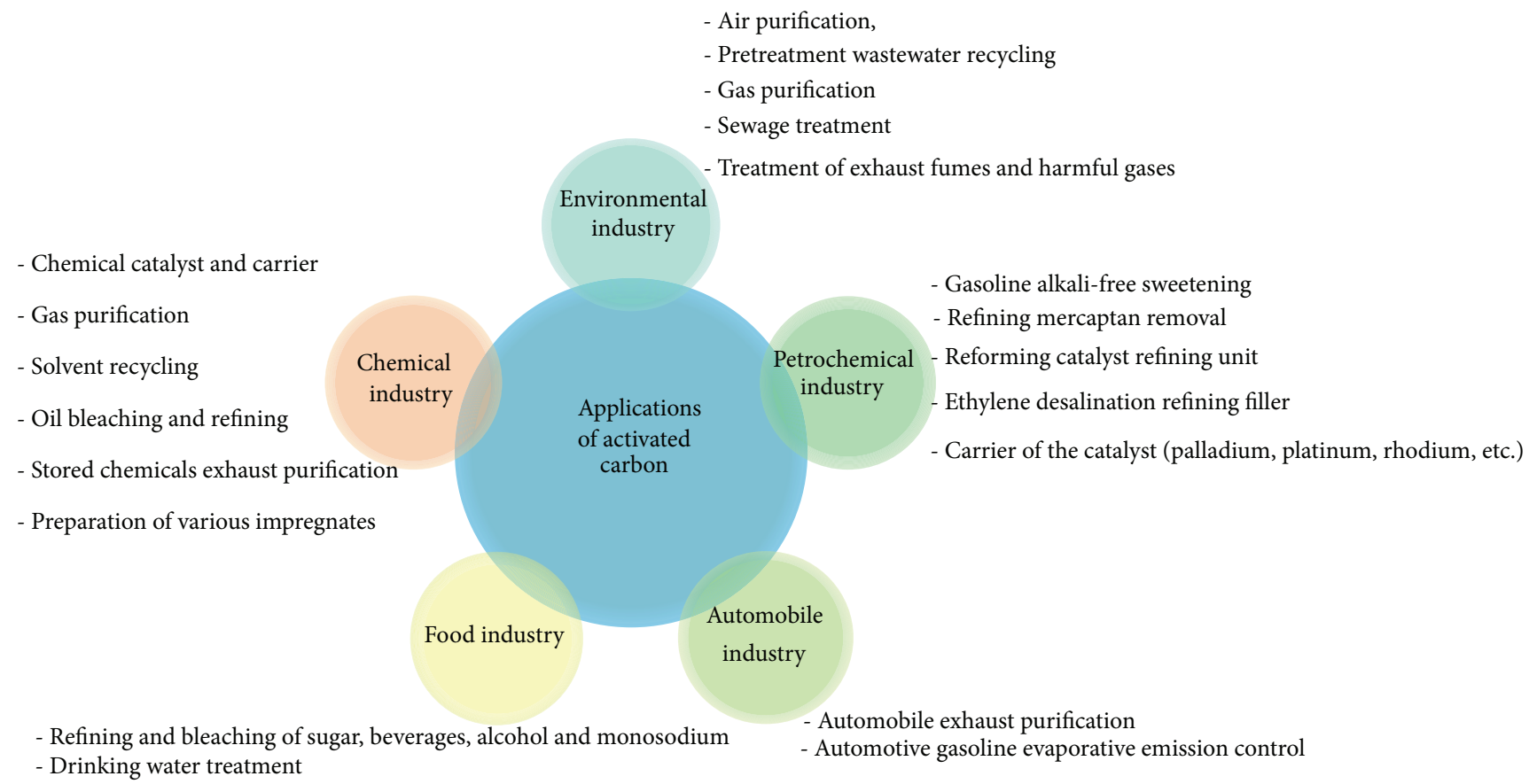

FIGURE 2: General prospective on application of AC.

and finally appearance of short burst of nucleation [56-59] (Figure 4).

2.3. Catalytic Conversion of Biomass to Carbon. Green chemistry, now days, is becoming more and more connected with the catalytic process on biomass conversion to carbon materials. Table 2 shows the list of catalysts corresponding to their category and advantages towards the conversion process of cellulose to carbon based materials.

2.3.1. Homogeneous Catalyst. Convention of sulfuric acid solution and catalyst cellulose hydrolysis into glucose is a time-consuming and well-formulated process [56-58, 6065]. Many large scale segments have been developed, but there are rigid conditions including the treatment and the recycling of the waste sulfuric solutions of acids, which also suffer from the complex separation of products from the solution, the lack of glucose selectivity, toxicity, and high prices which take this process away from the original approach of sustainability [56-58, 60-63].

Thus, the solvents of catalyst as ionic liquids have received enough attention because of their low vapor pressure, stability, and recyclability [62, 62-73]. The kinds of novel green solvent are ionic liquids with relatively less melting point and appear as a crystal in general conditions [64]. Cellulose is balanced via inter- and intramolecular bonds of hydrogen, so that rigid bundles could be created, which makes it difficult to solubilise with common organic solvents and water [16$18,74-79]$. It is important to make solvents for cellulose so as 
TABLE 1: Classification of AC materials.

\begin{tabular}{llll}
\hline Criteria & Particle size & Properties & Applications \\
\hline Powdered AC & $\begin{array}{l}<1.0 \mathrm{~mm} \\
\text { Diameter: } \\
0.15-0.25 \mathrm{~mm}\end{array}$ & $\begin{array}{l}\text { Higher surface area, } \\
\text { extraordinary volume per gram, } \\
\text { and greater purity }\end{array}$ & $\begin{array}{l}\text { As an additive in vessel, waste } \\
\text { water treatment, classifiers, and } \\
\text { gravity filter }\end{array}$ \\
\hline Granule AC & 0.42 to $0.84 \mathrm{~mm}$ & $\begin{array}{l}\text { Suitable for many organic } \\
\text { chemicals, able to improve } \\
\text { taste/odor, and removes chlorine }\end{array}$ & $\begin{array}{l}\text { Vapor and liquid adsorption, } \\
\text { water treatment, deodorization, } \\
\text { separation of components }\end{array}$ \\
\hline Extruded AC & 0.8 to $130 \mathrm{~mm}$ & $\begin{array}{l}\text { Low pressure drop, high } \\
\text { mechanical strength, and low } \\
\text { dust content }\end{array}$ & Gas phase applications \\
\hline Beads AC & 0.35 to $0.8 \mathrm{~mm}$ & $\begin{array}{l}\text { Low pressure drop, high } \\
\text { mechanical strength, and low } \\
\text { dust content }\end{array}$ & Adsorbent for waste water \\
\hline Impregnated AC & 0.8 to $200 \mathrm{~mm}$ & $\begin{array}{l}\text { Porous carbon impregnated with } \\
\text { inorganic materials (iodine, } \\
\text { silver, cations) and } \\
\text { antimicrobial } \\
\text { antiseptic }\end{array}$ & Pollution control and \\
purification of domestic water
\end{tabular}

TABLE 2: Catalytic approach on conversion of cellulose to carbon based materials.

\begin{tabular}{|c|c|c|}
\hline Categories & Types & Advantages \\
\hline Homogeneous & $\begin{array}{l}\text { Ionic liquid } \\
\left(\text { e.g.: }\left[\mathrm{BMIM}^{\mathrm{C}} \mathrm{Cl} ;[\mathrm{EMIM}] \mathrm{Cl} \text { and }\right.\right. \\
\left.[\mathrm{EMIM}] \mathrm{BF}_{4}\right)\end{array}$ & $\begin{array}{l}\text { (i) Low melting point } \\
\text { (ii) Appears as crystal in normal condition } \\
\text { (iii) Acts as template on production of porous carbon structure } \\
\text { (iv) Solvent reaction media } \\
\text { (v) High yield of carbon production }\end{array}$ \\
\hline Heterogeneous & $\begin{array}{l}\text { Solid acid catalyst } \\
\text { (i) Bronsted/Lewis solid acid } \\
\text { (e.g.: } \mathrm{ZrP} ; \mathrm{SiO}_{2}-\mathrm{Al}_{2} \mathrm{O}_{3}, \mathrm{WOX} / \mathrm{ZrO}_{2} \text {, } \\
\text { c- } \mathrm{Al}_{2} \mathrm{O}_{3} \text {,) } \\
\text { (ii) } \mathrm{HPA} \\
\text { (e.g.: } \mathrm{H}_{3} \mathrm{PW}_{12} \mathrm{O}_{46} ; \mathrm{H}_{4} \mathrm{SiW}_{12} \mathrm{O}_{40} \text {; } \\
\mathrm{Cs}_{2.5} \mathrm{H}_{0.5} \mathrm{PW} ; \mathrm{Cs}_{2.5} \mathrm{H}_{0.5} \mathrm{PW}_{2} \mathrm{O}_{40} \text { ) }\end{array}$ & $\begin{array}{l}\text { (i) High catalyst selectivity } \\
\text { (ii) Good separation process } \\
\text { (iii) High promotion on depolymerization of cellulose } \\
\text { (iv) Low formation of soluble oligomer } \\
\text { (v) Low cellulose self-hydrolysis } \\
\text { (vi) Favors direct formation of lactic acid } \\
\text { (vii) High stability }\end{array}$ \\
\hline Heterogeneous & $\begin{array}{l}\text { Ion exchange resin } \\
\text { (e.g.,: Amberlyst; } \mathrm{McM}-41 ; \mathrm{HnbM}_{0} \mathrm{O}_{6} \text {; } \\
\text { mixed oxides; niobic acid; } \\
\text { silica-niobic; niobium phosphate) }\end{array}$ & $\begin{array}{l}\text { (i) High accessibility of saccharides } \\
\text { (ii) Satisfactory reaction rate }\end{array}$ \\
\hline Heterogeneous & $\begin{array}{l}\text { Zeolite } \\
\text { (e.g.: ZSM-5; Beta; Mordenite; } \\
\text { Ferrient; FCC; Al-MCM-42; SBA-15; } \\
\text { Al-MSU-F; MOR) }\end{array}$ & $\begin{array}{l}\text { (i) High selectivity to adsorb molecules } \\
\text { (ii) Good separation process } \\
\text { (iii) Good thermal and hydrothermal stabilities } \\
\text { (iv) Production of porous carbon }\end{array}$ \\
\hline Heterogeneous & $\begin{array}{l}\text { Metal ions } \\
\left(\text { e.g.: } \mathrm{Cr}^{3+} ; \mathrm{Mn}^{2+} ; \mathrm{Fe}^{3+} ; \mathrm{Fe}^{2+} ; \mathrm{Co}^{2+}\right)\end{array}$ & $\begin{array}{l}\text { (i) Good catalyst for ring opening and hydrogenation cellulose } \\
\text { (ii) Require short reaction time } \\
\text { (iii) High yield of glucose } \\
\text { (iv) High turnover amount of catalyst } \\
\text { (v) High activity and selectivity } \\
\text { (vi) Good recyclability } \\
\text { (vii) Easily separable }\end{array}$ \\
\hline Heterogeneous & $\begin{array}{l}\text { Metal oxide } \\
\left.\text { (e.g.: } \mathrm{HnbM}_{0} \mathrm{O}_{6} ; \mathrm{Al}_{2} \mathrm{O}_{3}\right)\end{array}$ & $\begin{array}{l}\text { (i) Green process } \\
\text { (ii) Nonvolatility } \\
\text { (iii) Highly stable } \\
\text { (iv) Nontoxic } \\
\text { (v) Reusability } \\
\text { (vi) Low cost }\end{array}$ \\
\hline
\end{tabular}




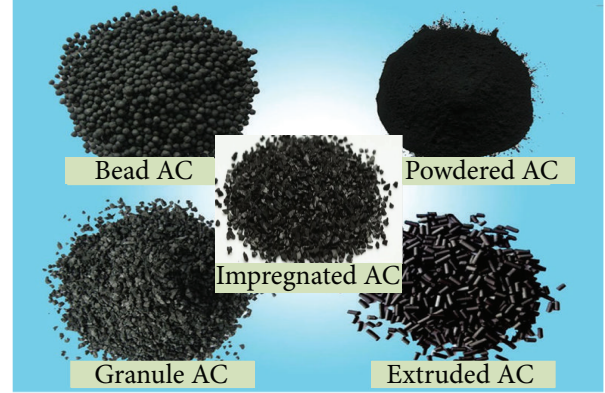

Figure 3: Classification of AC materials.

to initiate a system of minimal efficiency to confirm greater yield of carbon materials in the conversion of biomass [1720]. Ionic liquids have significant roles; it acts both as a soft template to formulate the characterized pore structuring for the development of a hierarchical porous carbon structure and as a catalyst which results in enhanced ionothermal carbon yields [64-66, 71-79]. Thus, it has been demonstrated that in the presence of an acid catalyst, the utilization of ionic liquids, can embrace the efficiency of the hydrolysis of glucose cellulose [66, 67, 80-84].

2.3.2. Heterogeneous Catalyst. The utilization of heterogeneous catalysis along with an immense range of designs is less expensive and extraordinarily stable at high temperature [85-88]. They are believed to upgrade catalyst characteristics and process conditions to get high yields of hydrocarbons while minimizing coke development in the wide range of reaction conditions [86-88]. This method has the benefit of being very economical and mild if we follow some rules of green chemistry since it does not add organic solvent $[85,86]$ with resulting carbon, which is spherically shaped and the surface is decorated with oxygenated functional groups [86]. This method also involves simple reaction mechanisms for the creation of carbon, which involves the dehydration of carbohydrate into a furan like molecules, mainly 5-(hydroxymethyl)-2-furaldehyde as an initial step and further polymerization and carbonization as the next step [89-92]. This reaction possesses high potential for the catalytic improvement biomass since $-\mathrm{C}-\mathrm{C}$ - coupling takes place with consistent oxygen removal (the reaction involves the dispatchment of $\mathrm{CO}_{2}$ and $\mathrm{H}_{2} \mathrm{O}$ ) from carboxylic acids $[89,90]$, and the latter of which are mutual intermediates in the process of biomass conversion [91, 92]. If we compare homogeneous catalysis, carbon materials obtained through a heterogeneous catalytic process consist of an aromatic core containing polyfuran-type units which is surrounded by oxygen rich polar functional groups such as $\mathrm{COOH},-\mathrm{OH},-$ $\mathrm{C}-$, and -O-, which makes the materials more hydroscopic, hydrophilic, and have a lesser degree of graphitisations [93, 94]. These functional surface groups could act as a premier binder and depositor to promote and stabilize the carbon to form nanocables [95-98], a novel carbon-encapsulated core-shell composite, and hybrids. Moreover, heterogeneous catalysts are easy to recover and reuse $[96,97]$ (Figure 5).
Nevertheless, the effective exploitation of cellulose is a main challenge in heterogeneous catalysis application, since cellulose itself has a tough, mainly crystalline, chemically stable, and water insoluble characteristics, which are induced from the intra/intermolecular hydrogen bonds [99-101]. The most commonly used heterogeneous catalysts for the conversion of biomass are alkali salts $[76,102,103]$, metals $(\mathrm{Ni}$, $\mathrm{Rh}, \mathrm{PT}, \mathrm{Ru}, \mathrm{Pd}$, Ir, and Ag) [104-106], metal oxides $\left(\mathrm{CeO}_{2}\right.$, $\mathrm{ZrO}_{3} \mathrm{TiO}_{2}$, and $\mathrm{Al}_{2} \mathrm{O}_{3}$ ) $[107,108]$ usually on supports, and metal oxide catalysts at medium temperatures $\left(300\right.$ to $425^{\circ} \mathrm{C}$ ) which involves deoxygenation reaction combined with $-\mathrm{C}-$ C- coupling processes [109].

(1) Solid Acid Catalyst. Transformation of cellulose to water soluble sugars via solid acid catalysts has received much attention in these years as a solution to remove mineral acids in the formulation of furfural which is easily recovered from the reaction mixture, reused without losing the activity, and minimized the posttreatment cost [75, 110-113]. Solid acid catalysts are basically a Bronsted or Lewis acid $[113,114]$ and it is of various types such as Vanadyl phosphate, $\mathrm{ZrO}_{2}$, zeolites, inorganic oxides, and ion exchange resins.

(1.1) Bronsted or Lewis Solid Acid Catalyst. These series of catalysts include $\mathrm{WO}_{x} / \mathrm{ZrO}_{2}, \mathrm{C}-\mathrm{Al}_{2} \mathrm{O}_{3}, \mathrm{Zr}-\mathrm{P}, \mathrm{SiO}_{2}-\mathrm{Al}_{2} \mathrm{O}_{3}$, and $\mathrm{HY}$ Zeolite which are used for mainly aqueous phase dehydration of xylose [115-119]. Lewis acid sites lower furfural selectivity through catalyzing a side reaction. In the hot water $\left(190^{\circ} \mathrm{C}\right)$, solid Lewis acids promoted the cellulose depolymerization and lowered the creation of soluble oligomers and polymers as in connection to the cellulose selfhydrolysis which occurred in the familiar conditions [117124]. By contrast, in normal conditions, strong Bronsted solid acid has not improved the extent of the cellulose depolymerization but has affected the product distribution [98, 122, 123]. By comparison, Lewis solid acids were not only potential to upgrade the extent of cellulose depolymerization but also favorable for direct formation of lactic acid, which gives high yield, approximately 30\% [96, 125]. This comparison represents highly potential ways to optimize the conversion of cellulose and stabilize Bronsted acid catalyst which helps to understand the reaction pathways [111].

This also brought an idea for various researchers to study the effect of Bronsted acidities of water soluble heteropoly acid catalyst, known as HPA [112]. This heterogeneous HPA catalyst which is micellar, clean, economical, facile, and environmentally friendly could be recycled via centrifuge $[112,126]$. The exhibited activity for the hydrolysis of polysaccharides comprising disaccharides, starch, and cellulose, is known to be HPA [121, 126]. Tungstophosphoric acids $\left(\mathrm{H}_{3} \mathrm{PW}_{12} \mathrm{O}_{40}\right)$ [119] and tungstosilicious acids $\left(\mathrm{H}_{4} \mathrm{SiW}_{12} \mathrm{O}_{40}\right)$ [109] are the vigorous acids used in the series of HPA catalysts in reaction of hydrocarbons and have been employed, for example, in alkylation, acylation, esterification, dehydration, and isomerization of the ethanol process [127-129]. Salt of acidic cesium $\mathrm{H}_{3} \mathrm{PW}_{12} \mathrm{O}_{40}$ and $\mathrm{Cs}_{2.5} \mathrm{H}_{0.5} \mathrm{PW}_{12} \mathrm{O}_{40}$ $\left(\mathrm{Cs}_{2.5} \mathrm{H}_{0.5} \mathrm{PW}\right)$ with intense acidity is insoluble in organic solvents and water and has meso- and micropores with relatively high surface area $\left(130 \mathrm{~m}^{2} \mathrm{gk}\right)$ [119]. This $\mathrm{Cs}_{2.5} \mathrm{H}_{0.5} \mathrm{PW}$ 


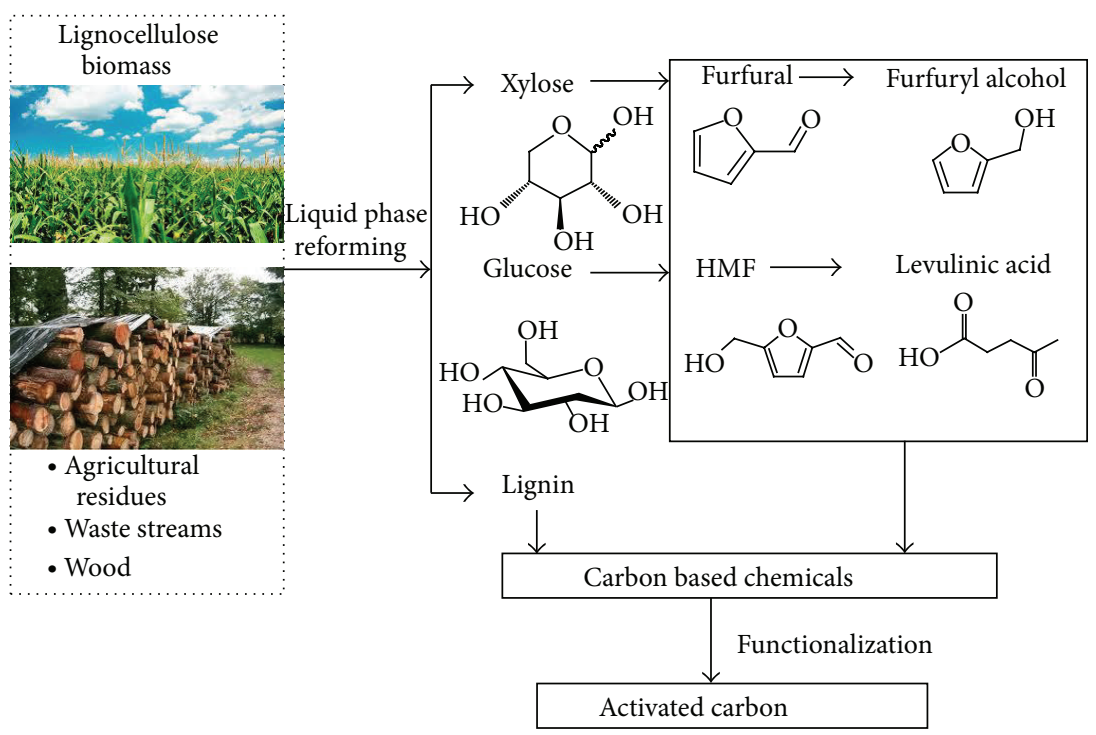

FIGURE 4: The route of AC derived from biomass.

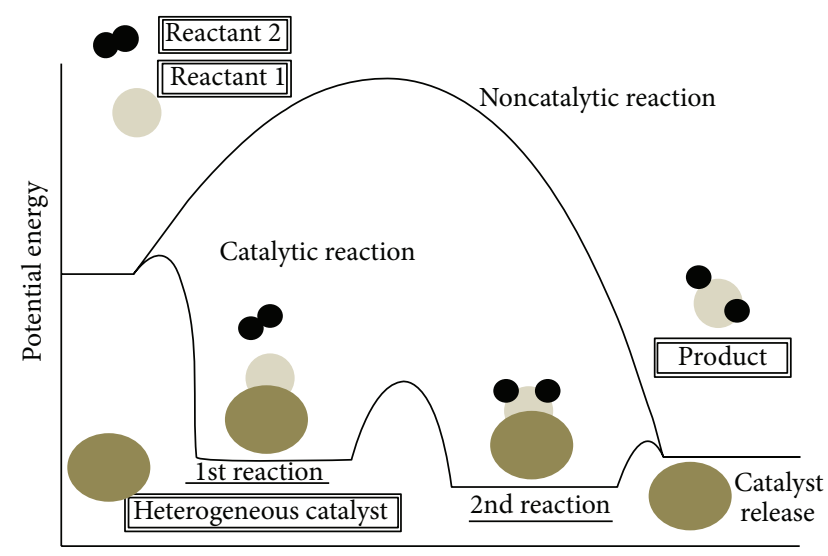

FIGURE 5: Heterogeneous catalytic routes in chemical reaction.

has been described as a solid acid catalyst with prudent and environment friendly specifications and is recommendable in industrial process like hydration of olefins or ester and liquid phase dehydrated alcohol $[130,131]$. Till now, cellulose hydrolysis into saccharides employing a range of HPA catalyst has been researched for capable applications, in contrast to conventional acid-catalyzed reaction, whereas the yield of glucose is less [130-132]. It is because of the insolubility of cellulose in any of the solvents and problems of solid to solid mass transport $[77,133]$. In a few cases, the acidity of mineral acid is lower than that of HPA. For example, $\left(\mathrm{H}_{0}\right)$ of $\mathrm{H}_{5} \mathrm{BW}_{12} \mathrm{O}_{40}\left(0.7 \mathrm{M}\right.$ at $\left.100^{\circ} \mathrm{C}\right)$, the Hammet acidity function, is -2.1 lower than that of $\mathrm{HCl}(0.7 \mathrm{M})$ and $\mathrm{H}_{2} \mathrm{SO}_{4}$. Hence, HPAs have been anticipated to be reusable and active catalyst for the hydrolysis. Along with that theory, amorphous carbon bearing $\mathrm{SO}_{3} \mathrm{H}, \mathrm{COOH}$, and $\mathrm{OH}$ groups had been described to show hydrolysis activity (10\% of glucose yield) for 3 hours at $100^{\circ} \mathrm{C}$. Meantime, Yabushita et al. demonstrated that the cellobiose hydrolysis and cellulose in water assisted by HPAs such as $\mathrm{Sn}_{0.75} \mathrm{PW}_{12} \mathrm{O}_{40}, \mathrm{H}_{3} \mathrm{PW}_{12} \mathrm{O}_{40}$, and $\mathrm{H}_{4} \mathrm{SiW}_{12} \mathrm{O}_{40}$ record total yields of decreasing sugar and it was around $40 \%$ at $200^{\circ} \mathrm{C}$ for 16 hours of reaction [134]. It has been found by Hara that $\mathrm{H}_{5} \mathrm{BW}_{12} \mathrm{O}_{40}$ exhibited a good performance for the transformation of crystalline cellulose to give glucose $77 \%$ yield and various types of HPAs like $\mathrm{H}_{3} \mathrm{PW}_{12} \mathrm{O}_{40}$ (glucose yields $8 \%$ ) and $\mathrm{H}_{4} \mathrm{SiW}_{12} \mathrm{O}_{40}(37 \%)$ which are less active than $\mathrm{H}_{5} \mathrm{BW}_{12} \mathrm{O}_{40}$ [135]. Other research groups also administered the screening of counter cations of $\mathrm{PW}_{12} \mathrm{O}_{40}$ for the cellobiose hydrolysis and they found that there was a volcano-type correlation between Lewis acidities [136-138] and TOFs for glucose formation. They also observed that the acidity and the role of decreasing CrI were the significant factors for the catalytic activity of HPAs [139]. In reality, the $\mathrm{H}_{0}$ role was $\mathrm{H}_{3} \mathrm{PW}_{12} \mathrm{O}_{40}<\mathrm{H}_{4} \mathrm{SiW}_{12} \mathrm{O}_{40}<\mathrm{H}_{5} \mathrm{BW}_{12} \mathrm{O}_{40}$ in a similar order of catalytic activity. The $\mathrm{H}_{0}$ roles were corresponding to the concentration of acids and the number of anions. Hence, HPAs involving highly negatively charged ions are desirable. The anions were dissociated from hydrogen bonding between cellulose molecules to lower the CrI. Moreover, HPAs protons have also exhausted the bonds of hydrogen from cellulose and greater concentration of protons was effective in this role $[135,140]$. Therefore, a strong catalyst for the cellulose hydrolysis is $\mathrm{H}_{5} \mathrm{BW}_{12} \mathrm{O}_{40}$, which was recovered through the extraction and it was recycled for around 10 times [141].

(2) Ion Exchange Resins. Sulfonic acid functionalities of ion exchange resin with solid acid catalyst and sulfonic acid functioned materials resulted in high yield at $63 \%$ and $76 \%$ in pure dimethyl sulfoxide (DMSO) solvent, correspondingly $[142$, 143]. Solid acids such as amorphous carbon materials consisting of $\mathrm{SO}_{3} \mathrm{H}$ groups layered transition $\left(\mathrm{HNbMoO}_{6}\right)$ metal oxide and resin sulfated have been tested for the cellulose hydrolysis, but the yield of glucose is still comparatively less $[144,145]$. It has been hypothesized that side reactions were abolished employing aprotic or organic solvents [146]. Vigorous acidic resins (Amberlite IR-200 and IR-120), niobic 
acid, mixed oxides (silica-zirconia and silica-alumina), silicaniobia, and niobium phosphate created a strong acidity which was protonic and accessibility of simple saccharides to the most effective sites on the surface catalyst allows satisfactory reaction rates to be obtained [147-150].

Sulfonic resins which are acidic are represented in different literatures of active catalyst system for the hydrolysis of starch, cellulose, and disaccharides [151-153]. Generally, the rigid conditions in terms of temperature $\left(>120^{\circ} \mathrm{C}\right.$ temperature in the water and in critical condition) and high concentration of saccharide ( $>100 \mathrm{~g}$ ) were employed to push the catalytic actions of solid acid towards the achievement of high transformations [154-156]. Sulfonated activated-carbon could transform cellulose of amorphous into glucose with $41 \%$ of yield for 24 hours at a temperature of $200^{\circ} \mathrm{C}$ [157]. Such things have been founded by Sun and Zhang demonstrated that p-toluenesulfonic acid can catalyze cellulose hydrolysis in ionic [EMIM] [Cl] system, giving THF yields of $28 \%$ and $13 \%$ and a yield of mono- and disaccharides $10 \%$ and $3 \%$, respectively [158]. Natural bamboo can be converted by a sulfonated biomass char with cotton and starch around 20\% yield of glucose under microwave assistance [159-161]. The process of hydrolysis consisting of starch and cellulose was obtained via layered transition metal oxide, despite the fact that the yield from glucose was less than cellulose. Sulfonated carbon with a mesoporous like structure was used by the groups of Vyver for cellulose hydrolysis getting the yield of glucose around $75 \%$, which is considered to be the highest recorded yield via solid-acid catalyst [162, 163]. Similarly, some interest has been shown in cellulose depolymerization in water because solid supported acid catalysis was used [164166].

Current reports describe the cellulose hydrolysis by solid catalysts such as layered transition metal oxides, Amberlyst resin acid modified amorphous carbon, and sulfonated silica or carbon nanocomposites [167-169]. Also, the depolymerization of cellulose was also considered under catalysis of both $\mathrm{FeCl}_{3}$ and Nafion supported on amorphous silica to be tested on a continuous flow reactor, given the residual that unreacted cellulose can be easily eliminated from the system $[75,170]$. For the conversion of glucose, these surface species which are acidic were quite active [169]. Certainly, we are aware that the hydrolysis rate of cellulose depends on the acid strength. As an expansion on the previous reports on the usage of Nafion as a solid assisted acid catalyst for the transformation of cellulose into glucose and levulinic acid, many researchers have incorporated the reaction with alkali metal salts to embrace the reaction's yield $[171,172]$. Namchot et al. and Klamrassamee et al. have recently formulated carbonbased solid acid with immense density of Bronsted acid sites $\left(\mathrm{SO}_{3} \mathrm{H}\right.$ and $\left.\mathrm{COOH}\right)$ to pyrolytically carbonize sugar, such as cellulose, sucrose, or glucose, and subsequently sulfonate the prepared carbons $[173,174]$. Interestingly, these sulfonated carbon materials are very strong for the microcrystalline cellulose hydrolysis to produce water soluble saccharides with low reaction temperature $\left(100^{\circ} \mathrm{C}\right)$ with the conventional and strong Bronsted acid catalyst such as $\mathrm{H}$-mordenite, niobic acid, and others. The particular surface area of the sulfonated carbon was around $2 \mathrm{~m}^{2} \mathrm{~g}^{-1}$ but the soluble saccharides yield reached nearly 70\%. Catalytic performance of soluble saccharides was applied to its intrinsic ability to adsorb $\beta$ 1,4-glucan, which is not absorbed on the other solid acids. Thus, it can be concluded that heterogeneous catalysis are more active and environmentally benign, mainly because of a hasty product separation and also catalysts recovery. Jule and Schoonover described that acid resins with considerably big pores could actively depolymerize cellulose in ionic liquid, but the main products were cellooligomers which failed to be dissolved in water [175].

(3) Zeolite Catalyst. The workhorse of the petroleum industry is zeolite catalyst that efficiently converts petroleum based feedstocks into the targeted chemicals and fuels and chemicals [176-178]. Crystalline microporous solids are an important part of zeolites because of their widespread application in absorption, separation, and catalysis [178]. Its importance stems from its unique structures of pores, which makes it highly particular to absorb molecules for separation reasons or towards product molecules in catalysis $[175,179,180]$. Furthermore, during heterogenous catalytic reaction, zeolite shows good hydrothermal and thermal stabilities. However, from the last twenty years, there have been many studies that focused on the catalytic transformation of biomass and its derived feedstocks with a variety of zeolite catalysts, including Ferrient, FCC, Al-MCM-41, ZSM-5, beta zeolite, Y zeolite, SSZ-20, IM-5, TNU-9, MOR mordenite, SBA-15, AlMSU-F FER, ZSM-23, MCM-22, and MFI [181-186]. ZSM11 and ZSM-5 among these series had the lowest amount of coke and the highest yield of aromatic because of its pore space and steric effects [181]. Manufacturization of ordered porous carbon material has been obtained previously through replication of ordered zeolite inorganic and nanocasting [187, 188]. Inside zeolite many reactions have occurred which include decarbonylation, dehydration, isomerisation, and decarboxylation and with that removing oxygen as carbon dioxide, water, and carbon monoxide and conversion of carbon and hydrogen into aromatics and olefins [181-188]. In these catalysts of zeolite, ZSM-5 has exhibited the highest olefin and aromatic yields from biomass of lignocellulosic. With a pore size of around 5.5 to $5.6 \mathrm{~A}, \mathrm{ZSM}-5$ has a threedimensional pore system. This small size of pore, internal volume, and internal structure has made it problematic for greater aromatic coke antecedents to form inside the pores [189]. It has been demonstrated by Zapata et al. that tin consisting zeolite is a highly efficient catalyst for the isomerisation of glucose in water [190]. Nevertheless, other studies have mentioned that, at low conversions in aqueous environments, faujasite and mordenite both resulted in great furfural selectivities up to $80 \%$ and $90 \%$ in $200 \circ \mathrm{C}$ as the selectivity lowers with high conversion and the final yield was relative $[191,192]$.

(4) Metal Ion Catalyst. Furfural and HMF are the two main and significant intermediates which are derived from biomass. They were directly manufactured from the microcrystalline cellulose hydrolysis with metal ions in ionic liquids such as $\mathrm{Fe}^{3+}, \mathrm{Fe}^{2+}, \mathrm{Cr}^{3+}, \mathrm{Co}^{2+}$, and $\mathrm{Mn}^{2+}$ as a catalyst under mild conditions [193-195]. Metal ions as an acidic support are 
a nice catalyst for hydrogenation and ring opening of cellulose polymers.

Many reports are there on carbon production through cellulose hydrolysis at a moderate temperature up to 250 and $300^{\circ} \mathrm{C}$ metal catalyst in a very less reaction time to control the deep exploitation of the formed glucose [196]. Some researchers even used $\mathrm{Ru}$ that is a ruthenium catalyst to enhance the transformation of oligosaccharides and increased glucose yield (almost 30\%) with the TON that is the turnover number of the catalyst was immense (145 based on bulk $\mathrm{Ru}$ ) in contrast to those of the sulfonated catalysts of carbon [197, 198]. Wang et al. found that the glucose yield was increased around $31 \%$ by upgrading the $\mathrm{Ru}$ loading to $10 \mathrm{wt} \%$ along with the recyclable number of catalyst up to five times without losing the activity or Ru leaching [199]. Various reports on the efficiency of the hydrolyzate of cellulose formulated by $\mathrm{Ru}$ catalysis as a source of carbon for the bacterial PHA production found that under the aqueous solution the reaction which occurs is desirable for delivering microbes which thereupon make it easily disconnected from yielded sugar via facilitating the race of the catalyst and filtration [200-203]. Such reports have accepted that Ru species were in fact in an oxidized state and acted as the real and effective site for the oligosaccharides hydrolysis. Prior, $\mathrm{Ru} / \mathrm{Co}_{3} \mathrm{O}_{4}$ catalyst has showed considerate selectivity and activity and good recyclability in the biomass conversion to carbon [204].

Researchers have even exclaimed that iron oxide nanoparticles and iron ions could adequately catalyze the hydrothermal carbonization of rice grains and starch beneath mild conditions $\left(<200^{\circ} \mathrm{C}\right)$ and had a powerful influence on the creation of nanomaterials of carbon with different shapes $[205,206]$. Catalysts of magnetite with sulfonic groups like a mesoporous silica composite, $\mathrm{Fe}_{3} \mathrm{O}_{4}, \mathrm{SBA}-15$ treated by sulfonated $\mathrm{CoFe}_{2} \mathrm{O}_{4}$ embedded silica, and sulfuric acid were also employed for the cellulose hydrolysis [207, 208]. After the catalytic reactions they were easily separable via magnet. $\mathrm{Fe}_{3} \mathrm{O}_{4}-\mathrm{SBA}-\mathrm{SO}_{3} \mathrm{H}$ catalyst managed glucose in $26 \%$ yield from microcrystalline cellulose at a temperature of $200^{\circ} \mathrm{C}$ for 3 hours, though levulinic acid becomes an important product giving $42 \%$ yield by delaying the reaction time up to 12 hours [209].

(5) Metal Oxide Catalyst. In many catalytic processes metal oxides play an important role [210, 211]. For example, metal oxide nanostructures are important components commercially available for synthesis of methanol [212-215]. There are many more benefits of these catalysts which make them efficient candidates for green processes. The characteristics of such catalysts are stable, nontoxic, low cost, availability, nonvolatility, and reusability [214]. Several studies have observed the processes of decomposition connected with formic acid on nanometal oxide surface, methanol, and formaldehyde [210-215]. It is strongly expected that metal oxide nanostructures would have a better catalytic activity in developing the conversion of cellulose to the value added products in hydrothermal media with an efficient separation from the reaction matrix in regard to the increased surface area of the nanomaterials [214]. Layered transition metal oxides containing niobium were found to be specifically active in the hydrolysis of disaccharide, suggesting the importance to investigate niobium containing catalyst as an energy inefficient factor for the conversion of biomass [213-215].

The employment of transition metal oxide like $\mathrm{HNbMoO}_{6}$ was also reported as an efficient solid catalyst to generate glucose from cellulose. Similarly, in the presence of noble metal consisting catalyst, for example, $\mathrm{Pt} / \mathrm{Al}_{2} \mathrm{O}_{3}$, Felica et al. have found the creation of sugar alcohols in yield up to $31 \%$ from cellulose in hydrothermal conditions. On the other hand, the researchers proclaimed that Pt free catalysts have generated only poor glucose hexitols amount [216].

\section{Activated Carbon in Photocatalyst System}

Activated carbon (AC), a carbonaceous material structured on plant-based material, is a porous, amorphous solid carbon [31, 32]. Well-developed porous surface, high pore volume, and extended surface area make AC the most commonly used technique for controlling pollution [35]. Well-developed pores over the surface are one of the main uses of AC as the photocatalyst. Nontoxic, chemical stability and being economical are the main reasons that in the past decades the heterogeneous technology has attracted the attention of many researchers $[217,218]$. As the organic pollutants can be mineralized into neutral by-products such as $\mathrm{H}_{2} \mathrm{O}, \mathrm{CO}_{2}$, and mineral acids as one of the main properties of heterogeneous AC, photocatalysis methods include the destruction of the wider category of organic compounds. Promoting solar radiation and working on the low temperature, eventually saving a lot of energy, make it very economical [35-39]. One of the advantages of the AC includes the regeneration of spending absorbent and demolishing of absorbed organic material on the site converting the loss of absorbents to burn them concluding that thermal regeneration is efficient $[218,219]$. AC being the strong light absorbing compound has been successfully used as photoactive species [38]. Determining the band gap of the AC (band gap less than $4 \mathrm{eV}$ ) resulted in a semiconductor and therefore, a photoelectric material in the presence of ultraviolet radiations [218]. Recent reports suggest the abnormal reaction towards the aqueous environment by directing ultraviolet irradiation of the sample in the presence of the AC provided that no other photoactive materials are present [220] showing that the AC improved the photooxidation of phenol, beyond the degradation of photolysis in comparison to bare or unmoved $\mathrm{TiO}_{2}[220$, 221]. To find the difference whether this reaction is only shown by the AC or also by other carbon compounds, some researchers have worked on different porous AC materials obtained from different sites, procedures, and reactions and examined their behavior to the exposed ultraviolet radiations $[222,223]$. The final solution we want to reach is that to remove any vagueness in the aqueous medium, ultraviolet radiations and absence of semiconductor $\mathrm{AC}$ are able to demolish the organic materials in the respective conditions [220]. Regardless of the type, AC acts as a catalyst during the removal of diatrizoate. Gamma radiations based AC is more efficient in a way that it has a higher proportion of $\mathrm{C}$ atoms 
and contains $\mathrm{sp}^{2}$ hybridized [224]. With more than $53 \%$ of synergistic effect in diatrizoate in the first minute of reaction, commercial carbon is produced from the ultraviolet/AC system [222, 223]. Providing more oxygen, the synergistic act of $\mathrm{AC}$ is boosted up. The reutilized $\mathrm{AC}$ is quite similar to the original $\mathrm{C}$; presence of $\mathrm{O}$ in the sample increases the rate of removing diatrizoate by the ultraviolet/AC system, but the ultraviolet inclusion of system results in some modifications in AC chemically. There is a very vague relationship between the textual properties and the synergistic contribution of the AC. Gamma radiation involvement with AC reduces the band gap which results in a more efficient removal of organic compounds $[225,226]$. One of the actions proposed include that $\mathrm{AC}$ is the photocatalyst which will promote the electrons in the valence band to the conducting band, resulting in enhanced generation of $\mathrm{OH}$ free compounds present in the polluting medium.

\subsection{Activated Carbon Surface Properties in Photocatalyst} System. For commercial use, textures and surface properties can alter, depending on the crude material used, activation conditions and carbonization procedure which may potentially result in well-defined photocatalytic performance [39]. Many researchers and authors reported many surface and textual features of AC $[227,228]$. It is clear that basic AC in the presence of low oxygen in this medium has much more potential than the phenol adsorption [225]. An increase in the physical absorption and surface polymerization of phenols can be done by ensuring the deprivation of the acidic categories on the surface of the AC. Irreversible absorption and catalyzing the oxidative coupling of phenolic compounds can be enhanced by the $\mathrm{O}_{2}$ containing basic categories over the face of AC [221]. Boosting up the interactions between $\pi$ $\pi$ electrons in $\mathrm{AC}$ and phenols is due to the graphene layers of an activated carbon which increases $\pi$ electron density [222]. In carbon of basic nature, phenol is considered to be higher regardless of textual propertie and absorption capacity [228]. Retention of phenol is supposed to become less in the acidic carbon as compared to the basic carbon; in fact there is no clear relationship between the two.

On of AC limitations is that the waste organic materials are not really destroyed but are transformed from one phase to another and in result the used AC is transformed into a dangerous product [226]. So, regenerating AC becomes necessary for its reusability, which makes an economical process. The AC is carrying some limitations like its adsorption capacity, which is a function of inert concentration that results in low quality products [229]. Already used $\mathrm{AC}$ is to be disposed of as it is hazardous material or is regenerated to be used again. Thermal regeneration contains many disadvantages because of its off-site regeneration that hardly converts the pollutant from one phase to another. This may result due to depletion of carbon and may cause damage to the structure of activated carbon.

The process, which could produce high yield efficiencies, could be a chemical regeneration of spent AC but it has some drawbacks regarding chemical consumption nondestructive pollutant elimination and creation of unimportant steams of waste [230, 231]. However, techniques like ultrasonic regeneration, microwave regeneration, and electrochemical regeneration are also being proposed as alternative techniques for the process of chemical regeneration of spent $\mathrm{AC}$ [230]. Chemical consumption, having increased footprints of carbon or having expensive facility requirement, is through the bench scale studies in which it has been proved to be effective but in industrial applications it has a limited appeal. Due to the limitations of the present technique, there is a need to develop another technique, which is more economical and environmentally friendly. Thus, to make one hybrid system, there is a need to merge semiconductor with AC $[230,231]$. Organic pollutants, issues of destruction, and other hazardous problems are expected to arise from the oxidation semiconductor element. The reason lies in the generation of radical species like $\mathrm{O}^{*}$ and $\mathrm{OH}^{*}$ from the catalyst particles of the semiconductor, which causes oxidation of such species [230]. Another technique that has been studied for AC is the combination of heterogeneous photocatalysis and the Fenton reaction with the catalytic process, which is an oxidation based process.

Studies on this spent AC carried out previously were mostly about granular AC. As an example, it was demonstrated that there was an improved efficiency in herbicide removal from the water when granular AC adsorption photocatalyst hybrid system was used in comparison with a photocatalysis system [227, 228]. Similarly, it was also reported that the combination of photocatalytic and rotating adsorbent showed better efficiency in removing formaldehyde in comparison with adsorption [232].

\subsection{Transition Metal Oxide Hybrids: AC in Photocatalysis} System. In future, it anticipated that the coming photocatalyst generation would have improved internal efficiency regarding separation and also would be placed in contact with molecules of external pollutants [222-224]. So to improve the photocatalytic efficiency and separating catalyst from aqueous solution, the hybrid photocatalyst was designed by not moving the metal oxides having a large surface area, to condense pollutants which are diluted $[233,234]$. In environmental purification field, heterogeneous photocatalysis with metal oxides of semiconductor has been applied as an efficient method [235].

By impregnation and adsorption along with various methods, metal oxides are expected to be impregnated into the surface of carbon; the same is applied for complex experimental procedures and process, which operate at high temperature. Considering ideal conditions, a photocatalyst should be inexpensive, highly proactive, nontoxic, and stable [233]. One more criterion that plays a role in the degradation of organic compounds is the potential of the redox residing in the band gap of the semiconductor. There are many semiconductors with the band gap energies ample to catalyze several chemical reactions, which include $\mathrm{WO}_{3}, \mathrm{Fe}_{2} \mathrm{O}_{3}$, $\mathrm{SrTiO}_{3}, \mathrm{ZnS}, \mathrm{TiO}_{2}$, and $\mathrm{ZnO}$ [233-236]. The metal sulfate group with insufficient stability in the process of catalysis is kids, $\mathrm{PbS}$, or $\mathrm{CdS}$. This compound undergoes photoanodic corrosion readily and is toxic. For example, $\mathrm{Fe}_{3} \mathrm{O}_{4}$ undergoes 


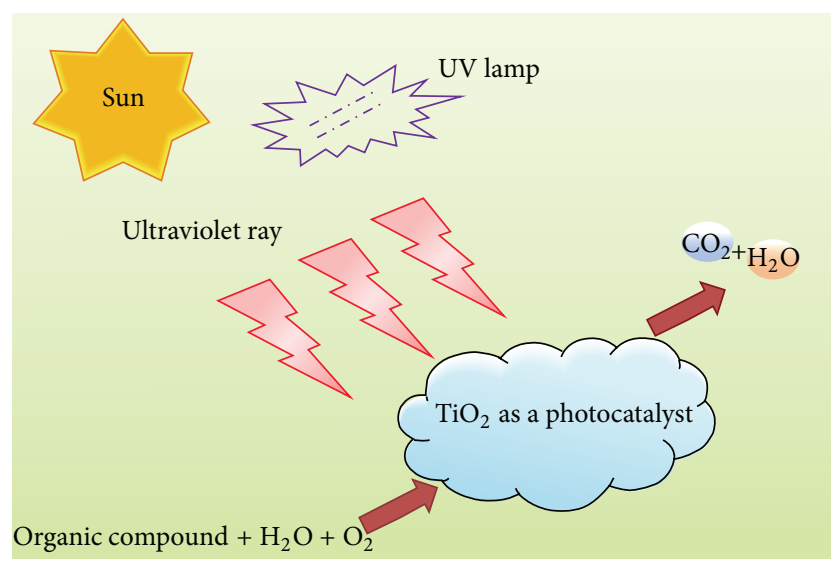

FIgURE 6: Basic principle on $\mathrm{TiO}_{2}$ photocatalyst.

photoanodic corrosion readily so they are not suitable [233]. $\mathrm{ZnO}(3.2 \mathrm{eV})$ is unstable with $\mathrm{Zn}(\mathrm{OH})_{2}$ in water; also it has band gap similar to anatase, so it results in the deactivation of the catalyst [228].

\subsection{1. $\mathrm{TiO}_{2}$ : AC Photocatalyst System}

(1) $\mathrm{TiO}_{2}$ Photocatalyst System. The most promising semiconductor for photocatalytic destruction organic pollutants is titanium dioxide $\left(\mathrm{TiO}_{2}\right)$ [229]. It provides the most excellent agreement in aqueous media between stability and catalytic performance. Since it is nontoxic, cheap, biocompatible, and stable in sunlight, so it is of immense importance and that is why it is also considered usable in cleaning environmental operations $[230,231]$. Consequently, the electron pairs and positive holes are created at the surface of $\mathrm{TiO}_{2}$. Once it has been irradiated with the UV light of the wavelength of $380 \mathrm{~nm}, \mathrm{TiO}_{2}$ would form reactive oxidants, such as $\mathrm{OH}$ radicals, hydrogen peroxide, superoxide anions, and other reactive species of oxygen and reactions that are reductive, to contribute in the organic compound decomposes which are adsorbed on the surface of $\mathrm{TiO}_{2}$ [235-237] (Figure 6). The highest photocatalytic detoxification of $\mathrm{TiO}_{2}$ is anatase phase. Deep studies have shown that photodegeneration of components like herbicides, phenols, dyes, pesticides, surfactants, and organic components (e.g: salicylic acid and sulfosalicylic acid) has been possessed by $\mathrm{TiO}_{2}$ that is present in water wastes $[238,239]$.

$\mathrm{TiO}_{2}$ powders contributed to some drawbacks in separating phase in photocatalysis, with the purpose of its emission in the atmosphere because of their small particle size and recovery, the loss of photocatalyst if the separation is not promising, the need of fluidization of the powder in gaseous phase with cost and energy, and the scaling difficulties involved [237, 240]. Also, since radiation from the light compromises $47 \%$ of visible light, $48 \%$ infrared radiation, and $5 \%$ UV light, so $\mathrm{TiO}_{2}$ acts as a benchmark of UV photocatalysis that it goes deactivated under visible light because of its wide band gap [241]. Moving on, the holes and photogenerated electrons present in an excited state play a vital role in the degeneration of pollutant and are unstable and without any effort they can recombine, they lead to low order efficiency which results in photocatalysis activities [231]. It is clear that the use of high potential solar photocatalysis cannot be made by $\mathrm{TiO}_{2}$.

(2) Activated Carbon Supported $\mathrm{TiO}_{2}$ in Photocatalyst System. For easy manipulation in a process of total photocatalytic operation and quick decomposition of organic pollutants, it might speed up the process to load photocatalysis to suitable adsorbents to increase the strength of pollutants around the photocatalysis system $[237,238]$. Therefore, researchers had made attempts to support $\mathrm{TiO}_{2}$ on different matrixes as silica gel, clay, carbon materials, alumina, and zeolites which can be nanotubes, carbon microspheres, carbon black, carbon nanofibres, and $\mathrm{AC}[242,243]$. $\mathrm{TiO}_{2}$ particles are hydrophilic when exposed to direct UV light whereas organic pollutants are hydrophobic [229]. The use of AC as a reference will provide help to molecules of pollutant closer to the active site of $\mathrm{TiO}_{2}$ for a quick and effective photodegeneration process (Figure 7). The AC in comparison to organic pollutants that are approaching, in which secondary degradation takes place intermediately in situ, can generate new adsorption centers.

In gas and water remediation for support purposes, AC is used widely because of its high porosity, good adsorption, supported $\mathrm{TiO}_{2}$, and low cost that has marked the effects on disappearance of pollutants kinetics, with each pollutant being more quickly degenerated [244]. For example, the $\mathrm{TiO}_{2}$ surface becomes static over glass surface; it has the benefits of high photodegradation productivity. The major limitation is the adhesion force in $\mathrm{TiO}_{2}$ membrane and glass is poor, so $\mathrm{TiO}_{2}$ is easy to decrease, which causes the decrease of the photodegradation productivity [231].

Hybrid of $\mathrm{TiO}_{2}$ with $\mathrm{AC}$ support, as a sensitizer which is able to absorb light, was proven to be the best approach to developed photo-responding photocatalyst with great activity. The formation of heterojunction between $\mathrm{TiO}_{2}$ with a small band gap and negatively charged AC may result in the inoculation of conducting band electrons from $\mathrm{AC}$ to $\mathrm{TiO}_{2}$ and it is very useful for electrons and hole division $[245,246]$. At the same time, the immobilization of $\mathrm{TiO}_{2}$ onto the AC support can compromise for the loss of photocatalytic ability of $\mathrm{TiO}_{2}$ because of the difficulty to effectively disperse in water for complete interaction with pollutants. So, many researchers reported that there is an optimum used amount of $\mathrm{TiO}_{2}$ and $\mathrm{AC}$ pore formation for attaining the higher photocatalytic productivity than $\mathrm{TiO}_{2}$ [245-247]. The 3D relation between the particles of $\mathrm{AC}, \mathrm{TiO}_{2}$ photocatalyst small particles, and the molecules of organic toxic is reported representationally in the absence of light and in the presence of ultraviolet enlightenment $[245,248]$. The organic pollutants are supposed to be small to be adsorbed in microspores. In most of the AC amounts, a large group of micropores exists over the broad surface of the substantial pores, mesopores, and macropores; a large amount of toxic particles is well balanced due to physical adsorption [247-250]. Instead, only a little number of pollutant particles are adsorbed on the surface of $\mathrm{TiO}_{2}$. By depositing $\mathrm{TiO}_{2}$ molecules onto $\mathrm{AC}$ particles, some mesopores and micropores become closer to 


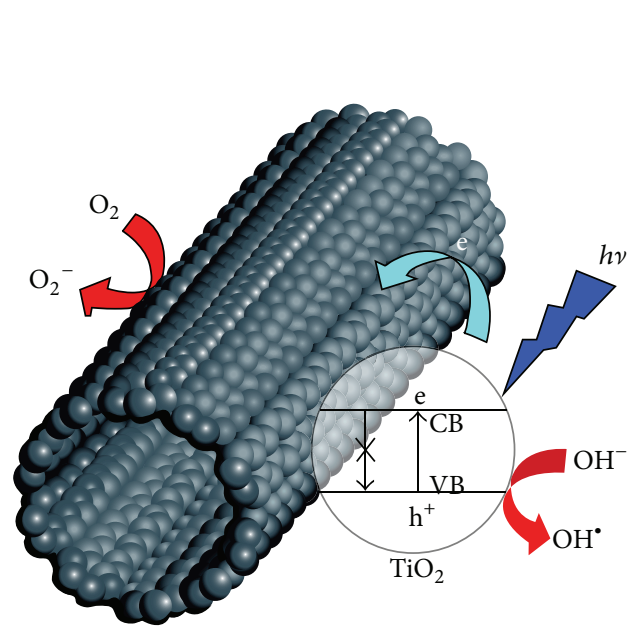

(a)

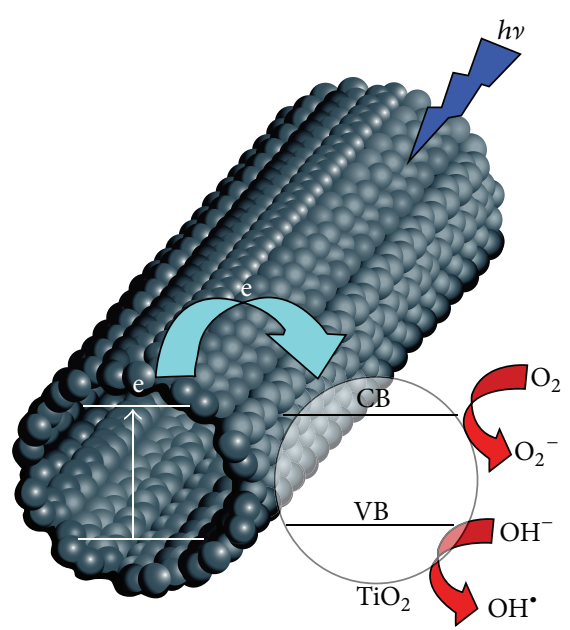

(b)

FIGURE 7: General mechanism of adsorption and photodegradation of $\mathrm{TiO}_{2}$ supported CNTs photocatalyst [243].

their openings and this causes a marked lessening in the uncovered surface area [245]. The ultraviolet enlightenment over such $\mathrm{TiO}_{2}$ used AC molecules; oxidative $\mathrm{OH}$ free radicals take birth on the $\mathrm{TiO}_{2}$ and can destroy toxic molecules by oxidation (Figure 8 ).

Though these radicals will take birth over the surface of $\mathrm{TiO}_{2}$ molecules and they are in the access of ultraviolet radiations and do not locate on the surface in the same radicals, they cannot diffuse through long distances and are limited to an area close to the active centers in $\mathrm{TiO}_{2}$ [231-235, 251] (Figure 9). Adsorbed pollutant particles are photocatalytically demoted; they have to move along the surface of $\mathrm{AC}$ and $\mathrm{TiO}_{2}$ molecules with the surface are not necessarily interacted to ultraviolet radiations [249].

The moving force of migration is actually the saturated gradient between organic toxic particles over the enlightenment of $\mathrm{TiO}_{2}$ interface and on the other side some are over the surface of changing pore sizes of the AC molecules. The molecules diffused inside micropores of AC migrate with greater retaliation towards $\mathrm{TiO}_{2}$ molecules resided on the interface of the AC particles. Thus, highly microporous AC particles are not usually advantageous for the $\mathrm{TiO}_{2}$ : $\mathrm{AC}$ to have preferred the photocatalytic response $[247,248]$. The effect of the substrate pore skeleton has been observed using AC surface area $\left(770-1150 \mathrm{~m}^{2} \mathrm{~g}^{-1}\right)$ and a dip-hydrothermal process of photocatalyst preparation. Improved photocatalytic demoting of methyl orange (MO) has been attained with $\mathrm{TiO}_{2}$ : AC than with a simple mixture of $\mathrm{TiO}_{2}$ and $\mathrm{AC}$ [255] (Figure 10) and (Figure 11).

This got into the design of highly effective $\mathrm{TiO}_{2}$ : AC hybrid heterojunction photocatalyst; also the demand of commonsensible crosscheck capacity of band potentials among hybrid modules, the spatially and flat accessible transmission of holes and electron at the exposed surface, and the hole and electron movement of the hybrid system are important to enhance the photocatalytic action. It has been reported that the surface chemistry and map of AC revealed major effect on the collection of $\mathrm{TiO}_{2}$ particles and photocatalytic deprivation of 4-chlorophenol [256, 257]. Adding to this, some researchers have constructed $\mathrm{TiO}_{2}$ with $\mathrm{AC}$ microspheres to both maintain spreading and speeding up separation due to the $\mathrm{AC}$ microsphere that can be balanced with airy bubbles and it can be speedily settled in the reactor base with the help of some gravity due to the air bubbles [241]. In addition, some authors have fabricated $\mathrm{TiO}_{2}$ with $\mathrm{AC}$ microspheres to both sustain spreading and acceleration division, because $\mathrm{AC}$ microsphere can be balanced with air bubbles and be able to speedily settle on top of the reactor base by gravity due to air bubbly. To overcome this shortcoming, the use of cobinder upholds the expansion of another method to obtain a fresh form of the $\mathrm{TiO}_{2}$ : AC photocatalyst for such a high action and better division performance.

Jamil et al. found that $\mathrm{TiO}_{2}$ supported with AC sample heated at almost $500^{\circ} \mathrm{C}$, which mainly consisted of rutile phase, showed the greatest photoactivity for deprivation and elimination of methyl orange from aqueous medium [255]. Therefore, most samples which were cooked at higher temperature were very detrimental to photoactivity. Also, using different types of AC revealed the connected effects between $\mathrm{TiO}_{2}$ and $\mathrm{AC}$ during the 4-chlorophenol photodegradation and found a clear enhancement of photoactivity due to an increase in electron density of the AC support [258, 259]. It is researched that attendance of $\mathrm{AC}$ in interaction by $\mathrm{TiO}_{2}$ is beneficial due to its burly adsorption capability. In the same way it advances the relocation rate of the interfacial change and lessens the rejoining rate of the holes and electrons $[260,261]$. This synergistic effect of the interaction of AC and $\mathrm{TiO}_{2}$ has been previously been stated for deprivation of some organic compounds in the photocatalytic process. It has been credited to a common contact between the different solid phases, in which AC acts as an efficient adsorption agent for the organic pollutants [257] (Figure 12).

The organic more efficiently moved to the $\mathrm{TiO}_{2}$ surface, where it is immediately photocatalytically degraded by a mass movement of the photoactivated $\mathrm{TiO}_{2}$ [258]. Thus, the organic burning rate observed on $\mathrm{TiO}_{2}: \mathrm{AC}$ is like heading 


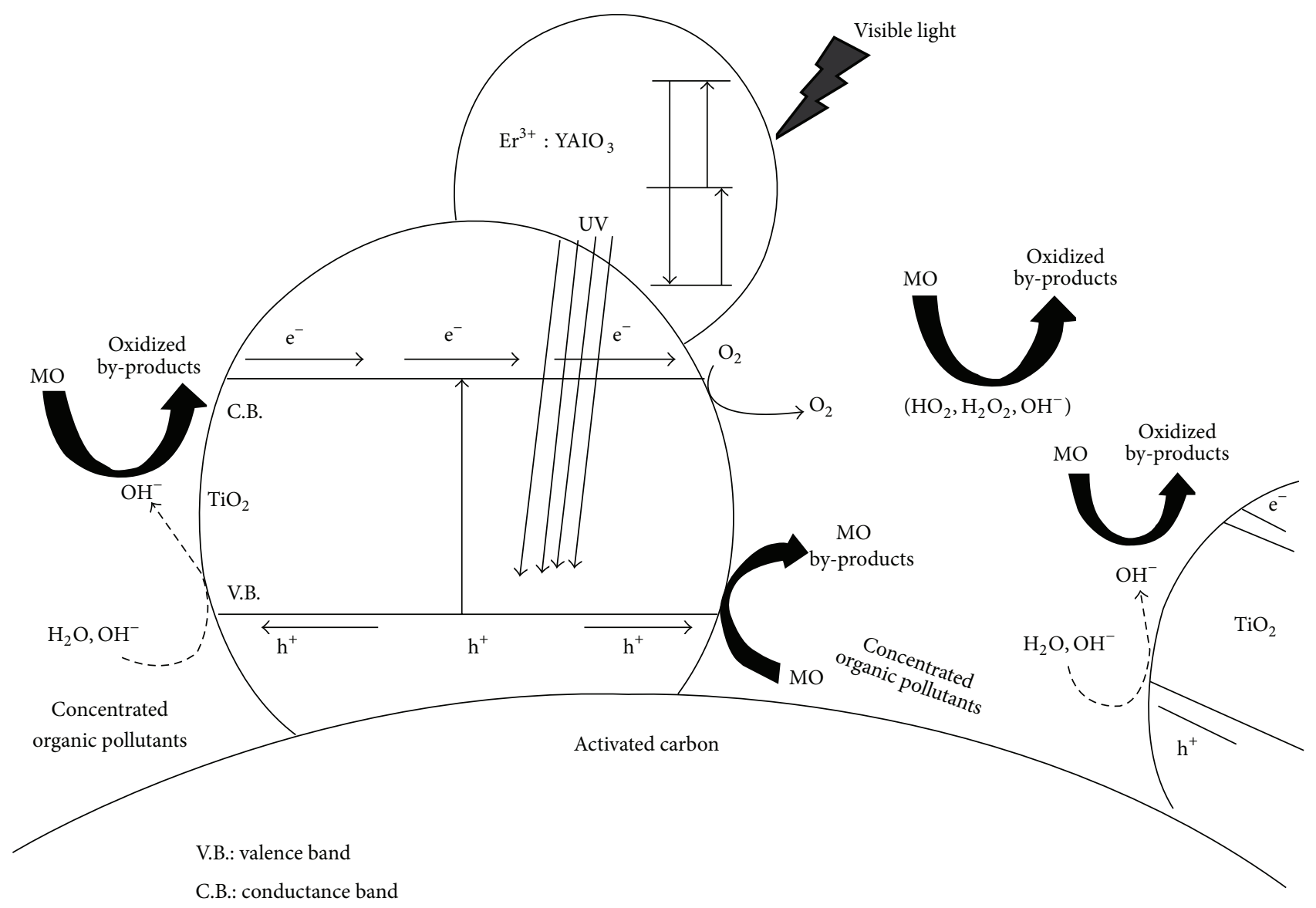

FIgUre 8: Mechanism on photodegradation of $\mathrm{MO}$ with $\mathrm{TiO}_{2} / \mathrm{AC}$ under visible light irradiation [245].
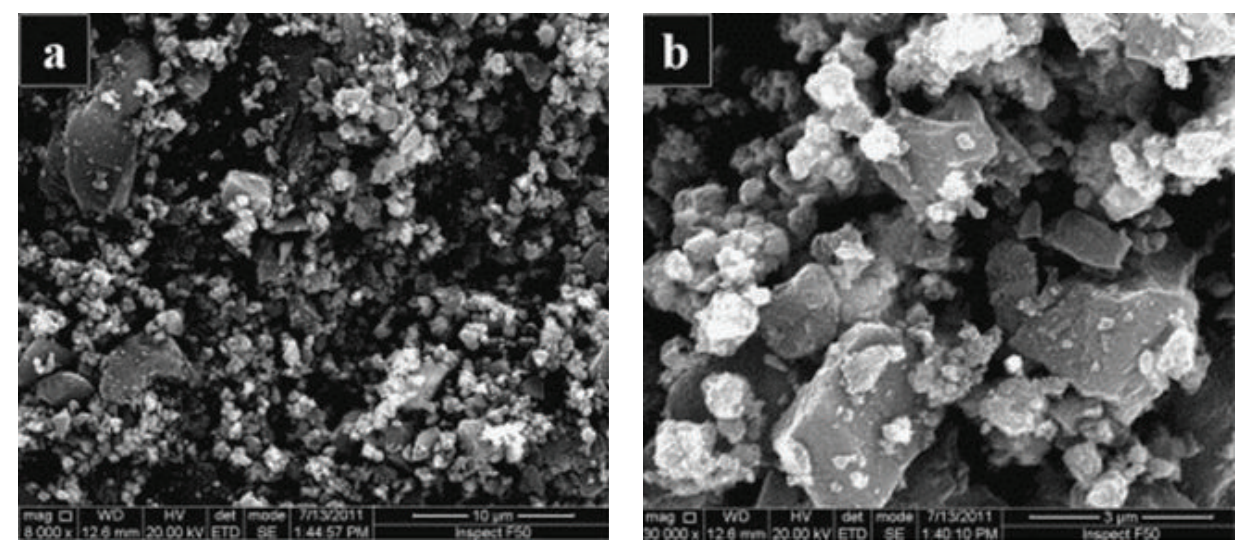

Figure 9: SEM images of $\mathrm{TiO}_{2} / \mathrm{AC}$ powder. (a) $10 \mu \mathrm{m}$ and (b) $3 \mu \mathrm{m}$ [250].

both with surface diffusion toxin particles with the photocatalytic process rate; because adsorption occurs gradually, the variation in relative pollutant proportion with irradiation time depends on both adsorption and photodecomposition, mainly at the start of ultraviolet treatment. It is stated that the variance of the proportion of phenol (as model of organic pollutants) remaining in the solution by ultraviolet treatment time is compared for $\mathrm{TiO}_{2}: \mathrm{AC}$, which were prepared by hydrolysis of tetraisopropyl orthotitanate and heat treatment at 650 to $900^{\circ} \mathrm{C}$. For example, we noted that, in the duration of first 1 hour, adsorption of $\mathrm{pH}$ occurs in native AC and after 3 hours, in the presence of UV irradiations saturation achieved [261]. Adsorption as well as the photodecomposition of $\mathrm{pH}$ takes place simultaneously, but on the other side the former is supposed to become the dominate method in the beginning, being similarly latter in the next stage $[221,222]$. The noted 


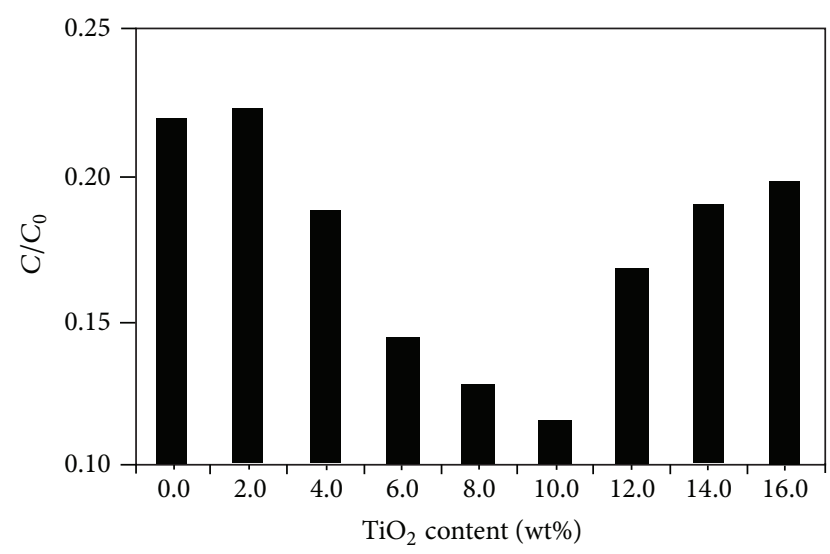

Figure 10: Effect on $\mathrm{TiO}_{2} / \mathrm{AC}$ photocatalyst at different contents of $\mathrm{TiO}_{2}$ on MO degradation [250].

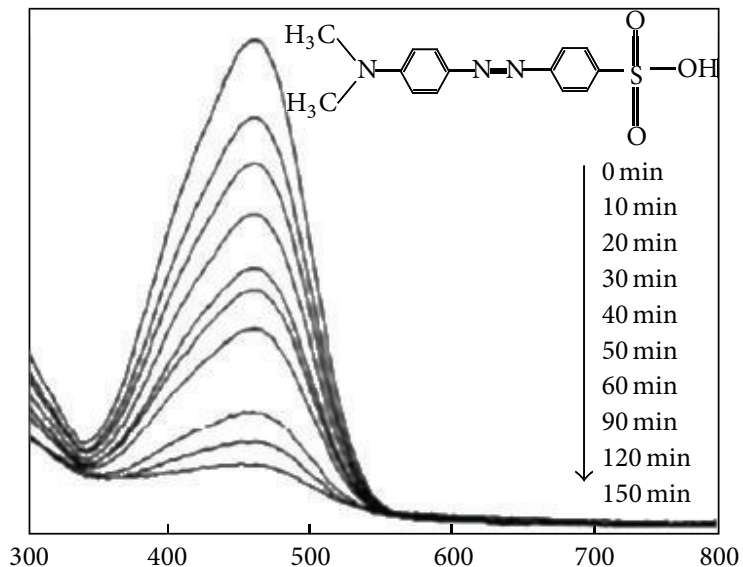

FIGURE 11: UV-Vis spectra of MO degradation with $\mathrm{TiO}_{2} / \mathrm{AC}$ under visible light [245].

trend was based on two linear processes; the change of one process to the other takes place approximately in 1 hour of irradiation.

(3) Synthesis of $\mathrm{TiO}_{2}$ : AC Photocatalyst. A number of methods are available for the composition of $\mathrm{TiO}_{2}: \mathrm{AC}$ catalyst, such as precipitation, chemical vapor deposition (CVD), hydrothermal, aerosol pyrolysis, hydrolysis, dip coating, and sol-gel $[235,262,263]$. However, selection process which is used for the selection of a suitable impregnation method depends only on the support used in it and the pollutant which is degraded [262]. It is clear that those physicochemical properties of $\mathrm{TiO}_{2}$ : AC catalyst have a heavy impact on the structure of the supported catalyst and they depend basically on the preparation method used, for example, thermal treatments. The main advantages of using physical methods are simple, lowcost and the use of commercially is present for photocatalyst with the wanted functionalities. By using the common wet methods, $\mathrm{TiO}_{2}$ : AC hybrid was also being prepared, the mismatches in the level of lattice among two hybrid components lessen the required efficiency of separation and transmission

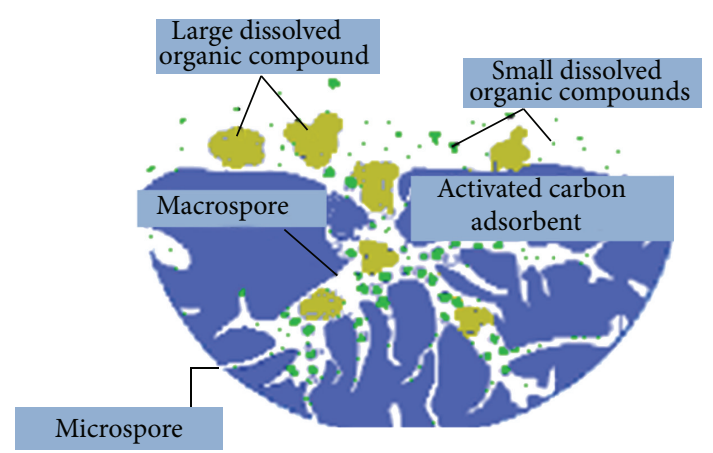

Figure 12: Adsorption mechanism of AC towards organic compounds.

of photogenerated carriers (electron and hole) [264, 265]. Adherence of AC surface to $\mathrm{TiO}_{2}$ particles appears significant for increment of photocatalytic action and as well for useful applications of hybrid system. To increase the anchorage of $\mathrm{TiO}_{2}$ on AC, the wet process of synthesis is warranted [264]. This is only because the physical stable $\mathrm{TiO}_{2}$ : AC hybrid is in disagreement with hydrodynamic shearing method, surface chemistry plus AC pore structure can have a sufficient impact on spreading of $\mathrm{TiO}_{2}$ over the synthesis; it results in the different photocatalytic presentations of $\mathrm{TiO}_{2}: \mathrm{AC}$. Nevertheless, $\mathrm{TiO}_{2}$ photocatalyst usually has low precise surface region. Due to the crystalline particle development to happens in heat operation like that. To prevent $\mathrm{TiO}_{2}$ sintering, or else to make it precise surface region better, AC can be examined like a better help for photocatalysis material [266]. They found that the $\mathrm{TiO}_{2}$ particles calculated at $450^{\circ} \mathrm{C}$ can collect and go through the great pores of the activated carbon substrate, including a very burly contact among carbon matrix and $\mathrm{TiO}_{2}$. The contact between them leads to visible synergy to increase photocatalytic capacity for the degradation of the chromotrope $2 \mathrm{R}$ [267]. The prepared nanocrystal anatase $\mathrm{TiO}_{2}$ particles are installed on activated carbon at a fewer temperature with the hydrolysis of the titanium but oxide in the acidic aqueous solution [268]. It is noticed that phenol toxin was absorbed by AC and after that drifted constantly over $\mathrm{TiO}_{2}$, which consequently accelerate photocatalytic oxidation. On the other side, for the chemical vapor, deposition method is used for nanosized $\mathrm{TiO}_{2}$ particles which were exposed to stick to activated carbon and tetra-butyl titanate and to offer large activities on the behalf of the photodecomposition of methylene orange in the water. Adding of water in titanium tetraisopropoxide vapors was described to make possible CVD method at a higher deposition rate and lower temperature [269]. Introduction of $\mathrm{H}_{2} \mathrm{O}$ vapors for the duration of CVD method and adsorption on the $\mathrm{AC}$ in prior were announced to be critical to get hold of anatase type $\mathrm{TiO}_{2}$ nanoparticles at AC surface [270]. Investigations have also made it clear that the $\mathrm{HNO}_{3}$ treatment results in more orderly $\mathrm{TiO}_{2}$ loading by $\mathrm{CVD}$, in comparison with other oxidation treatment. $\mathrm{TiO}_{2}$ : AC ratio has been formed as a result of using dropping the support in solution produce with the alkoxide hydrolysis 
as well $[269,270]$ and subjected to heat operation at 300 to $500^{\circ} \mathrm{C}$. In an alternative process, it can be produced by adding $\mathrm{TiCl}_{4}$ drop by drop in aqueous suspensions of $\mathrm{AC}$, come after by heat operation at $500^{\circ} \mathrm{C}$ in $\mathrm{N}_{2}$ atmosphere [271]. Load the $\mathrm{TiO}_{2}$ powder exactly over $\mathrm{AC}$ has been achieved as a result of combining $\mathrm{TiO}_{2}$ in $\mathrm{AC}$ aqueous suspension with stirring. On the other side, loading over AC filter was produced as a result of gluing granular AC over the glass cloth and it was formed by the water suspension of five mass $\% \mathrm{TiO}_{2}$ and the conclusion $\mathrm{TiO}_{2}$ : AC particles inside $\mathrm{CCl}_{4}$ solution of pitch, come after by heat operation at $750^{\circ} \mathrm{C}$ [263]. In resultant hybrid system, $\mathrm{TiO}_{2}$ particles over $\mathrm{AC}$ were expected to be layered with carbon, composed of the pitch at the stage of the heat operation; it may function as a mean repair $\mathrm{TiO}_{2}$ particle over the $\mathrm{AC}$ surfaces. $\mathrm{TiO}_{2}$ particles also were able to load over AC by spray-desiccation procedure, with a little modification in the pore structure of the $\mathrm{AC}[272,273]$. In the other study, loading of $\mathrm{TiO}_{2}$ over the AC surface was taking place via dipping the $\mathrm{AC}$ particles in a peroxotitanate solution; after that heating at $180^{\circ} \mathrm{C}$ in a Teflon lined stainless-steel vessel came after in calcinations at 300 to $800^{\circ} \mathrm{C}[274,275]$. With the help of the AC particles of 0.16 to 0.26 millimeter, the disjunction of the particles from the solution was not too much harder, and photocatalytic action on behalf of the decomposition of $\mathrm{MO}$ almost remains identical for 5 cycles. $\mathrm{TiO}_{2}$ has also been achieved by plugging the pore of AC by paraffin [275]. After loading $\mathrm{TiO}_{2}$, by removing the paraffin at $250^{\circ} \mathrm{C}$ in the air, the high surface region of pristine $\mathrm{AC}$, it could be recuperated and the high photocatalytic action was procured basically for the decay of methylene blue (MB) [276]. $\mathrm{TiO}_{2}$ : $\mathrm{AC}$ has also been composed by mixing $\mathrm{TiO}_{2}$ particles with some liquid or solid state carbon precursor. By hydrolysis of tetraisopropyl orthotitanate, $\mathrm{TiO}_{2}$ was caused in the exterior region of the poly vinyl butyral (PVB) and $\mathrm{TiO}_{2}$ overloaded PVB was carbonized at a high temperature in the flow of $\mathrm{CO}_{2}$. $\mathrm{TiO}_{2}$ loaded carbon microspheres with $25 \mu \mathrm{m}$ diameter have been prepared from the $\mathrm{TiO}_{2}$ loaded cellulose microspheres, composed with one step stage division by using the sodium polyacrylate aqueous solutions and cellulose xanthate with the isolated $\mathrm{TiO}_{2}$ powder [277-279].

(4) Performance of $\mathrm{TiO}_{2}$ : AC Photocatalyst. Although it is a hard to understand how light could it penetrate the carbon particles to reach the inoperative photocatalyst, $\mathrm{TiO}_{2}$ : AC composites have quite clear high efficiencies for the photodegradation of a variety of pollutants [238]. In such a case, the presence of the AC seems to change the photocatalytic activity of $\mathrm{TiO}_{2}$ towards the abasement of organic pollutants beyond the so-called "synergistic" effect [227]. The harmonious aftereffect of the adsorption with AC and photocatalytic disintegration by $\mathrm{TiO}_{2}$ has been noticed during the deprivation of many kinds of organic toxin.

The basic principle of photocatalysis over illuminated $\mathrm{TiO}_{2}$ : AC system. But model of a $\mathrm{TiO}_{2}$ : AC photocatalytic process can be more of a complex issue, it starts the photointensity to the classical aspects of the heterogeneous catalytic system; for example, temporal variations in concentration of iminoctadine triacetate (IT) that is frequently used in excess plus orchard fields like an insecticide and in the water path of the fields are exposed for pristine $\mathrm{AC}$ and three $\mathrm{TiO}_{2}: \mathrm{AC}$ [280, 281]. The hybrid systems were kept without any light on them for $200 \mathrm{~h}$ to saturate IT adsorption and after that were exposed to ultraviolet irradiation. $800 \mathrm{~h}$ behind this [280], the sample was separated from given test solution and spread once more in the virgin $1.87 \times 10^{-4} \mathrm{~mol} / \mathrm{L}$ solution and again kept without any light in it for approximately $200 \mathrm{~h}$ and then exposed to ultraviolet radiations. As far as pristine AC is concerned, concentration of pollutants was initiated to survive approximately steady without any light and to spread to some extent beneath ultraviolet irradiation. The bottom line is that the photocatalyst system of $\mathrm{TiO}_{2}: \mathrm{AC}$ could have similar photocatalytic results without any light and under ultraviolet radiations [282]. Before mentioned data was supported by the one who stated that the enhancement of photocatalytic activity for the organic burning of pollutants via $\mathrm{TiO}_{2}$ : AC enzyme. Stated that is, the concentration of 4-chlorophenol solution demotes rapidly for the $\mathrm{TiO}_{2}$ : $\mathrm{AC}$ than $\mathrm{TiO}_{2}$, saying that it enhances photoorganic burning approximate by a pseudo-first-order equation with a linear relationship between time and concentration change. The same harmonious result was noticed in the organic burning of $\mathrm{pH}$ and 2,4-dichlorophenoxyacetic acid applying similar AC and $\mathrm{TiO}_{2}$ sample [283]. Furthermore, the $\mathrm{pH}$ disintegration is found to be dependent on the mass ratio of $\mathrm{TiO}_{2}$ to $\mathrm{AC}(5 / 10$ to $75 / 10)[231,284,285]$. The harmonious result is thought to be attributable to the fast movement of $\mathrm{pH}$ molecules at the start adsorbed on the $\mathrm{AC}$ on the outer surface of $\mathrm{TiO}_{2}$; the motivating force of that movement is most probably the differentiation in the surface concentration of $\mathrm{pH}$ between $\mathrm{AC}$ and $\mathrm{TiO}_{2}$. Defined proportion of $\mathrm{pH}$ was found to remain at $\mathrm{AC}$, even after the proportion in sample becomes negligibly small.

3.2.2. $\mathrm{ZnO}:$ AC Photocatalyst System. After $\mathrm{TiO}_{2}, \mathrm{ZnO}$ supported AC finds broader attraction of use, due to some of the excellent behaviors of $\mathrm{ZnO}$, such as wider availability, stability, and suitable band gap of energy [228]. Problems associated with the usage of $\mathrm{ZnO}$ alone as photocatalyst are as well partitioned, especially the complexity in unraveling the powder with the sample after the reaction is over; gathering of particles in delay, particularly at high loading and complexity in purpose to the consistent flow of the domain system has been approved by its surface properties [37, 235] (Figure 13).

The problem is AC has been declared good as for the support of the $\mathrm{ZnO}$ photocatalysis system. Replying on using of dioxygen, photo-, and entirely mineralized organic as well as inorganic substances and particularly biorecalcitrant, make the technique is environmentally friendly for toxic waste reduction schemes [225]. Spherical AC particles having $\mathrm{ZnS}$ and $\mathrm{ZnO}$ were formed from a caption-exchange resin (polystyrene with sulfonate groups and cross-linked by divinylbenzene) and $\mathrm{ZnCl}_{2}$ aqueous solution, followed by carbonization at almost 500 to $900^{\circ} \mathrm{C}$ [286]. It has been reported that $\mathrm{ZnO}$ is an appropriate substitute to $\mathrm{TiO}_{2}$ for the photodegradation of Acid Red 14, an azo dye, because it is 
photodegradation process that has been proved to be similar to $\mathrm{TiO}_{2}[37,287]$ (Figure 14).

Recently it was reported that the instantaneous destruction of inorganic toxin like $\mathrm{Cr}(\mathrm{VI})$ and organic toxin, like 4$\mathrm{CP}$, can be recognized in $\mathrm{ZnO}$ : AC photocatalytic reaction system [286-289]. Hence, this technique can be functional over the broader level for aqueous waste reduction.

\section{Advance Activated Carbon Photocatalytic System}

4.1. Granular and Spherical Activated Carbon Photocatalytic Systems. In all kinds of AC, the spherical AC has benefits, such as its frictionless surface, high quality fluidity, and good strength on the powdered and rough AC. Carrying this forward, many proposals have lately examined the sustain of $\mathrm{TiO}_{2}$ to spherical AC $[290,291]$. But there are some statements on the granular $\mathrm{AC}$ that supported $\mathrm{TiO}_{2}$ photocatalyst which could enhance the demolishing efficiency of many organic compounds, regarding many environmentally related conditions [252, 292] (Figure 15).

Granule AC supports $\mathrm{TiO}_{2}$ powdered by adding more pollutants and alternatives around the $\mathrm{TiO}_{2}$. The pollutants and alternatives can diffuse to the surface of $\mathrm{TiO}_{2}$. Granular AC also reduces $\mathrm{TiO}_{2}$ jelling, which lessens its surface, thereby reducing its enzymatic activities [292]. This was brought by the theory that the absorptivity of AC depending strongly on the molecular morphology and size of the pollutant particles to the $\mathrm{TiO}_{2}$ surface happens straightforwardly from the solution, and not through the AC surface [293, 294]. The $\mathrm{TiO}_{2}$ can destroy the pollutants, leading again to generation of granular AC in this situation [294]. Most of the porous AC still in granules, and the problem of separation and recovering of the photocatalyst from the reaction environment is already present.

4.2. ACF Photocatalytic Systems. AC is a freshly developed type of photocatalyst supporting materials consisting of nanographites known as AC fiber ACF. In comparison to the granular AC, ACF has a larger surface area, having greater pore volume, more uniform micropores size distribution, a greater rate of adsorption and desorption, and a rapid attainment of adsorption equilibrium with ACF in the form of fleet are preferable to the handling than granular supports $[245,253]$ (Figure 16).

The surface-area characteristics of the ACF are identified to depend powerfully on the creative processes, affecting the load of $\mathrm{TiO}_{2}$ and eventually the adsorption of pollutant particles [255]. Nevertheless, the ACF supported $\mathrm{TiO}_{2}$ photocatalyst has sometimes been used for the removal of gas phase pollutants in the environment (Figure 17).

4.3. $\mathrm{TiO}_{2}$ : Graphene Photocatalyst System. Meanwhile, the beginning of graphene supply is an idea to resolve the limitation brought by the $\mathrm{TiO}_{2}$ : AC photocatalyst. Recently, functionalized grapheme based semiconductor photocatalyst has attracted attention because of its larger definite surface area, higher electron conductivity, and adsorption [248] (Figure 18).

A lot of the hard work is used for the combination of $\mathrm{TiO}_{2}$-graphene photocatalysis hybrid system [295, 296]. Considering advantages due to a higher specified surface region, graphene appeared like a better help to prepare the overloaded nanoparticle metal oxides to attain an identical division not including aggregation. Betterment of the photocatalytic actions of $\mathrm{TiO}_{2}$-graphene hybrid is associated with huge two-dimensional planar graphene structure supporting the dye adsorption plus squeezing electron hole rejoining because of higher electrical conduction property as has been indicated by the morphological analysis of $\mathrm{TiO}_{2}$ /grapheme photocatalyst [226, 254] (Figure 19).

Additionally, absorption of additional catalyst particles into a particularly graphene leaf at individual places can supply better dynamically in achieving the choosy catalytic otherwise logical procedures and adjusts the composition also the morphology of photocatalysts to enhance their photocatalytic results [297].

4.4. $\mathrm{TiO}_{2}$ : CNT Photocatalyst System. Barring graphene, carbon nanotube (CNT) has been regarded as a more attractive catalytic support than activated carbon because of combination of electronic, adsorption, and specific semiconducting characteristics [298]. Studies of $\mathrm{TiO}_{2}$ : CNTs reveal a considerable synergy effect with the metal oxides and carbon phases [298, 299]. Going further, researchers have shown that CNTs can enhance the adsorption and photocatalytic activity of $\mathrm{TiO}_{2}$ in the presence of ultraviolet [300]. Single walled CNTs execute enhanced and selective photocatalytic oxidation of $\mathrm{pH}$ [299]. Heterostructure CNT consists of $\mathrm{TiO}_{2}-\mathrm{xNx}$ and $\mathrm{C}$ prepared by carbonization of electron-spun polyacrylonitrile nanofibers containing stabilized titanium oxoacetate [301]. So, CNTs can be used as a reliable material for environmental pollution clearing and can be used to improve the photocatalytic efficiency of $\mathrm{TiO}_{2}$.

4.5. $\mathrm{TiO}_{2}:$ AC Semiconductor Doped Photocatalyst System. The term "doping" means an additional semiconductor having unusual parallel valence bands and conduction of energy levels with the $\mathrm{TiO}_{2}$ over the outer surface of $\mathrm{TiO}_{2}$ has been authorized the outcome to progress the photocatalytic results. The method of using coupled semiconductors is the enhancement of the photocatalytic with good organization by raising the charge division and increasing the photoresponding domain. Some researches upon doping an additional semiconductor over outer surface of $\mathrm{TiO}_{2}: \mathrm{AC}$ includes $\mathrm{SnO}_{2}$, $\mathrm{V}_{2} \mathrm{O}_{5}, \mathrm{ZnO}, \mathrm{ZrO}_{2}$, and CsS $[239,260,302,303]$. The entire of it confirms the superior photodegradation efficiency as compared to the $\mathrm{TiO}_{2}$ : AC. Recent researches have reported the modification of $\mathrm{TiO}_{2}$ : AC by semi-conductor doping that has led to the improvement of removal of specific containments in the gas resulting in the changes of the physical and chemical properties of the carbon materials. Iron $\left(\mathrm{Fe}_{3} \mathrm{O}_{4}\right)$ dopant $\mathrm{TiO}_{2}$ : AC has been found to be a promoter to photocatalysis with a good performance on degradation of Congo red and methyl orange [32]. Some researchers have 

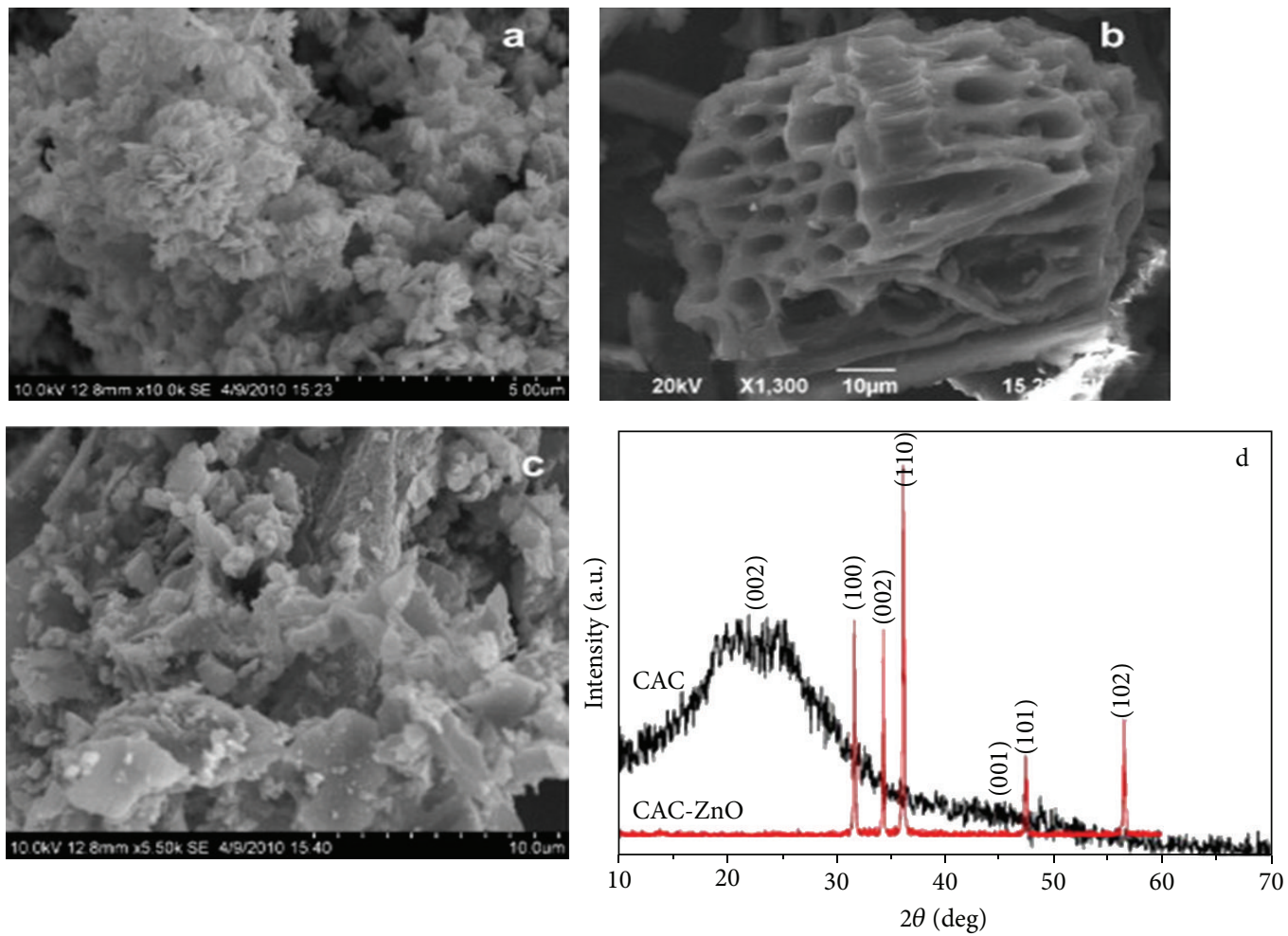

FIGURE 13: Surface morphology of the (a) pure $\mathrm{ZnO}$, (b) pure $\mathrm{AC}$, and (c) $\mathrm{AC}-\mathrm{ZnO}$ mixture. $\mathrm{XRD}$ spectrum of pure $\mathrm{AC}$ and $\mathrm{AC}-\mathrm{TiO}{ }_{2}$ mixture [37].

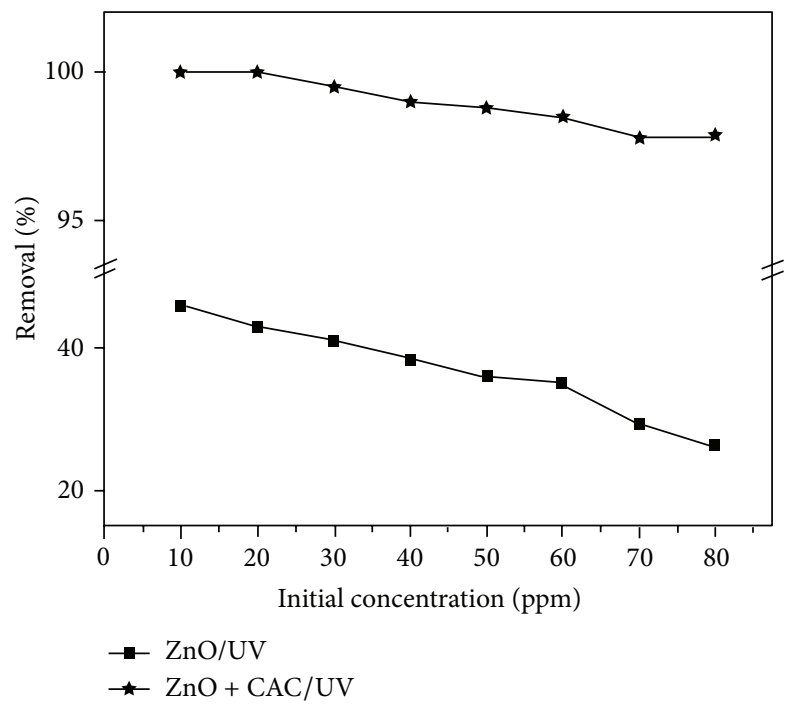

FIGURE 14: Effect of initial concentration of dye in the presence and absence of AC in ZnO/AC photocatalyst system (contact time: 90 min; dose of the catalyst: $200 \mathrm{mg}$; dose of the CAC: $40 \mathrm{mg}$ ) [37].

combined the $\mathrm{Fe}_{3} \mathrm{O}_{4}$ compound with $\mathrm{TiO}_{2}$ : $\mathrm{AC}$ aiming at preparing photocatalyst with magnetic core and photoactive encapsulation [234]. They proved that hybrid systems had magnetic properties and could be separated by magnetic materials. Furthermore, the magnetic hybrid photocatalyst can also be magnetically distributed by a discontinuous magnetic field in an interrupted system [304]. But they found that the photocatalytic activity of the hybrid system declined because the magnetic particles experienced light dissolution [305].

4.6. $\mathrm{TiO}_{2}$ : AC Nonmetal Doped Photocatalyst System. Doping of nonmetal, such as N, P, B, C, S, F, chlorine, and bromine, has been also widely used to improve the photocatalytic or 


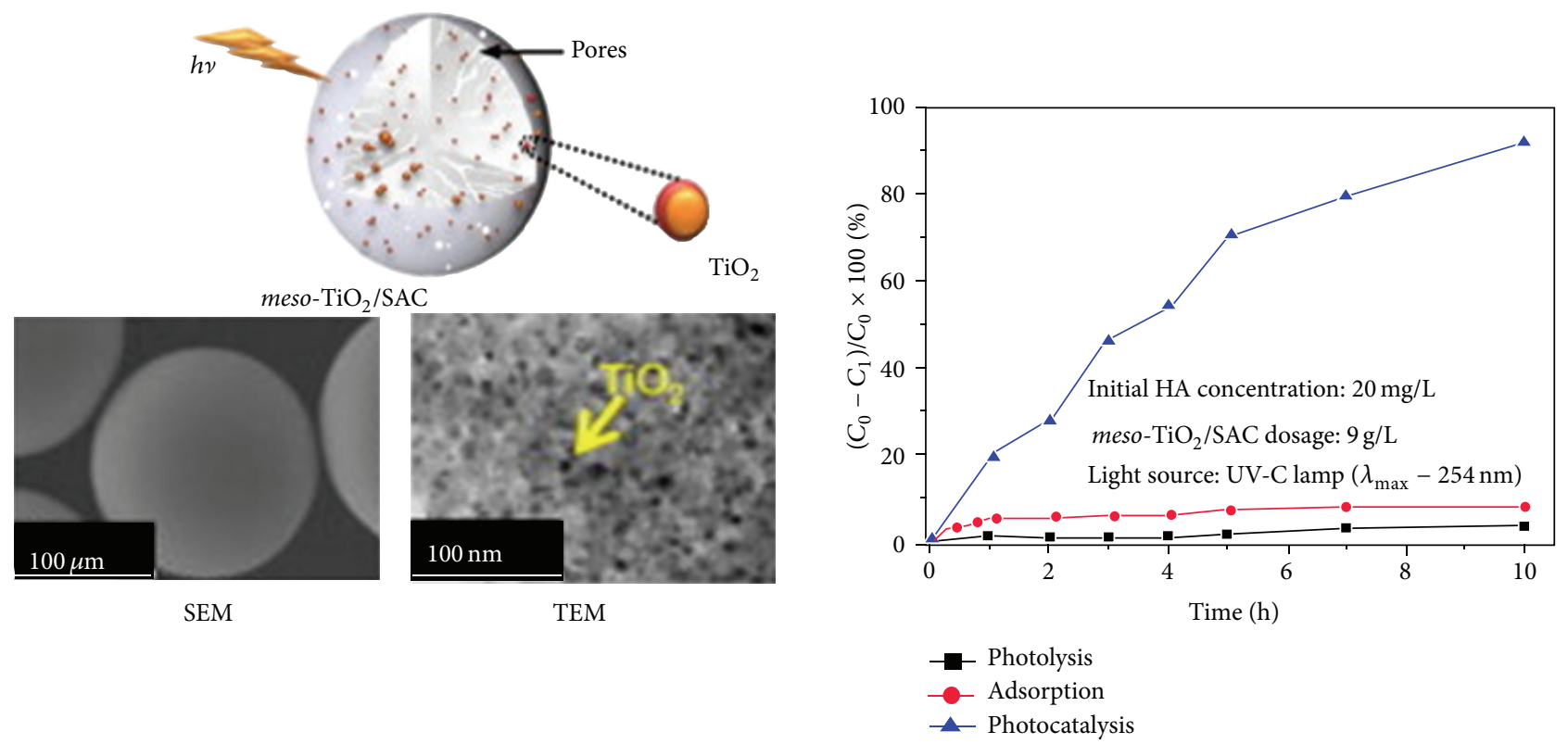

FIGURE 15: Effect of granular and spherical AC on adsorption and photocatalytic activity [252].

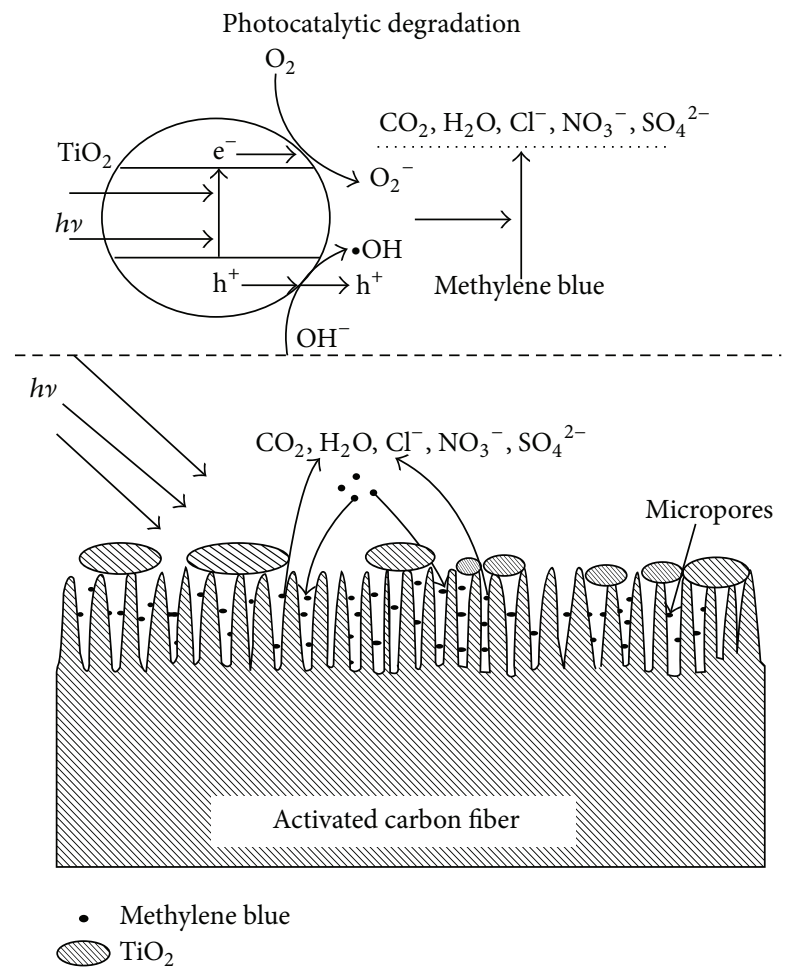

FIGURE 16: Schematic diagram for the adsorption and photocatalytic degradation of methylene blue on the $\mathrm{TiO}_{2} / \mathrm{ACFs}$ [253].

to extend the photoabsorption into visible light of $\mathrm{TiO}_{2}: \mathrm{AC}$ system [258]. Among them, the $\mathrm{P}$ doped $\mathrm{TiO}_{2}: \mathrm{AC}$ has recently attracted increasing interest due to its enhanced shows a little band gap. It has an adsorption property in the visible light region [306]. Also, it has been found that phosphorous-doped $\mathrm{TiO}_{2}$ : AC prepared by the buffer solution method with $\mathrm{NaH}_{2} \mathrm{PO}_{4}$ as precursor showed a greater photocatalytic activity of acetaldehyde organic burning under visible light absence than the pure sample [307]. It synthesizes the phosphorous-doped $\mathrm{TiO}_{2}: \mathrm{AC}$ with high crystallinity and large surface area of hydrothermal process. Methylene blue demoted performance on phosphorous-doped sample was pointedly increased and superior to the commercial Phosphorous 25 [308]. 

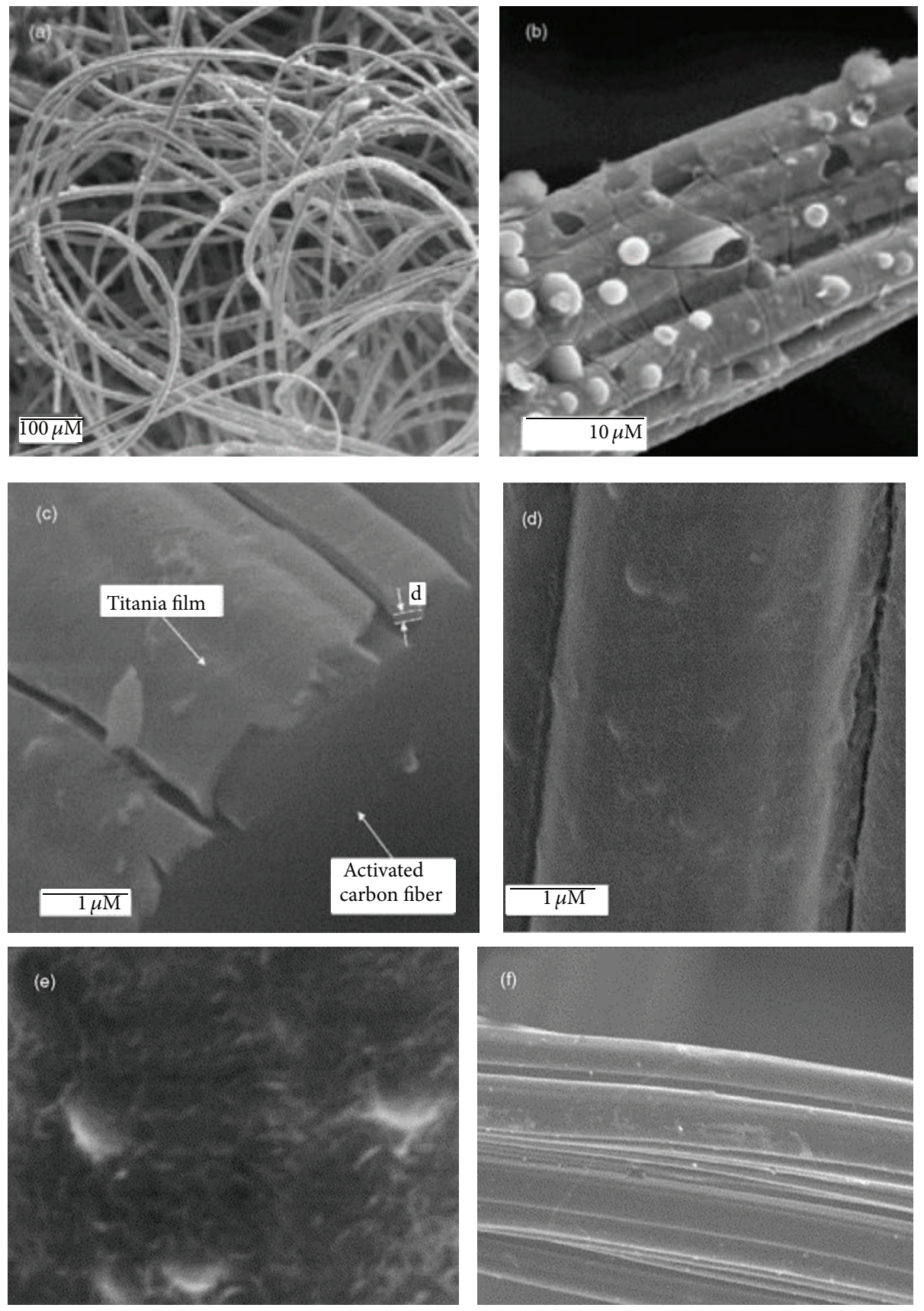

Figure 17: SEM micrographs of the $\mathrm{TiO}_{2} / \mathrm{ACF}$ photocatalyst and unmodified ACFs, (a) general view of the photocatalyst, 100x; (b) TiO 2 coating on single carbon fiber, 2000x; (c) cross-sectional view of $\mathrm{TiO}_{2}$ coating, 20,000x; (d) surface of $\mathrm{TiO}_{2}$ coating, 20,000x; (e) surface of $\mathrm{TiO}_{2}$ coating, 50,000x; and (f) single unmodified activated carbon fiber 4000x [253].

\section{Conclusion}

AC has been employed as an adsorbent for the control of many environmental pollutants due to its high pore density and large uncovered surface area-to-volume ratio. Many AC researches have targeted primarily with concentration in lower to higher concentrations than that associated with indoor aqueous quality. Loading of semiconductors on $\mathrm{AC}$ has drawn vast interest while the higher adsorption abilities of
AC can assist in the direction of improvement of organic pollutant about the enzyme, enhancing the toxin transmission method thus enhancing the photocatalytic results. In future, photocatalysis reaction in visible light can be addressed as the main challenge, as reflected by recent intensive scientific endeavors. The state-of-the-art accomplishments in visible light will be induced in selection of organic transformations by $\mathrm{AC}$ heterogeneous photocatalysis. In addition, the recent strides are to bridge between AC photocatalysis system 


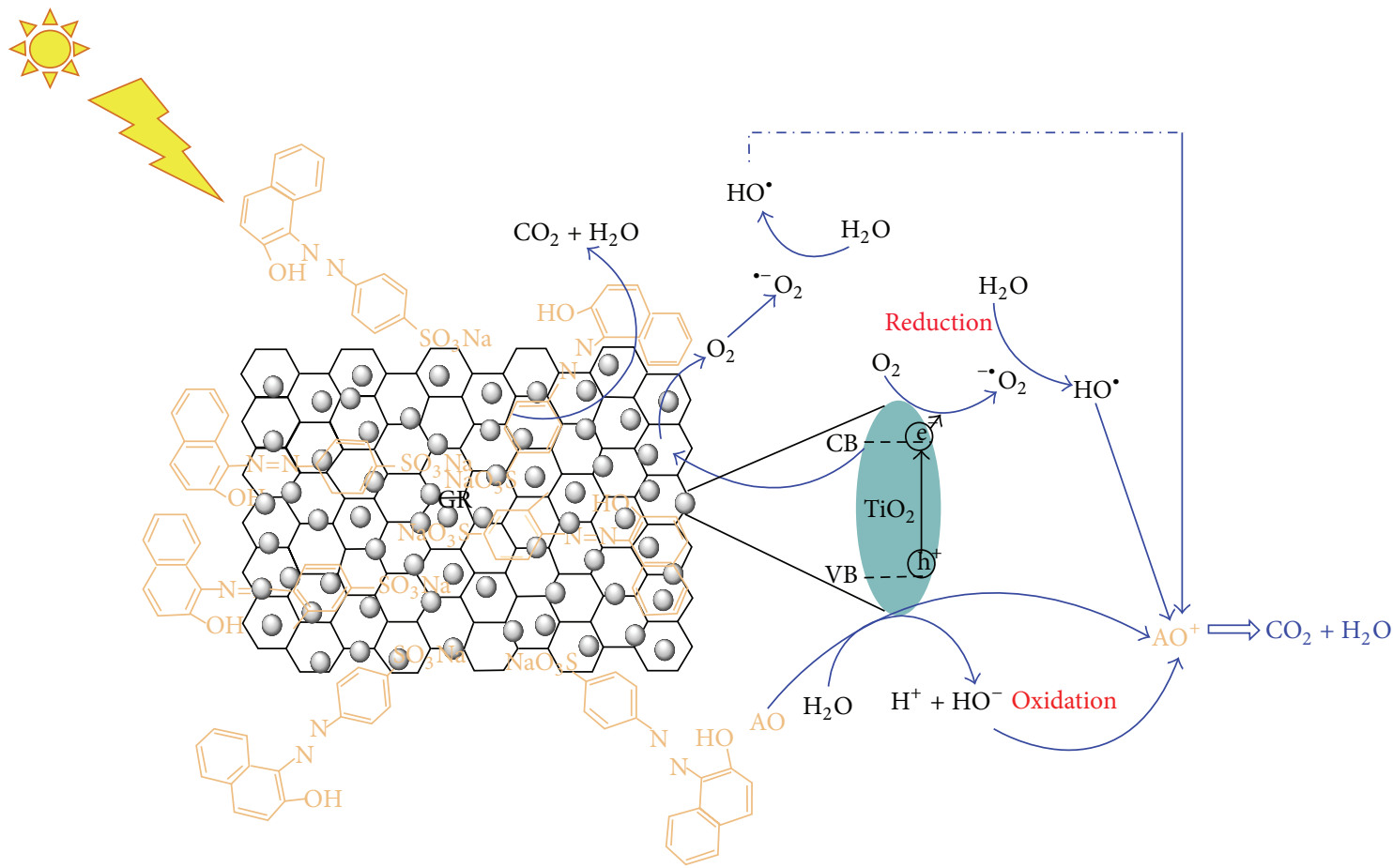

FIGURE 18: Schematic illustrations on the photodegradation mechanism of the synthetic dye on $\mathrm{TiO}_{2}$ /graphene nanocomposite [248].

and other area of the catalyst with the aim of overcoming the existing limitation of photocatalyst by developing more creative approaches.

\section{Abbreviations}

[BMIM]Cl: 1-Butyl-3-methylimidazolium chloride [EMIM] $\mathrm{BF}_{4}$ : 1-Ethyl-3-methylimidazolium tetrafluoroborate

[EMIM]Cl: 1-Ethyl-3-methylimidazolium chloride

AC: $\quad$ Activated carbon

ACF: $\quad$ Activated carbon fibers

Ag: $\quad$ Silver

$\mathrm{Al}_{2} \mathrm{O}_{3}: \quad$ Aluminum oxide

Al-MCM-42: Mesoporous aluminium silicate

Al-MSU-F: Mesostructure aluminosilicate

AuCl: $\quad$ Gold(I) chloride

C: $\quad$ Carbon

CdSe: $\quad$ Cadmium selenide

$\mathrm{CeO}_{2}$ : Cerium oxide

$\mathrm{CO}_{2}$ : Carbon dioxide

$\mathrm{Co}^{2+}: \quad$ Cobalt ions

$\mathrm{Co}_{3} \mathrm{O}_{4}$ : Cobalt(II) oxide

$\mathrm{CoFe}_{2} \mathrm{O}_{4}$ : Cobalt ferrite

$\mathrm{Cr}(\mathrm{VI}): \quad$ Chromium

$\mathrm{Cr}^{3+}$ : $\quad$ Chromium ions

$\mathrm{CrCl}_{2}$ : $\quad$ Chromium(II) chloride

$\mathrm{CrCl}_{3}$ : $\quad$ Chromium(III) chloride

CVD: $\quad$ Chemical Vapor Deposition

DMA: Dimethylacetate
DMF: Dimethylformamide

F: $\quad$ Fluoride

FCC: $\quad$ Fluid catalytic cracking

$\mathrm{Fe}^{3+}: \quad$ Iron ions

$\mathrm{Fe}_{3} \mathrm{C}: \quad$ Cementite

$\mathrm{H}_{2} \mathrm{O}$ : Water

$\mathrm{H}_{2} \mathrm{SO}_{4}$ : $\quad$ Sulfuric acid

$\mathrm{H}_{3} \mathrm{PW}_{12} \mathrm{O}_{40}$ : Tungstophosphoric acids

$\mathrm{H}_{3} \mathrm{PW}_{12} \mathrm{O}_{46}$ : Dodeca tungstosilicic acid

$\mathrm{H}_{4} \mathrm{SiW}_{12} \mathrm{O}_{40}$ : Tungstosilicious

$\mathrm{HCl} \quad$ Acid hydrochloride

HMF: $\quad$ Hydroxymethylfurfural

IrCl: Iridium(II) chloride

$\mathrm{LaCl}_{3}$ : $\quad$ Lanthanum(II) chloride

LiCl: $\quad$ Lithium chloride

McM 41: Self-bonded zeolite beta

$\mathrm{Mn}^{2+}: \quad$ Manganese ions

$\mathrm{N}$ : Nitrogen

$\mathrm{NaCl}$ Sodium chloride

$\mathrm{Ni} \quad \quad$ Nickel

$\mathrm{OH}: \quad$ Hydroxyl

P: $\quad$ Phosphate

Pd: $\quad$ Palladium

$\mathrm{PdCl}_{2}$ : $\quad$ Palladium(II) chloride

Pt: Platinum

PVB: $\quad$ Polyvinyl butyral

Rh: $\quad$ Rhodium

$\mathrm{Ru}$ : Ruthenium

S: $\quad$ Sulfide

SBA-15: $\quad$ Mesoporous silica

$\mathrm{SiO}^{2-}$ : $\quad$ Silicon dioxide 

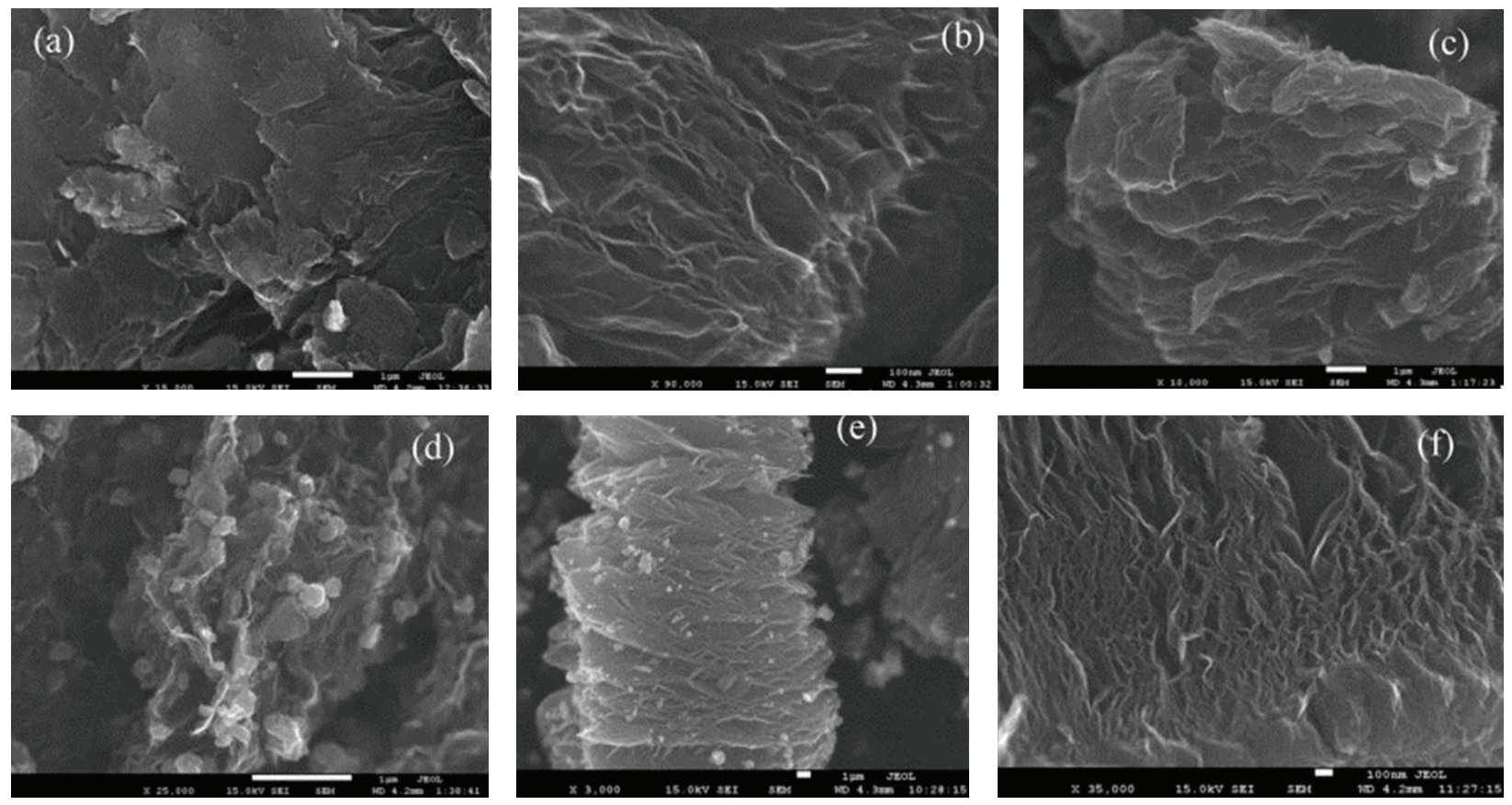

Figure 19: FE-SEM images of $\mathrm{TiO}_{2} /$ graphene nanocomposites at different $\mathrm{TiO}_{2}$ contents $1 \mathrm{wt} \%$ (a), $3 \mathrm{wt} \%$ (b), $5 \mathrm{wt} \%$ (c), and $10 \mathrm{wt} \%$ $\mathrm{TiO}_{2} /$ graphene heat treated at $450^{\circ} \mathrm{C}$ under reducing $\left(\mathrm{N}_{2} / \mathrm{H}_{2}\right)(\mathrm{e})$ and nitrogen (f) [254].

$\mathrm{SnCl}_{4}: \quad \operatorname{Tin}(\mathrm{IV})$ chloride

$\mathrm{SO}_{3} \mathrm{H}: \quad$ Sulfonic acid

$\mathrm{SrTiO}_{3}$ : Strontium titanate

$\mathrm{TiO}_{2}$ : Titanium oxide

UV: $\quad$ Ultraviolet

$\mathrm{V}_{2} \mathrm{O}_{5}$ : Vanadium pentoxide

$\mathrm{ZnO}$ : Zinc oxide

$\mathrm{ZrO}_{3}:$ Zirconia

ZrP: $\quad$ Zirconium phosphate

ZSM-5: Zeolite Socony mobile 5.

\section{Conflict of Interests}

The authors declare that there is no conflict of interests regarding the publication of this paper.

\section{Acknowledgments}

This work is financially supported by University Malaya Research Grant (UMRG RP022-2012E; UMRG RP0222012A) and Fundamental Research Grant Scheme (FRGS: FP049-2013B) by University of Malaya and Ministry of High Education (MOE), Malaysia.

\section{References}

[1] C. Baleizão, B. Gigante, H. Garcia, and A. Corma, "Ionic liquids as green solvents for the asymmetric synthesis of cyanohydrins catalysed by $\mathrm{VO}$ (salen) complexes," Green Chemistry, vol. 4, no. 3, pp. 272-274, 2002.
[2] V. L. Coluim, "The potential environmental impact of engineered nanomaterials," Nature Biotechnology, vol. 21, pp. 11661170, 2003.

[3] R. H. Hurt, M. Monthioux, and A. Kane, "Toxicology of carbon nanomaterials: status, trends, and perspectives on the special issue," Carbon, vol. 44, no. 6, pp. 1028-1033, 2006.

[4] V. Subramanian, H. Zhu, R. Vajtai, P. M. Ajayan, and B. Wei, "Hydrothermal synthesis and pseudocapacitance properties of $\mathrm{MnO}_{2}$ nanostructures," Journal of Physical Chemistry B, vol. 109, no. 43, pp. 20207-20214, 2005.

[5] W. Seiler and P. J. Crutzen, "Estimates of gross and net fluxes of carbon between the biosphere and the atmosphere from biomass burning," Climatic Change, vol. 2, no. 3, pp. 207-247, 1980.

[6] M. F. Philip, L. Niwton, and M. F. Fernondo, "Rainforest burning and the global carbon budget: biomass, combustion efficiency, and charcoal formation in the Brazilian Amazon," Journal of Geophysical Research: Atmospheres, vol. 98, pp. 16733$16743,1980$.

[7] Y. Kuzyakos, I. Subbotino, H. Chen, I. Bagomolova, and X. $\mathrm{Xu}$, "Black carbon decomposition and incorporation into soil microbial biomass estimated by ${ }^{14} \mathrm{C}$ labeling," Soil Biology and Biochemistry, vol. 41, no. 2, pp. 210-219, 2009.

[8] A. Demirbas, "Carbonization ranking of selected biomass for charcoal, liquid and gaseous products," Energy Conversion and Management, vol. 42, no. 10, pp. 1229-1238, 2001.

[9] E. N. Chidumayo, "Woody biomass structure and utilisation for charcoal production in a Zambian Miombo woodland," Bioresource Technology, vol. 37, no. 1, pp. 43-52, 1991.

[10] U. Hamer, B. Marschner, S. Brodowski, and W. Amelong, "Interactive priming of black carbon and glucose mineralisation," Organic Geochemistry, vol. 36, no. 7, pp. 823-830, 2004. 
[11] J. C. Akunna, C. Bizeau, and R. Moletta, "Nitrate and nitrite reductions with anaerobic sludge using various carbon sources: glucose, glycerol, acetic acid, lactic acid and methanol," Water Research, vol. 27, no. 8, pp. 1303-1312, 1993.

[12] J. Wang, L. Fang, D. Lopez, and H. Tobias, "Highly selective and sensitive amperometric biosensing of glucose at rutheniumdispersed carbon paste enzyme electrodes," Analytical Letters, vol. 26, no. 9, pp. 1819-1830, 1993.

[13] C. Bourdilon, J. P. Bourgeois, and D. Thomas, "Covalent linkage of glucose oxidase on modified glassy carbon electrodes. Kinetic phenomena," Journal of the American Chemical Society, vol. 102, no. 12, pp. 4231-4235, 1980.

[14] Y. Onal, S. Schimpt, and P. Claus, "Structure sensitivity and kinetics of d-glucose oxidation to d-gluconic acid over carbonsupported gold catalysts," Journal of Catalysis, vol. 223, no. 1, pp. 122-133, 2004.

[15] J. J. Manya, E. Velo, and L. Puigjaner, "Kinetics of biomass pyrolysis: a reformulated three-parallel-reactions model," Industrial \& Engineering Chemistry Research, vol. 42, no. 3, pp. 433-441, 2003.

[16] R. D. Cortright, R. R. Davda, and J. A. Dumesic, "Hydrogen from catalytic reforming of biomass-derived hydrocarbons in liquid water," Nature, vol. 418, no. 6901, pp. 964-967, 2002.

[17] D. Sutton, B. Kelleher, and J. R. H. Ross, "Review of literature on catalysts for biomass gasification," Fuel Processing Technology, vol. 73, no. 3, pp. 155-173, 2001.

[18] T. R. Carlson, T. P. Vispute, and G. W. Huber, "Green gasoline by catalytic fast pyrolysis of solid biomass derived compounds," ChemSusChem, vol. 1, no. 5, pp. 397-400, 2008.

[19] H. Mehdi, V. Fabos, R. Taba, A. Bodor, L. T. Mika, and I. T. Horvalth, "Integration of homogeneous and heterogeneous catalytic processes for a multi-step conversion of biomass: from sucrose to Levulinic acid, $\gamma$-valerolactone, 1,4-pentanediol, 2 methyl-tetrahydrofuran, and alkanes," Topics in Catalysis, vol. 48, no. 1-4, pp. 49-54, 2008.

[20] T. R. Carlson, G. A. Tompsett, W. C. Conner, and G. W. Huber, "Aromatic production from catalytic fast pyrolysis of biomassderived feedstocks," Topics in Catalysis, vol. 52, no. 3, pp. 241252, 2009.

[21] J.-P. Tessonnier, A. Villa, O. Majoulet, D. S. Su, and R. Schlögl, "Defect-mediated functionalization of carbon nanotubes as a route to design single-site basic heterogeneous catalysts for biomass conversion," Angewandte Chemie, vol. 48, no. 35, pp. 6543-6546, 2009.

[22] J. P. T. Dalsgaard, C. Lightfool, and V. Christensen, "Towards quantification of ecological sustainability in farming systems analysis," Ecological Engineering, vol. 4, pp. 181-189, 1995.

[23] M. Hoogwijk, A. Faaij, R. van den Broek, G. Berndes, D. Gielen, and W. Turkenburg, "Exploration of the ranges of the global potential of biomass for energy," Biomass and Bioenergy, vol. 25, no. 2, pp. 119-133, 2003.

[24] Y. Cong, M. Chen, T. Xu, Y. Zhang, and Q. Wang, "Tantalum and aluminum co-doped iron oxide as a robust photocatalyst for water oxidation," Applied Catalysis B: Environmental, vol. 147, pp. 733-740, 2014.

[25] D. Zhang, M. Wen, S. Zhang et al., "Au nanoparticles enhanced rutile $\mathrm{TiO}_{2}$ nanorod bundles with high visible-light photocatalytic performance for NO oxidation," Applied Catalysis B, pp. 610-616, 2014.

[26] Z. F. Huang, J. J. Zou, L. Pan et al., "Synergetic promotion on photoactivity and stability of $\mathrm{W}_{18} \mathrm{O}_{4} / \mathrm{TiO}_{2}$ hybrid," Applied Catalysis B: Environmental, vol. 147, pp. 167-174, 2014.
[27] B. Weng, S. Liu, N. Zhang, Z.-R. Tang, and Y.-J. Xu, "A simple yet efficient visible-light-driven CdS nanowires-carbon nanotube 1D-1D nanocomposite photocatalyst," Journal of Catalysis, vol. 309, pp. 146-155, 2014.

[28] S. N. R. Inturi, T. Boningari, M. Suidan, and P. G. Smirniotis, "Visible-light-induced photodegradation of gas phase acetonitrile using aerosol-made transition metal ( $\mathrm{V}, \mathrm{Cr}, \mathrm{Fe}, \mathrm{Co}, \mathrm{Mn}$, $\mathrm{Mo}, \mathrm{Ni}, \mathrm{Cu}, \mathrm{Y}, \mathrm{Ce}$, and $\mathrm{Zr}$ ) doped $\mathrm{TiO}_{2}$," Applied Catalysis $\mathrm{B}$ : Environmental, vol. 144, pp. 333-342, 2014.

[29] C. F. Chang and C. Y. Man, "Magnetic photocatalysts of copper phthalocyanine-sensitized titania for the photodegradation of dimethyl phthalate under visible light," Colloids and Surfaces A: Physicochemical and Engineering Aspects, vol. 441, pp. 255-261, 2014.

[30] S. Kumar, B. Kumar, T. Surender, and V. Shanker, " $\mathrm{g}-\mathrm{C}_{3} \mathrm{~N}_{4}$ / $\mathrm{NaTaO}_{3}$ organic-inorganic hybrid nanocomposite: Highperformance and recyclable visible light driven photocatalyst," Materials Research Bulletin, vol. 49, pp. 310-318, 2014.

[31] J. Gamage McEvoy, W. Cui, and Z. Zhang, "Synthesis and characterization of $\mathrm{Ag} / \mathrm{AgCl}$-activated carbon composites for enhanced visible light photocatalysis," Applied Catalysis B: Environmental, vol. 144, pp. 702-712, 2014.

[32] D. H. Quinones, A. Rey, P. M. Alvarez, F. J. Beltran, and P. K. Plucinski, "Enhanced activity and reusability of $\mathrm{TiO}_{2}$ loaded magnetic activated carbon for solar photocatalytic ozonation," Applied Catalysis B: Environmental, vol. 144, pp. 96-106, 2014.

[33] Z. Cherkezova-Zheleva, D. Paneva, M. Tsvetkov et al., "Preparation of improved catalytic materials for water purification," Hyperfine Interactions, vol. 226, no. 1-3, pp. 517-527, 2014.

[34] J. Yun, H. I. Kim, and Y. S. Lee, "A hybrid gas-sensing material based on porous carbon fibers and a $\mathrm{TiO}_{2}$ photocatalyst," Journal of Materials Science, vol. 48, pp. 8320-8328, 2013.

[35] B. Adeli and F. Taghipour, "A review of synthesis techniques for gallium-zinc oxynitride solar-activated photocatalyst for water splitting," ECS Journal of Solid State Science and Technology, vol. 2, no. 7, pp. Q118-Q126, 2013.

[36] Z. Ou-Yang, H. L. Xu, C. Xiong et al., "Prearation of $\mathrm{TiO}_{2}$ supported activated carbon and its application in papermaking wastewater," Advanced Materials Research, vol. 791, p. 7, 2013.

[37] P. Muthirulan, M. Meenakshisundararam, and N. Kannan, "Beneficial role of $\mathrm{ZnO}$ photocatalyst supported with porous activated carbon for the mineralization of alizarin cyanin green dye in aqueous solution," Journal of Advanced Research, vol. 4, no. 6, pp. 479-484, 2013.

[38] M. Smits, D. Huygh, B. Craeye, and S. Lenaerts, "Effect of process parameters on the photocatalytic soot degradation on self-cleaning cementitious materials," Catalysis Today, vol. 230, pp. 250-255, 2014.

[39] M. J. Nurhidayatullaili, B. Samira, and B. A. H. Sharifah, "Recent advances in heterogeneous photocatalytic decolorization of synthetic dyes," The Scientific World Journal, vol. 2014, Article ID 692307, 25 pages, 2014.

[40] M.-M. Titirice, A. Thomas, and M. Antonietti, "Aminated hydrophilic ordered mesoporous carbons," Journal of Materials Chemistry, vol. 17, pp. 3412-3418, 2013.

[41] V. Budarin, J. H. Clark, J. J. E. Hardy et al., "Starbons: new starchderived mesoporous carbonaceous materials with tunable properties," Angewandte Chemie, vol. 45, no. 23, pp. 3782-3786, 2006.

[42] Q. Wang, H. Li, L. Chen, and X. Huang, "Monodispersed hard carbon spherules with uniform nanopores," Carbon, vol. 39, no. 14, pp. 2211-2214, 2001. 
[43] C. Poonjarernsilp, N. Sano, and H. Tomon, "Hydrothermally sulfonated single-walled carbon nanohorns for use as solid catalysts in biodiesel production by esterification of palmitic acid," Applied Catalysis B: Environmental, vol. 147, pp. 726-732, 2014.

[44] Y. F. Zhang, "Research on low-carbon architectural development based on green life cycle," Applied Mechanics and Materials, vol. 443, pp. 263-267, 2014.

[45] N. M. Mubarak, J. N. Sahu, E. C. Abdullah, and N. S. Jayakumar, "Removal of heavy metals from wastewater using carbon nanotubes," Separation and Purification Reviews, vol. 43, no. 4, pp. 311-338, 2014.

[46] A. Fraczek-Szczypta, "Carbon nanomaterials for nerve tissue stimulation and regeneration," Materials Science and Engineering C, vol. 34, pp. 35-49, 2014.

[47] M. Vikkisk, I. Kruusenberg, U. Joost, E. Shulga, I. Kink, and K. Tammeveski, "Electrocatalytic oxygen reduction on nitrogen-doped graphene in alkaline media," Applied Catalysis B: Environmental, vol. 147, pp. 369-376, 2014.

[48] K. Takeba, M. Matsumoto, Y. Shida, and H. Nakazawa, "Determination of phenol in honey by liquid chromatography with amperometric detection," Journal of the Association of Official Analytical Chemists, vol. 73, no. 4, pp. 602-604, 1990.

[49] J. Yang, Y. Yu, J. Jan, S.-T. Tua, and E. Dahlquistc, "Effects of $\mathrm{SO}_{2}$ on $\mathrm{CO}_{2}$ capture using a hollow fiber membrane contactor," Applied Energy, vol. 112, pp. 755-764, 2013.

[50] R. A. Shawabkeh, M. Al-Harthi, and S. M. Al-Ghamdi, "The synthesis and characterization of microporous, high surface area activated carbon from palm seeds," Energy Sources A: Recovery, Utilization and Environmental Effects, vol. 36, no. 1, pp. 93-103, 2014.

[51] K. Labus, S. Gryglewicz, and J. Machnikowski, "Granular $\mathrm{KOH}$-activated carbons from coal-based cokes and their $\mathrm{CO}_{2}$ adsorption capacity," Fuel, vol. 118, pp. 9-15, 2014.

[52] Y.-Z. Xiang, X. Luo, W. Y. Han et al., "Preparation and catalytic activities of hydrolysis catalyst for carbonyl sulfide in light hydrocarbon," Modern Chemistry, vol. 33, p. 48, 2013.

[53] T. Li, Y. Ren, and C. Wei, "Study on preparation and properties of PVA-SA-PHB-AC composites carrier for microorganism immobilizatin," Journal of Applied Polymer Science, vol. 131, 2014.

[54] B. Zhang, X. P. Zhuang, B. Cheng, N. Wang, and Y. Ni, "Carbonaceous nanofiber-supported sulfonated poly(ether ether ketone) membranes for fuel cell applications," Materials Letters, vol. 115, pp. 248-251, 2014.

[55] W. Kangwanwatana, C. Saiwan, and P. Tontiwachwuthikul, "Study of $\mathrm{CO}_{2}$ adsorption using adsorbent modified with piperazine," Chemical Engineering Transactions, vol. 35, pp. 403-408, 2013.

[56] A. R. Milbrandt, D. M. Heimiller, A. D. Perry, and C. B. Field, "Renewable energy potential on marginal lands in the United States," Renewable and Sustainable Energy Reviews, vol. 29, pp. 473-481, 2014.

[57] T. Samus, B. Lang, and H. Rohn, "Assessing the natural resource use and the resource efficiency potential of the Desertec concept," Solar Energy, vol. 87, no. 1, pp. 176-183, 2013.

[58] A. Tavangar, B. Tan, and K. Venkatakishnan, “Transport properties of two finite armchair graphene nanoribbons," Nanoscale Research Letters, vol. 8, p. 1, 2013.

[59] M. Vukčević, B. Pejic, A. Kalijadis et al., "Carbon materials from waste short hemp fibers as a sorbent for heavy metal ions-mathematical modeling of sorbent structure and ions transport," Chemical Engineering Journal, vol. 235, pp. 284-292, 2014.

[60] Y. Xiong, Z. Zhang, X. Wang, B. Liu, and J. Lin, "Hydrolysis of cellulose in ionic liquids catalyzed by a magneticallyrecoverable solid acid catalyst," Chemical Engineering Journal, vol. 235, pp. 349-355, 2014.

[61] Y. Song, J. Zhoa, L. Zhang, and X. Wu, "Homogenous modification of cellulose with acrylamide in $\mathrm{NaOH}$ /urea aqueous solutions," Carbohydrate Polymers, vol. 73, no. 1, pp. 18-25, 2008.

[62] Z. Zhang, W. Wang, X. Liu et al., "Kinetic study of acid-catalyzed cellulose hydrolysis in 1-butyl-3-methylimidazolium chloride," Bioresource Technology, vol. 112, pp. 151-155, 2012.

[63] S. Ali, K. Andrea, and S. Valentin, "Formation and degradation pathways of intermediate products formed during the hydropyrolysis of glucose as a model substance for wet biomass in a tubular reactor," Engineering in Life Sciences, vol. 3, no. 12, pp. 469-473, 2003.

[64] M. Bicker, D. Kaiser, L. Ott, and H. Vogel, "Dehydration of D-fructose to hydroxymethylfurfural in sub- and supercritical fluids," Journal of Supercritical Fluids, vol. 36, no. 2, pp. 118-126, 2005.

[65] V. Budarin, R. Luque, D. J. Macquarrie, and J. H. Clark, "Towards a bio-based industry: Benign catalytic esterifications of succinic acid in the presence of water," Chemistry, vol. 13, no. 24, pp. 6914-6919, 2007.

[66] R. Demir-Cakan, N. Baccile, M. Antonietti, and M.-M. Titirici, "Carboxylate-rich carbonaceous materials via onestep hydrothermal carbonization of glucose in the presence of acrylic acid," Chemistry of Materials, vol. 21, no. 3, pp. 484-490, 2009.

[67] A. Thomas, P. Kuhn, J. Weber, M.-M. Titirici, and M. Antonietti, "Porous polymers: enabling solutions for energy applications," Macromolecular Rapid Communications, vol. 30, no. 4-5, pp. 221-236, 2009.

[68] M. Iguchi, T. M. Aida, M. Watanabe, and R. L. Smith Jr., "Dissolution and recovery of cellulose from 1-butyl-3methylimidazolium chloride in presence of water," Carbohydrate Polymers, vol. 92, no. 1, pp. 651-658, 2013.

[69] G. Fan, C. Liao, T. Fang, M. Wang, and G. Song, "Hydrolysis of cellulose catalyzed by sulfonated poly(styreneco-divinylbenzene) in the ionic liquid 1-n-butyl-3methylimidazolium bromide," Fuel Processing Technology, vol. 116, pp. 142-148, 2013.

[70] R. Göbel, Z. L. Xie, M. Neumann et al., "Synthesis of mesoporous carbon/iron carbide hybrids with unusually high surface areas from the ionic liquid precursor $\left[\mathrm{Bmim}^{-}\left[\mathrm{FeCl}_{4}\right]\right.$," CrystEngComm, vol. 14, no. 15, pp. 4946-4951, 2012.

[71] G. Centi, P. Lanzafame, and S. Perathoner, "Analysis of the alternative routes in the catalytic transformation of lignocellulosic materials," Catalysis Today, vol. 167, no. 1, pp. 14-30, 2011.

[72] F. Tao, H. Song, J. Yang, and L. Chou, "Catalytic hydrolysis of cellulose into furans in $\mathrm{MnCl} 2$-ionic liquid system," Carbohydrate Polymers, vol. 85, no. 2, pp. 363-368, 2011.

[73] S. Yu, M. B. Heather, L. Guosheng et al., "Accelerated cellulose depolymerization catalyzed by paired metal chlorides in ionic liquid solvent," Applied Catalysis A: General, vol. 391, no. 1-2, pp. 436-442, 2011.

[74] W.-H. Hsu, Y.-Y. Lee, W.-H. Kelven, and C.-W. Wu, “Cellulosic conversion in ionic liquids (ILs): effects of $\mathrm{H}_{2} \mathrm{O}$ /cellulose molar ratios, temperatures, times, and different ILs on the 
production of monosaccharides and 5-hydroxymethylfurfural (HMF)," Catalysis Today, vol. 174, no. 1, pp. 65-69, 2011.

[75] J. Potvin, E. Sorlien, J. Hegner, B. DeBoef, and B. L. Lucht, "Effect of $\mathrm{NaCl}$ on the conversion of cellulose to glucose and levulinic acid via solid supported acid catalysis," Tetrahedron Letters, vol. 52, no. 44, pp. 5891-5893, 2011.

[76] D. Liu and E. Y.-X. Chen, "Ubiquitous aluminum alkyls and alkoxides as effective catalysts for glucose to HMF conversion in ionic liquids," Applied Catalysis A: General, vol. 435-436, pp. 78-85, 2012.

[77] H. Abou-Yousef, E. B. Hassan, and P. Steele, "Rapid conversion of cellulose to 5-hydroxymethylfurfural using single and combined metal chloride catalysts in ionic liquid," Journal of Fuel Chemistry and Technology, vol. 41, no. 2, pp. 214-222, 2013.

[78] F. Tao, H. Song, and L. Chou, "Efficient conversion of cellulose into furans catalyzed by metal ions in ionic liquids," Journal of Molecular Catalysis A: Chemical, vol. 357, pp. 11-18, 2012.

[79] Z. Wei, Y. Li, D. Thurshara, Y. Liu, and Q. Ren, "Novel dehydration of carbohydrates to 5-hydroxymethylfurfural catalyzed by Ir and Au chlorides in ionic liquids," Journal of the Taiwan Institute of Chemical Engineers, vol. 42, no. 2, pp. 363-370, 2011.

[80] A. Amarasekara and O. S. Owereh, "Homogeneous phase synthesis of cellulose carbamate silica hybrid materials using 1-n-butyl-3-methylimidazolium chloride ionic liquid medium," Carbohydrate Polymers, vol. 78, no. 3, pp. 635-638, 2009.

[81] H. Nawaz, P. A. R. Pires, and O. A. El Seoud, "Kinetics and mechanism of imidazole-catalyzed acylation of cellulose in LiCl/N,N-dimethylacetamide," Carbohydrate Polymers, vol. 92, no. 2, pp. 997-1005, 2013.

[82] Z. Zhang and Z. K. Zhaoa, "Solid acid and microwave-assisted hydrolysis of cellulose in ionic liquid," Carbohydrate Research, vol. 344, no. 15, pp. 2069-2072, 2009.

[83] P. Yang, H. Kobayashi, and A. Fukuoka, "Recent developments in the catalytic conversion of cellulose into valuable chemicals," Chinese Journal of Catalysis, vol. 32, no. 5, pp. 716-722, 2011.

[84] L. Peng, L. Lin, J. Zhang, J. Shi, and S. Liu, "Solid acid catalyzed glucose conversion to ethyl levulinate," Applied Catalysis A: General, vol. 397, no. 1-2, pp. 259-265, 2011.

[85] S. Suganuma, K. Nakajima, M. Kitano et al., "Synthesis and acid catalysis of cellulose-derived carbon-based solid acid," Solid State Sciences, vol. 12, no. 6, pp. 1029-1034, 2010.

[86] M. Sevilla and A. B. Fuertes, "The production of carbon materials by hydrothermal carbonization of cellulose," Carbon, vol. 47, no. 9, pp. 2281-2289, 2009.

[87] M. Kaldstrom, N. Kumar, and D. Y. Murzin, "Valorization of cellulose over metal supported mesoporous materials," Catalysis Today, vol. 167, pp. 91-95, 2011.

[88] B. Girisuta, K. Dussan, D. Haverty, J. J. Leahy, and M. H. B. Hayes, "A kinetic study of acid catalysed hydrolysis of sugar cane bagasse to levulinic acid," Chemical Engineering Journal, vol. 217, pp. 61-70, 2013.

[89] A. Tanksale, J. N. Beltramini, and G. M. Lu, "A review of catalytic hydrogen production processes from biomass," Renewable and Sustainable Energy Reviews, vol. 14, no. 1, pp. 166-182, 2010.

[90] S. G. Wettstein, D. Martin Alonso, E. I. Gürbüz, and J. A. Dumesic, "A roadmap for conversion of lignocellulosic biomass to chemicals and fuels," Current Opinion in Chemical Engineering, vol. 1, no. 3, pp. 218-224, 2012.

[91] D. M. Alonso, J. Q. Bond, and J. A. Dumesic, "Catalytic conversion of biomass to biofuels," Green Chemistry, vol. 12, no. 9, pp. 1493-1513, 2010.
[92] X. Tong, Y. Ma, and Y. Li, "Biomass into chemicals: conversion of sugars to furan derivatives by catalytic processes," Applied Catalysis A: General, vol. 385, pp. 1-13, 2010.

[93] X. Du, Y. Liu, J. Wang, Y. Cao, and K. Fan, "Catalytic conversion of biomass-derived levulinic acid into $\gamma$-valerolactone using iridium nanoparticles supported on carbon nanotubes," Chinese Journal of Catalysis, vol. 34, no. 5, pp. 993-1001, 2013.

[94] L. E. Manzer, "Catalytic synthesis of $\alpha$-methylene- $\gamma$-valerolactone: a biomass-derived acrylic monomer," Applied Catalysis A: General, vol. 272, no. 1-2, pp. 249-256, 2004.

[95] F. Chambon, F. Rataboul, C. Pinel, A. Cabiac, E. Guillon, and N. Essayem, "Cellulose hydrothermal conversion promoted by heterogeneous Brønsted and Lewis acids: remarkable efficiency of solid Lewis acids to produce lactic acid," Applied Catalysis B, vol. 105, no. 1-2, pp. 171-181, 2011.

[96] C. Aandine, G. Emmanuella, C. Flora, P. Catherine, R. Franck, and E. Nadine, "Cellulose reactivity and glycosidic bond cleavage in aqueous phase by catalytic and non catalytic transformations," Applied Catalysis A: General, vol. 402, pp. 1-10, 2011.

[97] H. Jessica, C. P. Kyle, D. Brenston, and L. L. Brett, "Conversion of cellulose to glucose and levulinic acid via solid-supported acid catalysis," Tetrahedron Letters, vol. 51, no. 17, pp. 2356-2358, 2010.

[98] H.-S. Qian, S.-H. Yu, L.-B. Luo, J.-Y. Gong, L.-F. Fei, and X.M. Liu, "Catalytic conversion of biomass-derived levulinic acid into $\gamma$-valerolactone using iridium nanoparticles supported on carbon nanotubes," Chemistry of Materials, vol. 18, pp. 20122018, 2012.

[99] V. L. Budarin, J. H. Clark, R. Luque, and D. J. Macquarrie, "Versatile mesoporous carbonaceous materials for acid catalysis," Chemical Communications, no. 6, pp. 634-636, 2007.

[100] M.-M. Titirica and M. Antonietti, "Chemistry and materials options of sustainable carbon materials made by hydrothermal carbonization," Chemical Society Reviews, vol. 39, no. 1, pp. 103116, 2010.

[101] H. Cai, C. Li, A. Wang, G. Xu, and T. Zhang, "Zeolite-promoted hydrolysis of cellulose in ionic liquid, insight into the mutual behavior of zeolite, cellulose and ionic liquid," Applied Catalysis B: Environmental, vol. 123-124, pp. 333-338, 2012.

[102] I. Jiménez-Morales, J. Santamaría-González, P. Maireles-Torres, and A. Jiménez-López, "Aluminum doped SBA-15 silica as acid catalyst for the methanolysis of sunflower oil," Applied Catalysis B: Environmental, vol. 105, no. 1-2, pp. 199-205, 2011.

[103] M. Soorholtz, R. J. White, T. Zimmermann et al., "Direct methane oxidation over Pt-modified nitrogen-doped carbons," Chemical Communications, vol. 49, no. 3, pp. 240-242, 2013.

[104] S.-H. Yu, X. Cui, L. Li et al., "From starch to metal/carbon hybrid nanostructures: hydrothermal metal-catalyzed carbonization," Advanced Materials, vol. 16, no. 18, pp. 1636-1640, 2004.

[105] M. Kenichiro, K. Hirokazu, I. Koji, K. Takasuku, F. Atsushi, and T. Seiichi, "Immobilization of pectinase and lipase on macroporous resin coated with chitosan for treatment of whitewater from papermaking," Bioresource Technology, vol. 123, pp. 616619, 2011.

[106] A. Sinag, T. Yumak, V. Balci, and A. Kruse, "Catalytic hydrothermal conversion of cellulose over $\mathrm{SnO}_{2}$ and $\mathrm{ZnO}$ nanoparticle catalysts," Journal of Supercritical Fluids, vol. 56, no. 2, pp. 179$185,2011$.

[107] H. Zhang, Y.-T. Cheng, T. P. Vispute, R. Xiao, and G. W. Huber, "Catalytic conversion of biomass-derived feedstocks into olefins and aromatics with ZSM-5: the hydrogen to carbon effective 
ratio," Energy and Environmental Science, vol. 4, no. 6, pp. 22972307, 2011.

[108] H.-S. Qian, A. Markus, and S.-H. Yu, "Hybrid "golden fleece": synthesis and catalytic performance of uniform carbon nanofibers and silica nanotubes embedded with a high population of noble-metal nanoparticles," Advanced Functional Materials, vol. 17, pp. 637-643, 2007.

[109] W. Deng, M. Liu, Q. Zhang, and Y. Wang, "Direct transformation of cellulose into methyl and ethyl glucosides in methanol and ethanol media catalyzed by heteropolyacids," Catalysis Today, vol. 164, no. 1, pp. 461-466, 2011.

[110] A. Kruse, A. Funke, and M.-M. Titirici, "Hydrothermal conversion of biomass to fuels and energetic materials," Current Opinion in Chemical Biology, vol. 17, no. 3, pp. 515-521, 2013.

[111] Q. Zhao, L. Wang, S. Zhao, X. Wang, and S. Wang, "High selective production of 5-hydroymethylfurfural from fructose by a solid heteropolyacid catalyst," Fuel, vol. 90, no. 6, pp. 22892293, 2011.

[112] A. Alahiane, A. Rochdi, M. Taourirte, N. Redwane, S. Sebti, and H. B. Lazrek, "Natural phosphate as Lewis acid catalyst: a simple and convenient method for acyclonucleoside synthesis," Tetrahedron Letters, vol. 42, no. 21, pp. 3579-3581, 2001.

[113] M. Zahouily, M. Salah, B. Bahlaouane et al., "Solid catalysts for the production of fine chemicals: the use of natural phosphate alone and doped base catalysts for the synthesis of unsaturated arylsulfones," Tetrahedron, vol. 60, no. 7, pp. 1631-1635, 2004.

[114] M. Mariani, F. Zaccheria, R. Psaro, and N. Ravasio, "Some insight into the role of different copper species as acids in cellulose deconstruction," Catalysis Communications, vol. 44, pp. 19-23, 2014.

[115] D. A. Bulushev, S. Beloshapkin, P. E. Plyusnin et al., "Vapour phase formic acid decomposition over $\mathrm{PdAu} / \gamma-\mathrm{Al}_{2} \mathrm{O}_{3}$ catalysts: effect of composition of metallic particles," Journal of Catalysis, vol. 299, pp. 171-180, 2013.

[116] I. G. Baek, S. J. You, and E. Park, "Direct conversion of cellulose into polyols over $\mathrm{Ni} / \mathrm{W} / \mathrm{SiO}_{2}-\mathrm{Al}_{2} \mathrm{O}_{3}$," Bioresource Technology, vol. 114, pp. 684-690, 2012.

[117] R. Kourieh, S. Bennici, M. Marzo, A. Gervasini, and A. Auroux, "Investigation of the $\mathrm{WO}_{3} / \mathrm{ZrO}_{2}$ surface acidic properties for the aqueous hydrolysis of cellobiose," Catalysis Communications, vol. 19, pp. 119-126, 2012.

[118] A. Burcu and G. Gonul, "Isomerizaton of $\alpha$-pinene over $\mathrm{H}_{3} \mathrm{PW}_{12} \mathrm{O}_{40}$ catalysts supported on natural zeolite," Chemical Engineering Journal, vol. 168, no. 3, pp. 1311-1318, 2011.

[119] R. Ormsby, J. R. Kastner, and J. Miller, "Hemicellulose hydrolysis using solid acid catalysts generated from biochar," Catalysis Today, vol. 190, no. 1, pp. 89-97, 2012.

[120] M. Marzo, A. Gervasini, and P. Carniti, "Hydrolysis of disaccharides over solid acid catalysts under green conditions," Carbohydrate Research, vol. 347, no. 1, pp. 23-31, 2012.

[121] M. Cheng, T. Shi, H. Guan, S. Wang, X. Wang, and Z. Jiang, "Clean production of glucose from polysaccharides using a micellar heteropolyacid as a heterogeneous catalyst," Applied Catalysis B: Environmental, vol. 107, no. 1-2, pp. 104-109, 2011.

[122] X. Tong, Y. Ma, and Y. Li, "Biomass into chemicals: conversion of sugars to furan derivatives by catalytic processes," Applied Catalysis A: General, vol. 385, no. 1-2, pp. 1-13, 2010.

[123] R. Weingarten, G. A. Tompsett, W. C. Conner Jr., and G. W. Huber, "Design of solid acid catalysts for aqueous-phase dehydration of carbohydrates: the role of Lewis and Brønsted acid sites," Journal of Catalysis, vol. 279, no. 1, pp. 174-182, 2011.
[124] W. Edward, T. K. Yong, A. T. Geoffrey et al., "Conversion of glucose into levulinic acid with solid metal(IV) phosphate catalysts," Journal of Catalysis, vol. 304, pp. 123-134, 2013.

[125] J. C. Serrano-Ruiz, A. Pineda, A. M. Balu et al., "Catalytic transformations of biomass-derived acids into advanced biofuels," Catalysis Today, vol. 195, no. 1, pp. 162-168, 2012.

[126] L. Hu, Y. Sun, L. Lin, and S. Liu, "12-Tungstophosphoric acid/boric acid as synergetic catalysts for the conversion of glucose into 5-hydroxymethylfurfural in ionic liquid," Biomass and Bioenergy, vol. 47, pp. 289-294, 2012.

[127] Y. Qu, C. Huang, J. Zhang, and B. Chen, "Efficient dehydration of fructose to 5-hydroxymethylfurfural catalyzed by a recyclable sulfonated organic heteropolyacid salt," Bioresource Technology, vol. 106, pp. 170-172, 2012.

[128] J. S. Choi, I. K. Song, and W. Y. Lee, "Performance of shell and tube-type membrane reactors equipped with heteropolyacidpolymer composite catalytic membranes," Catalysis Today, vol. 67, no. 1-3, pp. 237-245, 2001.

[129] X. Duan, G. Sun, Z. Sun et al., "A heteropolyacid-based ionic liquid as a thermoregulated and environmentally friendly catalyst in esterification reaction under microwave assistance," Catalysis Communications, vol. 42, pp. 125-128, 2013.

[130] M. Cheng, T. Shi, H. Guan, S. Wang, X. Wang, and Z. Jiang, "Clean production of glucose from polysaccharides using a micellar heteropolyacid as a heterogeneous catalyst," Applied Catalysis B, vol. 107, pp. 104-109, 2011.

[131] C. Larabi, W. al Maksoud, K. C. Szeto et al., “Thermal decomposition of lignocellulosic biomass in the presence of acid catalysts," Bioresource Technology, vol. 148, pp. 255-260, 2013.

[132] M. M. Titrici, A. Markus, and B. Niki, "Hydrothermal carbon from biomass: a comparison of the local structure from poly- to monosaccharides and pentoses/hexoses," Green Chemistry, vol. 10, pp. 1204-1212, 2008.

[133] T. Pullawan, A. N. Wilkinson, L. N. Zhang, and S. J. Eichhorn, "Deformation micromechanics of all-cellulose nanocomposites: comparing matrix and reinforcing components," Carbohydrate Polymers, vol. 100, pp. 31-39, 2014.

[134] M. Yabushita, H. Kobayashi, and A. Fukuoka, "Catalytic transformation of cellulose into platform chemicals," Applied Catalysis B: Environmental, vol. 145, pp. 1-9, 2014.

[135] M. Hara, "Biomass conversion by a solid acid catalyst," Energy and Environmental Science, vol. 3, no. 5, pp. 601-607, 2010.

[136] E. Gürbüz, J. Q. Bond, J. A. Dumesic, and Y. Román-Leshkov, "Chapter 8. Role of acid catalysis in the conversion of lignocellulosic biomass to fuels and chemicals," in The Role of Catalysis for the Sustainable Production of Bio-fuels and Bio-chemicals, pp. 261-288, 2013.

[137] F. Chambon, F. Rataboul, C. Pinel, A. Cabiac, E. Guillon, and N. Essayem, "Cellulose hydrothermal conversion promoted by heterogeneous Brønsted and Lewis acids: remarkable efficiency of solid Lewis acids to produce lactic acid," Applied Catalysis B: Environmental, vol. 105, no. 1-2, pp. 171-181, 2011.

[138] J. Hegner, K. C. Pereira, B. DeBoef, and B. L. Lucht, "Conversion of cellulose to glucose and levulinic acid via solid-supported acid catalysis," Tetrahedron Letters, vol. 51, no. 17, pp. 2356-2358, 2010.

[139] P. Rutkowski, "Pyrolytic behavior of cellulose in presence of montmorillonite K10 as catalyst," Journal of Analytical and Applied Pyrolysis, vol. 98, pp. 115-122, 2012.

[140] P. Lanzafame, D. M. Temi, S. Perathoner, A. N. Spadaro, and G. Centi, "Direct conversion of cellulose to glucose and 
valuable intermediates in mild reaction conditions over solid acid catalysts," Catalysis Today, vol. 179, no. 1, pp. 178-184, 2012.

[141] S. Dora, T. Bhasker, R. Singh, D. V. Naik, and D. K. Adhikari, "Effective catalytic conversion of cellulose into high yields of methyl glucosides over sulfonated carbon based catalyst," Bioresource Technology, vol. 120, pp. 318-321, 2012.

[142] B. Guo, Y. Zhang, S.-J. Ha, Y.-S. Jin, and E. Morgenroth, "Combined biomimetic and inorganic acids hydrolysis of hemicellulose in Miscanthus for bioethanol production," Bioresource Technology, vol. 110, pp. 278-287, 2012.

[143] A. Bai, X. Zhao, Y. Jin, G. Yang, and Y. Feng, "A novel thermophilic $\beta$-glucosidase from Caldicellulosiruptor bescii: characterization and its synergistic catalysis with other cellulases," Journal of Molecular Catalysis B: Enzymatic, vol. 85-86, pp. 248256, 2013.

[144] E. Gürbüz, J. Q. Bond, J. A. Dumesic, and Y. Román-Leshkov, "Chapter 8: role of acid catalysis in the conversion of lignocellulosic biomass to fuels and chemicals," in The Role of Catalysis for the Sustainable Production of Bio-fuels and Bio-chemicals, pp. 261-288, 2013.

[145] J. Huang and T. Kunitake, "Nano-precision replication of natural cellulosic substances by metal oxides," Journal of the American Chemical Society, vol. 125, no. 39, pp. 11834-11835, 2003.

[146] J. R. T. Johnson, "Water adsorption and hydrolysis on molecular transition metal oxides and oxyhydroxides," Inorganic Chemistry, vol. 39, no. 15, pp. 3181-3191, 2000.

[147] S. Suganuma, K. Nakajima, M. Kitano et al., "Hydrolysis of cellulose by amorphous carbon bearing $\mathrm{SO}_{3} \mathrm{H}, \mathrm{COOH}$, and $\mathrm{OH}$ groups," Journal of the American Chemical Society, vol. 130, no. 38, pp. 12787-12793, 2008.

[148] A. Omegna, J. A. Bokhaven, and R. Prins, "Flexible aluminum coordination in alumino-silicates. Structure of zeolite H-USY and amorphous silica-alumina," The Journal of Physical Chemistry B, vol. 107, no. 34, pp. 8854-8860, 2003.

[149] B. K. Sen and A. V. Saha, "On the nature and structure of "niobic acid" and its pyrolytic products: ${ }^{1} \mathrm{H}$ NMR, I.R., conductivity and Ion exchange studies," Materials Research Bulletin, vol. 16, no. 8, pp. 923-932, 1981.

[150] P. Carniti, A. Gervasini, S. Biella, and A. Auroux, "Intrinsic and effective acidity study of niobic acid and niobium phosphate by a multitechnique approach," Chemistry of Materials, vol. 17, no. 24, pp. 6128-6136, 2005.

[151] K. Shimomura, L. Dickson, and H. F. Walton, "Separation of amines by ligand exchange, part IV ligand exchange with chelating resins and cellulosic exchangers," Analytica Chimica Acta, vol. 37, pp. 102-111, 1967.

[152] C. Buttersack, "Accessibility and catalytic activity of sulfonic acid ion-exchange resins in different solvents," Reactive Polymers, vol. 10, no. 2-3, pp. 143-164, 1989.

[153] M. A. Harmer, W. E. Farneth, and Q. Sun, "High surface area nafion resin/silica nanocomposites: a new class of solid acid catalyst," Journal of the American Chemical Society, vol. 118, no. 33, pp. 7708-7715, 1996.

[154] M. E. Himmel, S.-Y. Ding, D. K. Johnson et al., "Biomass recalcitrance: engineering plants and enzymes for biofuels production," Science, vol. 315, no. 5813, pp. 804-807, 2007.

[155] T. E. Takasuka, A. J. Book, G. R. Lewin, C. R. Currie, and B. G. Fox, "Aerobic deconstruction of cellulosic biomass by an insectassociated Streptomyces," Scientific Reports, vol. 3, article 1030, 2013.
[156] K. Igarashi, "Cellulases: cooperative biomass breakdown," Nature Chemical Biology, vol. 9, no. 6, pp. 350-351, 2013.

[157] M. Sun and Y. Zhang, "Study on the preparation of activated carbons with Baijiu Vinasse," Applied Mechanics and Materials, vol. 448-453, pp. 669-673, 2013.

[158] T. Heinze and J. Schaller, "New water soluble cellulose esters synthesized by an effective acylation procedure," Macromolecular Chemistry and Physics, vol. 201, pp. 1214-1218, 2000.

[159] A. S. Amarasekara and B. Wiredu, "Degradation of cellulose in dilute aqueous solutions of acidic ionic liquid 1-(1propylsulfonic)-3-methylimidazolium chloride, and ptoluenesulfonic acid at moderate temperatures and pressures," Industrial and Engineering Chemistry Research, vol. 50, no. 21, pp. 12276-12280, 2011.

[160] G. Antova, P. Vasvasova, and M. Zlatanov, "Studies upon the synthesis of cellulose stearate under microwave heating," Carbohydrate Polymers, vol. 57, no. 2, pp. 131-134, 2004.

[161] A. Kržan and E. Žagar, "Microwave driven wood liquefaction with glycols," Bioresource Technology, vol. 100, no. 12, pp. 31433146, 2009.

[162] S. van de Vyver, L. Peng, J. Geboers et al., "Sulfonated silica/carbon nanocomposites as novel catalysts for hydrolysis of cellulose to glucose," Green Chemistry, vol. 12, no. 9, pp. 15601563, 2010.

[163] J. Pang, A. Wang, M. Zheng, and T. Zhang, "Hydrolysis of cellulose into glucose over carbons sulfonated at elevated temperatures," Chemical Communications, vol. 46, no. 37, pp. 6935-6937, 2010.

[164] D.-M. Lai, L. Deng, J. Li, B. Liao, Q.-X. Guo, and Y. Fu, "Hydrolysis of cellulose into glucose by magnetic solid acid," ChemSusChem, vol. 4, no. 1, pp. 55-58, 2011.

[165] L. Shuai and X. Pan, "Hydrolysis of cellulose by cellulasemimetic solid catalyst," Energy \& Environmental Science, no. 5, pp. 6889-6894, 2012.

[166] J. A. Geboers, S. van de Vyver, R. Ooms, B. Op de Beeck, P. A. Jacobs, and B. F. Sels, "Chemocatalytic conversion of cellulose: opportunities, advances and pitfalls," Catalysis Science and Technology, vol. 1, no. 5, pp. 714-726, 2011.

[167] W. Daengprasert, P. Boonnoun, N. Laosiripojana, M. Gato, and A. Shortipurk, "Application of sulfonated carbon-based catalyst for solvothermal conversion of cassava waste to hydroxymethylfurfural and furfural," Industrial \& Engineering Chemistry Research, vol. 50, no. 3, pp. 7903-7910, 2011.

[168] J. W. Han and H. Lee, "Direct conversion of cellulose into sorbitol using dual-functionalized catalysts in neutral aqueous solution," Catalysis Communications, vol. 19, pp. 115-118, 2012.

[169] P. L. Dhepe and A. Fukroku, "Cracking of cellulose over supported metal catalysts," Catalysis Surveys from Asia, vol. 11, no. 4, pp. 186-191, 2007.

[170] M. Benoit, A. Rodrigues, Q. Zhang et al., "Depolymerization of cellulose assisted by a nonthermal atmospheric plasma," Angewandte Chemie, vol. 38, pp. 9126-9129, 2011.

[171] G. Akiyama, R. Matsuda, H. Sato, M. Takata, and S. Kitagawa, "Cellulose hydrolysis by a new porous coordination polymer decorated with sulfonic acid functional groups," Advanced Materials, vol. 23, no. 29, pp. 3294-3297, 2011.

[172] P. Boonoun, N. Laosiripojana, C. Muangnapoh et al., "Application of sulfonated carbon-based catalyst for reactive extraction of 1,3-propanediol from model fermentation mixture," Industrial and Engineering Chemistry Research, vol. 49, no. 24, pp. 12352-12357, 2010. 
[173] W. Namchot, N. Panyacharay, W. Jonglertjunya, and C. Sakdaronnarong, "Hydrolysis of delignified sugarcane bagasse using hydrothermal technique catalyzed by carbonaceous acid catalysts," Fuel, vol. 116, pp. 608-616, 2014.

[174] T. Klamrassamee, V. Champreda, V. Reunglek, and N. Laosiripojana, "Comparison of homogeneous and heterogeneous acid promoters in single-step aqueous-organosolv fractionation of eucalyptus wood chips," Bioresource Technology, vol. 147, pp. 276-284, 2013.

[175] A. R. Jule and M. W. Schoonover, "Early discoveries in zeolite chemistry and catalysis at Union Carbide, and follow-up in industrial catalysis," Applied Catalysis A, vol. 222, no. 1-2, pp. 261-275, 2001.

[176] M. Guisnet, “Ideal' bifunctional catalysis over Pt-acid zeolites," Catalysis Today, vol. 218-219, pp. 123-134, 2013.

[177] M. Stöcker, "Gas phase catalysis by zeolites," Microporous and Mesoporous Materials, vol. 82, no. 3, pp. 257-292, 2005.

[178] L. Dixit and T. S. R. P. Rao, "New approach to acid catalysis and hydrocarbon-zeolite interactions," Studies in Surface Science and Catalysis, vol. 113, pp. 313-319, 1998.

[179] L. D. Rollmann, L. A. Green, R. A. Bradway, and H. K. C. Timken, "Adamantanes from petroleum with zeolites," Catalysis Today, vol. 31, no. 1-2, pp. 163-169, 1996.

[180] J. Weitkamp, "New directions in zeolite catalysis," Studies in Surface Science and Catalysis, vol. 65, pp. 21-46, 1991.

[181] Y. Chen, G. Li, F. Yang, and S.-M. Zhang, "Mn/ZSM-5 participation in the degradation of cellulose under phosphoric acid media," Polymer Degradation and Stability, vol. 96, no. 5, pp. 863-869, 2011.

[182] L. R. Ferreira, S. Lima, P. Neves et al., "Hydrolysis of delignified sugarcane bagasse using hydrothermal technique catalyzed by carbonaceous acid catalysts," Chemical Engineering Journal, vol. 215, p. 772, 2013.

[183] M. Hernandez, E. Lima, A. Guzman, M. Vera, O. Novelo, and V. Lara, "A small change in the surface polarity of cellulose causes a significant improvement in its conversion to glucose and subsequent catalytic oxidation," Applied Catalysis B: Environmental, vol. 144, pp. 528-537, 2014.

[184] G. Gliozzi, A. Innorta, A. Mancini et al., " $\mathrm{Zr} / \mathrm{P} / \mathrm{O}$ catalyst for the direct acid chemo-hydrolysis of non-pretreated microcrystalline cellulose and softwood sawdust," Applied Catalysis B: Environmental, vol. 145, pp. 24-33, 2014.

[185] J. Cejka, G. Centi, J. Perez-Pariente, and M. Horacek, "Preface," Catalysis Today, vol. 179, no. 1, p. 1, 2012.

[186] F. Ocampo, J. A. Cunha, M. R. L. Santo et al., "Synthesis of zeolite crystals with unusual morphology: application in acid catalysis," Applied Catalysis A: General, vol. 390, pp. 102-109, 2010.

[187] F. F. Brites-Nobrega, A. N. B. Polo, A. M. Benedetti, M. M. D. Leão, V. Slusarski-Santana, and N. R. C. Fernandes-Machadoa, "Evaluation of photocatalytic activities of supported catalysts on $\mathrm{NaX}$ zeolite or activated charcoal," Journal of Hazardous Materials, vol. 263, pp. 61-66, 2013.

[188] A. M. Azeez, D. Meier, J. Odermatt, and T. Willner, "Effects of zeolites on volatile products of beech wood using analytical pyrolysis," Journal of Analytical and Applied Pyrolysis, vol. 91, no. 2, pp. 296-302, 2011.

[189] O. D. Mante, F. A. Agblevor, and R. McClung, "A study on catalytic pyrolysis of biomass with Y-zeolite based FCC catalyst using response surface methodology," Fuel, vol. 108, pp. 451464, 2013.
[190] D. A. Zapata, Y. Huang, M. A. Gonzalez-Borja, and D. E. Resosca, Journal of Catalysis, vol. 308, p. 62, 2013.

[191] R. Otomo, T. Yokoi, J. N. Kondo, and T. Tatsumi, "Dealuminated Beta zeolite as effective bifunctional catalyst for direct transformation of glucose to 5-hydroxymethylfurfural," Applied Catalysis A, vol. 470, pp. 318-326, 2014.

[192] Y. Yu, X. Li, L. Su, Y. Zhang, Y. Wang, and H. Zhang, "The role of shape selectivity in catalytic fast pyrolysis of lignin with zeolite catalysts," Applied Catalysis A, vol. 447-448, pp. 115-123, 2012.

[193] F. Tao, H. Song, and L. Chou, "Efficient conversion of cellulose into furans catalyzed by metal ions in ionic liquids," Journal of Molecular Catalysis A, vol. 357, pp. 11-18, 2012.

[194] A. Nzihou, B. Stanmore, and P. Sharrock, "A review of catalysts for the gasification of biomass char, with some reference to coal," Energy, vol. 58, pp. 305-317, 2013.

[195] A. Saddawi, J. M. Jones, and A. Williams, "Influence of alkali metals on the kinetics of the thermal decomposition of biomass," Fuel Processing Technology, vol. 104, pp. 189-197, 2012.

[196] K. R. Vuyyuru and P. Strasser, "Oxidation of biomass derived 5hydroxymethylfurfural using heterogeneous and electrochemical catalysis," Catalysis Today, vol. 195, no. 1, pp. 144-154, 2012.

[197] Q. Gu, J. Long, L. Fan et al., "Single-site Sn-grafted Ru/TiO photocatalysts for biomass reforming: Synergistic effect of dual co-catalysts and molecular mechanism," Journal of Catalysis, vol. 303, pp. 141-155, 2013.

[198] M. Dreher, B. Johnson, A. A. Peterson, M. Nachtegaal, J. Wambach, and F. Vogel, "Catalysis in supercritical water: pathway of the methanation reaction and sulfur poisoning over a $\mathrm{Ru} / \mathrm{C}$ catalyst during the reforming of biomolecules," Journal of Catalysis, vol. 301, pp. 38-45, 2013.

[199] H. Wang, L. Zhu, S. Peng, F. Peng, H. Yu, and J. Yang, "High efficient conversion of cellulose to polyols with $\mathrm{Ru} / \mathrm{CNTs}$ as catalyst," Renewable Energy, vol. 37, no. 1, pp. 192-196, 2012.

[200] C. M. Osmundsen, K. Egeblad, and E. Toarning, "Silyted hydrophobic zeolites with enchanced tolerance to hot liquid water," in New \& Future Developments in Catalysis, pp. 73-89, 2011.

[201] J. C. Serrano-Ruiz, R. Luque, and J. H. Clark, "Chapter 17-The role of heterogeneous catalysis in the biorefinery of the future," in The Role of Catalysis for the Sustainable Production of Bio-fuels and Bio-chemicals, pp. 557-576, 2013.

[202] C. M. Andrew and S. Liu, "Combining bio- and chemocatalysis: from enzymes to cells, from petroleum to biomass," Trends in Biotechnology, vol. 29, no. 5, pp. 199-204, 2011.

[203] M. N. Uddin, W. M. A. WanDaud, and H. F. Abbas, "Potential hydrogen and non-condensable gases production from biomass pyrolysis: insights into the process variables," Renewable and Sustainable Energy Reviews, vol. 27, pp. 204-224, 2013.

[204] Y. Zu, P. Yang, J. Wang et al., "Efficient production of the liquid fuel 2,5-dimethylfuran from 5-hydroxymethylfurfural over Ru/Co3O4 catalyst," Applied Catalysis B: Environmental, vol. 146, pp. 244-248, 2014.

[205] V. Skoulou and A. Zabaniotou, "Fe catalysis for lignocellulosic biomass conversion to fuels and materials via thermochemical processes," Catalysis Today, vol. 196, no. 1, pp. 56-66, 2012.

[206] G. Guan, G. Chen, Y. Kasai et al., "Catalytic steam reforming of biomass tar over iron- or nickel-based catalyst supported on calcined scallop shell," Applied Catalysis B: Environmental, vol. 115-116, pp. 159-168, 2012.

[207] T. Yoshikawa, S. Shinohara, T. Yagi et al., "Production of phenols from lignin-derived slurry liquid using iron oxide catalyst," Applied Catalysis B, vol. 146, pp. 289-297, 2014. 
[208] A. Aho, N. Kumar, A. V. Lashkul et al., "Catalytic upgrading of woody biomass derived pyrolysis vapours over iron modified zeolites in a dual-fluidized bed reactor," Fuel, vol. 89, no. 8, pp. 1992-2000, 2010.

[209] P. V. Aravid and W. Jong, "Evaluation of high temperature gas cleaning options for biomass gasification product gas for solid oxide fuel cells," Progress in Energy and Combustion Science, vol. 38, no. 6, pp. 737-764, 2012.

[210] L. Pino, A. Vita, M. Laganà, and V. Recupero, "Hydrogen from biogas: catalytic tri-reforming process with $\mathrm{Ni} / \mathrm{La}-\mathrm{Ce}-$ O mixed oxides," Applied Catalysis B, vol. 148-149, pp. 91-105, 2014.

[211] A. Rahmatpour and S. Mohammadian, "Polystyrene-supported $\mathrm{TiCl} 4$ as a novel, efficient and reusable polymeric Lewis acid catalyst for the chemoselective synthesis and deprotection of 1,1-diacetates under eco-friendly conditions," Comptes Rendus Chimie, vol. 16, no. 10, pp. 912-919, 2013.

[212] H. J. Park, S. H. Park, J. M. Sohn et al., "Steam reforming of biomass gasification tar using benzene as a model compound over various $\mathrm{Ni}$ supported metal oxide catalysts," Bioresource Technology, vol. 101, no. 1, pp. S101-S103, 2010.

[213] L. Faba, E. Diaz, and S. Ordanez, "Improvement of the stability of basic mixed oxides used as catalysts for aldol condensation of bio-derived compound by palladium addition," Biomass \& Bioenergy, vol. 56, pp. 592-599, 2013.

[214] D. Li, C. Ishikawa, M. Koike, L. Wang, Y. Nakagawa, and K. Tomishige, "Production of renewable hydrogen by steam reforming of tar from biomass pyrolysis over supported Co catalysts," International Journal of Hydrogen Energy, vol. 38, no. 9, pp. 3572-3581, 2013.

[215] L. V. Antisarri, S. Carbone, A. Gatti, G. Vianello, and P. Nannipieri, "Toxicity of metal oxide $\left(\mathrm{CeO}_{2}, \mathrm{Fe}_{3} \mathrm{O}_{4}, \mathrm{SnO}_{2}\right)$ engineered nanoparticles on soilmicrobial biomass and their distribution in soil," Soil Biology and Biochemistry, vol. 60, no. 5, pp. 87-94, 2013.

[216] L.-D. Felica, C. Courson, P. U. Foscoto, and A. Kiennemann, "Iron and nickel doped alkaline-earth catalysts for biomass gasification with simultaneous tar reformation and $\mathrm{CO}_{2}$ capture," An International Journal of Hydrogen Energy, vol. 36, no. 9, pp. 5296-5310, 2011.

[217] M. Khan and W. Cao, "Development of photocatalyst by combined nitrogen and yttrium doping," Materials Research Bulletin, vol. 49, pp. 21-27, 2014.

[218] X. Zhang, J. Zhoa, and L. Guo, "Band gap-tunable $(\mathrm{CuAg})_{x} \mathrm{In}_{2 x} \mathrm{Zn}_{2(1-2 x)} \mathrm{S}_{2}$ solid solutions synthesized by hydrothermal method with ultrasonic assistance and their photocatalytic $\mathrm{H}_{2}$ production performance," Journal of Alloys and Compounds, vol. 582, pp. 617-622, 2014.

[219] J. G. Mcevoy, D. A. Bilodeau, W. Cui, and Z. Zhang, "Visiblelight-driven inactivation of Escherichia coli K-12 using an $\mathrm{Ag} / \mathrm{AgCl}$-activated carbon composite photocatalyst," Journal of Photochemistry and Photobiology A, vol. 267, pp. 25-34, 2013.

[220] I. Velo-Gala, J. J. López-Peñalver, M. Sánchez-Polo, and J. Rivera-Utrilla, "Activated carbon as photocatalyst of reactions in aqueous phase," Applied Catalysis B: Environmental, vol. 142143, pp. 694-704, 2013.

[221] C. Andriantsiferana, E. F. Mohamed, and H. Delmas, "Photocatalytic degradation of an azo-dye on $\mathrm{TiO}_{2}$ /activated carbon composite material," Environmental Technologies, vol. 35, no. 14, pp. 355-363, 2014.

[222] J. Han and C. J. Li, "Steam reforming of biomass gasification tar using benzene as a model compound over various Ni supported metal oxide cataysts," Advanced Materials Research, vol. 750, p. $1864,2013$.

[223] R. H. Jie, G.-B. Guo, W.-G. Zhao, and S.-L. An, "Preparation and photocatalytic degradation of methyl orange of nano-powder $\mathrm{TiO}_{2}$ by hydrothermal method supported on activated carbon," Journal of Synthetic Crystals, vol. 42, pp. 2144-2149, 2013.

[224] K. Nagai and T. Abe, "Full-spectrum-visible-light photocatalyst based on the active layer of organic solar cell-towards water splitting and volatile molecule degradation-," Kobunshi Ronbunshu, vol. 70, no. 9, pp. 459-475, 2013.

[225] J. Xing, H. B. Jiang, J. F. Chen et al., "Active sites on hydrogen evolution photocatalyst," Journal of Materials Chemistry A, vol. 1, pp. 15258-15264, 2013.

[226] H. Huang, Z. Yue, G. Li et al., "Ultraviolet-assisted preparation of mesoporous $\mathrm{WO}_{3}$ /reduced graphene oxide composites: Superior interfacial contacts and enhanced photocatalysis," Journal of Materials Chemistry A, vol. 1, no. 47, pp. 15110-15116, 2013.

[227] H. Gulyas, A. S. O. Argaez, F. Kong, C. L. Jorge, S. Eggers, and R. Otterphol, "Combining activated carbon adsorption with heterogeneous photocatalytic oxidation: lack of synergy for biologically treated greywater and tetraethylene glycol dimethyl ether," Environmental Technology, vol. 34, no. 11, pp. 1393-1403, 2013.

[228] N. Sobana, B. Krishnakumar, and M. Swaminathan, "Synergism and effect of operational parameters on solar photocatalytic degradation of an azo dye (Direct Yellow 4) using activated carbon-loaded zinc oxide," Materials Science in Semiconductor Processing, vol. 16, no. 3, pp. 1046-1051, 2013.

[229] F. Chekin, S. Bagheri, and S. B. Abd Hamid, "Synthesis of Pt doped $\mathrm{TiO}_{2}$ nanoparticles: Characterization and application for electrocatalytic oxidation of l-methionine," Sensors and Actuators B: Chemical, vol. 177, pp. 898-903, 2013.

[230] A. E. Eliyas, L. Ljutzkanov, I. D. Stambolova et al., "Visible light photocatalytic activity of $\mathrm{TiO}_{2}$ deposited on activated carbon," Central European Journal of Chemistry, vol. 11, no. 3, pp. 464470, 2013.

[231] K. Wantala, S. Neramittagapong, A. Neramittagapong, K. Kasipar, S. Khaownetr, and S. Chuichulcherm, "Photocatalytic

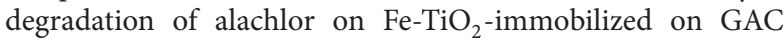
under black light irradiation using Box-Behnken design," Materials Science Forum, vol. 734, pp. 306-316, 2013.

[232] J.-W. Yoon, M.-H. Baek, J.-S. Hong, C.-Y. Lee, and J.-K. Suh, "Photocatalytic degradation of azo dye using $\mathrm{TiO}_{2}$ supported on spherical activated carbon," Korean Journal of Chemical Engineering, vol. 29, no. 12, pp. 1722-1729, 2012.

[233] Y.-F. Zhang, L.-G. Qiu, Y.-P. Yuan, Y.-J. Zhu, X. Jiang, and J.D. Xiao, "Magnetic $\mathrm{Fe}_{3} \mathrm{O}_{4} @ \mathrm{C} / \mathrm{Cu}$ and $\mathrm{Fe}_{3} \mathrm{O}_{4} @ \mathrm{CuO}$ core-shell composites constructed from MOF-based materials and their photocatalytic properties under visible light," Applied Catalysis B: Environmental, vol. 144, pp. 863-869, 2014.

[234] S. Vivekanandhan, M. Schreiber, C. Mason, A. K. Mohanty, and M. Misra, "Maple leaf (Acer sp.) extract mediated green process for the functionalization of $\mathrm{ZnO}$ powders with silver nanoparticles," Colloids and Surfaces B: Biointerfaces, vol. 113, pp. 169-175, 2014.

[235] Y. Wang, P. Ren, C. Feng, X. Zheng, Z. Wang, and D. Li, "Photocatalytic behavior and photo-corrosion of visible-lightactive silver carbonate/titanium dioxide," Materials Letters, vol. 115, pp. 85-88, 2014.

[236] B. Yang and M. D. Bai, App Mech Mater, vol. 448, p. 2946, 2014. 
[237] D. Zhang, M. Wen, S. Zhang et al., "Au nanoparticles enhanced rutile $\mathrm{TiO}_{2}$ nanorod bundles with high visible-light photocatalytic performance for NO oxidation," Applied Catalysis B: Environmental, vol. 147, pp. 610-616, 2014.

[238] S.-Y. Ye, Y.-C. Fang, X.-L. Song, S.-C. Luo, and L. M. Ye, "Decomposition of ethylene in cold storage by plasma-assisted photocatalyst process with $\mathrm{TiO}_{2} /$ ACF-based photocatalyst prepared by gamma irradiation," Chemical Engineering Journal, vol. 225, pp. 499-508, 2013.

[239] C. Liu, Z. Lei, Y. Yang, H. Wang, and Z. Zhang, "Improvement in settleability and dewaterability of waste activated sludge by solar photocatalytic treatment in $\mathrm{Ag} / \mathrm{TiO}_{2}$-coated glass tubular reactor," Bioresource Technology, vol. 137, pp. 57-62, 2013.

[240] Y. Yang, S. Zhan, X. Goa et al., "Degradation of toluene using modified $\mathrm{TiO}_{2}$ as photocatalysts," Advanced Materials Research, vol. 669, pp. 7-18, 2013.

[241] I. W. Mwangi, J. C. Ngila, P. Ndungu, T. A. M. Msagati, and J. N. Kamau, "Immobilized Fe (III)-doped titanium dioxide for photodegradation of dissolved organic compounds in water," Environmental Science and Pollution Research, vol. 20, no. 9, pp. 6028-6038, 2013.

[242] Q. L. Yu and H. J. H. Brouwers, "Design of a novel photocatalytic gypsum plaster: with the indoor air purification property," Advanced Materials Research, vol. 651, pp. 751-756, 2013.

[243] W.-D. Zhang, B. Xu, and L.-C. Jiang, "Functional hybrid materials based on carbon nanotubes and metal oxides," Journal of Materials Chemistry, vol. 20, no. 31, pp. 6383-6391, 2010.

[244] R. C. Wang and C. W. Yu, "Phenol degradation under visible light irradiation in the continuous system of photocatalysis and sonolysis," Ultrasonics Sonochemistry, vol. 20, no. 1, pp. 553-564, 2013.

[245] S.-S. Dong, J.-B. Zhang, L.-L. Gao, Y.-L. Wang, and D.-D. Zhou, "Preparation of spherical activated carbon-supported and $\mathrm{Er}^{3+}: \mathrm{YAlO}_{3}$-doped $\mathrm{TiO}_{2}$ photocatalyst for methyl orange degradation under visible light," Transactions of Nonferrous Metals Society of China, vol. 22, no. 10, pp. 2477-2483, 2012.

[246] H.-J. Shang, Y.-L. Zhou, Y. Zhao et al., Modern Chem Indust, vol. 32, p. 59, 2012.

[247] S. Bagheri, K. Shameli, and S. Bee Abd Hamid, "Synthesis and characterization of anatase titanium dioxide nanoparticles using egg white solution via sol-gel method," Journal of Chemistry, vol. 2013, Article ID 848205, 5 pages, 2013.

[248] P. Muthirulan, C. N. Devi, and M. M. Sundaram, “ $\mathrm{TiO}_{2}$ wrapped graphene as a high performance photocatalyst for acid orange 7 dye degradation under solar/UV light irradiations," Ceramics International, vol. 40, no. 4, pp. 5945-5957, 2014.

[249] S. M. Sun, "Studies on photodegradation kinetics of rhodamine B by titanium dioxide-carbon composite materials," Advanced Materials Research, vol. 531, pp. 59-62, 2012.

[250] Z. Zhang, Y. Xu, X. Ma et al., "Microwave degradation of methyl orange dye in aqueous solution in the presence of nano$\mathrm{TiO}_{2}$-supported activated carbon (supported- $\mathrm{TiO}_{2} / \mathrm{AC} / \mathrm{MW}$ )," Journal of Hazardous Materials, vol. 209-210, pp. 271-277, 2012.

[251] W. Zhoa, J. Zhang, X. Zhu et al., "Enhanced nitrogen photofixation on Fe-doped $\mathrm{TiO}_{2}$ with highly exposed $\left(\begin{array}{lll}1 & 0 & 1\end{array}\right)$ facets in the presence of ethanol as scavenger," Applied Catalysis B: Environmental, vol. 144, pp. 468-477, 2014.

[252] M.-H. Baek, J.-W. Yoon, J.-S. Hong, and J.-K. Suh, "Application of $\mathrm{TiO}_{2}$-containing mesoporous spherical activated carbon in a fluidized bed photoreactor-adsorption and photocatalytic activity," Applied Catalysis A: General, vol. 450, pp. 222-229, 2013.
[253] P. Fu, Y. Luan, and X. Dai, "Preparation of activated carbon fibers supported $\mathrm{TiO}_{2}$ photocatalyst and evaluation of its photocatalytic reactivity," Journal of Molecular Catalysis A, vol. 221, no. 1, pp. 81-86, 2004.

[254] A. I. Adel, R. A. Geioushya, B. Houcine, A. A. Saleh, A.-H. Ali, and W. B. Detlef, " $\mathrm{TiO}_{2}$ decoration of graphene layers for highly efficient photocatalyst: Impact of calcination at different gas atmosphere on photocatalytic efficiency," Applied Catalysis B: Environmental, vol. 129, pp. 62-70, 2013.

[255] T. S. Jamil, M. Y. Ghaly, N. A. Fathy, T. A. Abd El-Halim, and L. Osterund, "Enhancement of $\mathrm{TiO}_{2}$ behavior on photocatalytic oxidation of $\mathrm{MO}$ dye using $\mathrm{TiO}_{2} / \mathrm{AC}$ under visible irradiation and sunlight radiation," Separation and Purification Technology, vol. 98, pp. 270-279, 2012.

[256] M. He and H. Xia, “ $\mathrm{TiO}_{2}$ /activated carbon fibers photocatalyst: effects of coating precedures on the microstructure, adhesion property and photocatalytic ability," Advanced Materials Research, vol. 518, p. 764, 2012.

[257] Q. Yang, Y. Liao, and L. Mao, "Kinetics of photocatalytic degradation of gaseous organic compounds on modified $\mathrm{TiO}_{2} / \mathrm{AC}$ composite photocatalyst," Chinese Journal of Chemical Engineering, vol. 20, no. 3, pp. 572-576, 2012.

[258] L.-Y. Hao, X.-X. Lin, D.-G. Fu, and X. Ji, "Photocatalytic properties of magnetic activated carbon supported F-doped $\mathrm{TiO}_{2}$," Journal of Inorganic Materials, vol. 28, pp. 997-1002, 2013.

[259] C.-Y. Kuo, C.-H. Wu, and S.-T. Chen, "Desalination and water treatment," In Press.

[260] M.-H. Baek, J.-S. Hong, J.-W. Yoon, and J.-K. Suh, "Photocatalytic degradation of humic acid by $\mathrm{Fe}-\mathrm{TiO}_{2}$ supported on spherical activated carbon with enhanced activity," International Journal of Photoenergy, vol. 2013, Article ID 296821, 5 pages, 2013.

[261] H.-J. Jung, J.-S. Hong, and J.-K. Suh, "A comparison of fenton oxidation and photocatalyst reaction efficiency for humic acid degradation," Journal of Industrial and Engineering Chemistry, vol. 19, no. 4, pp. 1325-1330, 2013.

[262] S. Li and G. Ye, "Photocatalytic degradation of formaldehyde by $\mathrm{TiO}_{2}$ nanoparticles immobilized in activated carbon fibers," Advanced Materials Research, vol. 482-484, pp. 2539-2542, 2012.

[263] S.-Y. Dong, F. Tian, X.-F. Pan, A.-X. Tian, C.-L. Ma, and T.L. Huang, "Preparation of oxygen-vacant $\mathrm{TiO}_{2-x}$ and activated carbon fiber composite using a single step thermal plasma method for low-concentration elemental mercury removal," Modern Chemical Industry, vol. 32, p. 55, 2012.

[264] S. M. Sun, "Enhancement of $\mathrm{TiO}_{2}$ behavior on photocatalytic oxidation of $\mathrm{MO}$ dye using $\mathrm{TiO}_{2} / \mathrm{AC}$ under visible irradiation and sunlight radiation," Applied Mechanics and Materials, vol. 485, p. 161, 2012.

[265] N. Riaz, F. K. Chong, B. K. Dutta, Z. B. Man, M. S. Khan, and E. Nurlaela, "Photodegradation of orange II under visible light using $\mathrm{Cu}-\mathrm{Ni} / \mathrm{TiO}_{2}$ : effect of calcination temperature," Chemical Engineering Journal, vol. 185-186, pp. 108-119, 2012.

[266] M. A. Gondal, C. Li, X. Chang et al., "Facile preparation of magnetic $\mathrm{C} / \mathrm{TiO}_{2} / \mathrm{Ni}$ composites and their photocatalytic performance for removal of a dye from water under UV light irradiation," Journal of Environmental Science and Health A, vol. 47, no. 4, pp. 570-576, 2012.

[267] W. Den and C.-C. Wang, "Enhancement of adsorptive chemical filters via titania photocatalysts to remove vapor-phase toluene and isopropanol," Separation and Purification Technology, vol. 85, pp. 101-111, 2012. 
[268] W. Zhou, P. Zhang, and W. Liu, "Decolarization of C.I Reactive Red 2 by $\mathrm{UV} / \mathrm{TiO}_{2} / \mathrm{PAC}$ and visible light/ $\mathrm{TiO}_{2} / \mathrm{PAC}$ system," International Journal of Photoenergy, Article ID 325902, 2012.

[269] S.-Y. Lu, Y.-L. Huang, Q.-L. Wang, X.-D. Li, and J.-H. Yan, "Photocatalytic degradation of gaseous 1,2-dichlorobenzene over $\mathrm{TiO}_{2} / \mathrm{AC}$ photocatalysts," Acta Physica, vol. 27, no. 9, p. 2191, 2011.

[270] X.-Y. Xing, D.-F. Zhao, G.-F. Zhu, and Y.-M. Liu, "Preparation of Ti-FAC composite photocatalyst by hydrothermal-sol impregnation method and its photocatalytic degradation of methylene blue in aqueous solution," Journal of Synthetic Crystals, vol. 40, p. 963, 2011.

[271] B. Tryba, A. W. Morawski, and M. Inagaki, "Application of $\mathrm{TiO}_{2}$ mounted activated carbon to the removal of phenol from water," Applied Catalysis B: Environmental, vol. 41, no. 4, pp. 427-433, 2003.

[272] Y. Gao and H. Liu, "Preparation and catalytic property study of a novel kind of suspended photocatalyst of $\mathrm{TiO}_{2}$-activated carbon immobilized on silicone rubber film," Materials Chemistry and Physics, vol. 92, no. 2-3, pp. 604-608, 2005.

[273] W. K. Jo, S. H. Shin, and E. S. Hwang, "Removal of dimethyl sulfide utilizing activated carbon fiber-supported photocatalyst in continuous-flow system," Journal of Hazardous Materials, vol. 191, no. 1-3, pp. 234-239, 2011.

[274] Y. Wang, Z. Hu, Y. Chen, G. Zhao, Y. Liu, and Z. Wen, "A novel approach towards high-performance composite photocatalyst of $\mathrm{TiO}_{2}$ deposited on activated carbon," Applied Surface Science, vol. 255, no. 7, pp. 3953-3958, 2009.

[275] H. Slimen, A. Houas, and J. P. Nogier, "Elaboration of stable anatase $\mathrm{TiO}_{2}$ through activated carbon addition with high photocatalytic activity under visible light," Journal of Photochemistry and Photobiology A: Chemistry, vol. 221, no. 1, pp. 1321, 2011.

[276] W. Li and S. Liu, "Bifunctional activated carbon with dual photocatalysis and adsorption capabilities for efficient phenol removal," Adsorption, vol. 18, no. 2, pp. 67-74, 2012.

[277] M. Janus, E. Kusiak, and A. W. Morawski, "Carbon modified $\mathrm{TiO}_{2}$ photocatalyst with enhanced adsorptivity for dyes from water," Catalysis Letters, vol. 131, no. 3-4, pp. 506-511, 2009.

[278] M. Janus, B. Tryba, M. Inagaki, and A. W. Morawski, "New preparation of a carbon- $\mathrm{TiO}_{2}$ photocatalyst by carbonization of $n$-hexane deposited on $\mathrm{TiO}_{2}$," Applied Catalysis B: Environmental, vol. 52, no. 1, pp. 61-67, 2004.

[279] D. D. Cui, J.-C. Jiang, K. Sun, and X.-C. Lu, "Photocatalytic degradation of gaseous 1,2-dicholorobenzene over $\mathrm{TiO}_{2} / \mathrm{AC}$ photocatalyst," Functional Materials, vol. 42, p. 438, 2011.

[280] M. Toyoda, T. Yano, T. Tomoki, Y. Amao, and M. Inagaki, "Effects of carbon coating on $\mathrm{Ti}_{n} \mathrm{O}_{2 n-i}$ for decomposition of iminoctadine triacetate in aqueous solution under visible light," Journal of Advanced Oxidation Technologies, vol. 9, no. 1, pp. 4952, 2006.

[281] M. Toyoda, Y. Nanbu, T. Kito, M. Hirano, and M. Inagaki, "Preparation and performance of anatase-loaded porous carbons for water purification," Desalination, vol. 159, no. 3, pp. 273-282, 2003.

[282] D. Huang, Y. Miyamoto, T. Matsumoto et al., "Preparation and characterization of high-surface-area $\mathrm{TiO}_{2}$ /activated carbon by low-temperature impregnation," Separation and Purification Technology, vol. 78, no. 1, pp. 9-15, 2011.

[283] A. Bolvin, S. Amellal, M. Schiavon, and M. T. Genuchten, "2,4Dichlorophenoxyacetic acid (2,4-D) sorption and degradation dynamics in three agricultural soils," Environmental Pollution, vol. 138, no. 1, pp. 92-99, 2005.

[284] U. Aruldoss, L. J. Kennedy, J. Judith Vijaya, and G. Sekaran, "Photocatalytic degradation of phenolic syntan using $\mathrm{TiO}_{2}$ impregnated activated carbon," Journal of Colloid and Interface Science, vol. 355, no. 1, pp. 204-209, 2011.

[285] M. V. Shankar, S. Anandan, N. Venkatachalam, B. Arabindoo, and V. Murugesan, "Fine route for an efficient removal of 2,4dichlorophenoxyacetic acid (2,4-D) by zeolite-supported $\mathrm{TiO}_{2}$," Chemosphere, vol. 63, no. 6, pp. 1014-1021, 2006.

[286] M. Cristina Yeber, J. Rodríguez, J. Freer, N. Durán, and H. D. Mansilla, "Photocatalytic degradation of cellulose bleaching effluent by supported $\mathrm{TiO}_{2}$ and $\mathrm{ZnO}$," Chemosphere, vol. 41, no. 8, pp. 1193-1197, 2000.

[287] K. Byrappa, A. K. Subramani, S. Ananda et al., "Impregnation of $\mathrm{ZnO}$ onto activated carbon under hydrothermal conditions and its photocatalytic properties," Journal of Materials Science, vol. 41, no. 5, pp. 1355-1362, 2006.

[288] J. Matos, E. Garcia-Lopez, L. Palmisano, A. Garcia, and G. Marci, "Influence of activated carbon in $\mathrm{TiO}_{2}$ and $\mathrm{ZnO}$ mediated photo-assisted degradation of 2-propanol in gas-solid regime," Applied Catalysis B: Environmental, vol. 99, no. 1-2, pp. 170-180, 2010.

[289] M. I. Litter and N. Quici, "Photochemical advanced oxidation processes for water and wastewater treatment," Recent Patents on Engineering, vol. 4, no. 3, pp. 217-241, 2010.

[290] S. H. Yao, Y. F. Jia, and S. L. Zhao, "Photocatalytic oxidation and removal of arsenite by titanium dioxide supported on granular activated carbon," Environmental Technology, vol. 33, pp. 983988, 2012.

[291] R. Jiang, H.-Y. Zhu, G.-M. Zeng, L. Xiao, and Y.-J. Guan, "Synergy of adsorption and visible light photocatalysis to decolor methyl orange by activated carbon/nanosized CdS/chitosan composite," Journal of Central South University of Technology, vol. 17, no. 6, pp. 1223-1229, 2010.

[292] S.-Y. Ye, Q.-M. Tian, X.-I. Song, and S.-C. Luo, "Photoelectrocatalytic degradation of ethylene by a combination of $\mathrm{TiO}_{2}$ and activated carbon felts," Journal of Photochemistry and Photobiology A, vol. 208, no. 1, pp. 27-35, 2009.

[293] S.-M. Lam, J.-C. Sin, and A. R. Mohamed, "Parameter effect on photocatalytic degradation of phenol using $\mathrm{TiO}_{2}-\mathrm{P} 25 /$ activated carbon (AC)," Korean Journal of Chemical Engineering, vol. 27, no. 4, pp. 1109-1116, 2010.

[294] K. M. Joshi and V. S. Shrivasta, "Removal of hazardious textile dyes from aqueous solution by using commercial activated carbon with $\mathrm{TiO}_{2}$ and ZNO as photocatalyst," International Journal of ChemTech Research, vol. 2, no. 1, pp. 427-435, 2010.

[295] J.-C. Sin, S.-M. Lam, and A. R. Mohamed, "Optimizing photocatalytic degradation of phenol by $\mathrm{TiO}_{2} / \mathrm{GAC}$ using response surface methodology," Korean Journal of Chemical Engineering, vol. 28, no. 1, pp. 84-92, 2011.

[296] Y. Zhang, Z.-R. Tang, X. Fu, and Y.-J. Xu, “TiO ${ }_{2}$-graphene nanocomposites for gas-phase photocatalytic degradation of volatile aromatic pollutant: is $\mathrm{TiO}_{2}$-graphene truly different from other $\mathrm{TiO}_{2}$-carbon composite materials?" ACS Nano, vol. 4, no. 12, pp. 7303-7314, 2010.

[297] X.-Y. Zhang, H.-P. Li, X.-L. Cui, and Y. Lin, “Graphene/ $/ \mathrm{TiO}_{2}$ nanocomposites: synthesis, characterization and application in hydrogen evolution from water photocatalytic splitting," Journal of Materials Chemistry, vol. 20, pp. 2801-2806, 2010. 
[298] K. Woan, G. Pyrgiotakis, and W. Sigmund, "Photocatalytic carbon-nanotube- $\mathrm{TiO}_{2}$ composites," Advanced Materials, vol. 21, no. 21, pp. 2233-2239, 2009.

[299] Y.-J. Xu, Y. Zhuang, and X. Fu, "New insight for enhanced photocatalytic activity of $\mathrm{TiO}_{2}$ by doping carbon nanotubes: a case study on degradation of benzene and methyl orange," The Journal of Physical Chemistry C, vol. 114, pp. 2669-2676, 2010.

[300] C.-Y. Yen, Y.-F. Lin, C.-H. Hung et al., "The effects of synthesis procedures on the morphology and photocatalytic activity of multi-walled carbon nanotubes $/ \mathrm{TiO}_{2}$ nanocomposites," Nanotechnology, vol. 19, no. 4, Article ID 045604, 2008.

[301] Y. Yu, J. C. Yu, J.-G. Yu et al., "Enhancement of photocatalytic activity of mesoporous $\mathrm{TiO}_{2}$ by using carbon nanotubes," Applied Catalysis A: General, vol. 289, no. 2, pp. 186-196, 2005.

[302] J.-W. Shi, H.-J. Cui, J.-W. Chen et al., “ $\mathrm{TiO}_{2} /$ activated carbon fibers photocatalyst: Effects of coating procedures on the microstructure, adhesion property, and photocatalytic ability," Journal of Colloid and Interface Science, vol. 388, pp. 201-208, 2012.

[303] Z.-H. Liao, J.-J. Chen, K. F. Yao, F. H. Zhao, and R.-X. Li, "Progress of nanometer-TiO $\mathrm{T}_{2}$ photocatalyst immobilization," Journal of Inorganic Materials, vol. 19, no. 1, 2004.

[304] Y. Li, S. Sun, M. Ma, Y. Ouyang, and W. Yan, "Kinetic study and model of the photocatalytic degradation of rhodamine $\mathrm{B}(\mathrm{RhB})$ by a $\mathrm{TiO}_{2}$-coated activated carbon catalyst: effects of initial RhB content, light intensity and $\mathrm{TiO}_{2}$ content in the catalyst," Chemical Engineering Journal, vol. 142, no. 2, pp. 147-155, 2008.

[305] Y. Ao, J. Xu, D. Fu, L. Ba, and C. Yuan, "Deposition of anatase titania onto carbon encapsulated magnetite nanoparticles," Nanotechnology, vol. 19, no. 40, Article ID 405604, 2008.

[306] X. Hong, Z. Wang, W. Cai et al., "Visible-light-activated nanoparticle photocatalyst of iodine-doped titanium dioxide," Chemistry of Materials, vol. 17, no. 6, pp. 1548-1552, 2005.

[307] X.-X. Lin, X. Ji, D.-G. Fu, and L.-Y. Hao, "Photocatalytic properties of magnetic activated carbon supported F-doped $\mathrm{TiO}_{2}$," International Journal of Inorganic Materials, vol. 28, no. 9, pp. 997-1002, 2013.

[308] D. Huang, Y. Miyamoto, J. Ding et al., "A new method to prepare high-surface-area $\mathrm{N}-\mathrm{TiO}_{2}$ /activated carbon," Materials Letters, vol. 65, no. 2, pp. 326-328, 2011. 

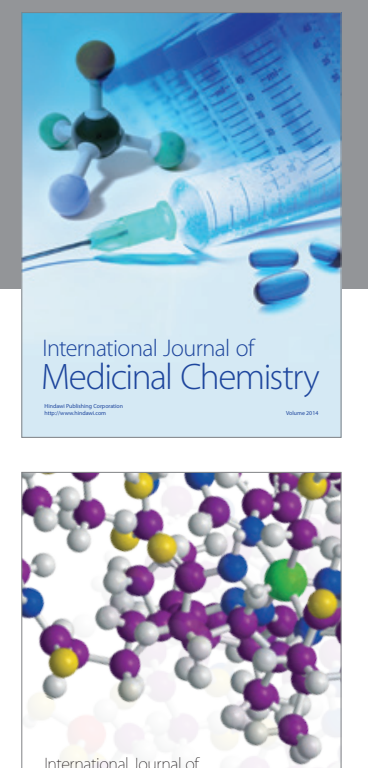

\section{Carbohydrate} Chemistry

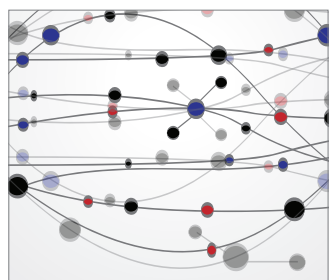

The Scientific World Journal
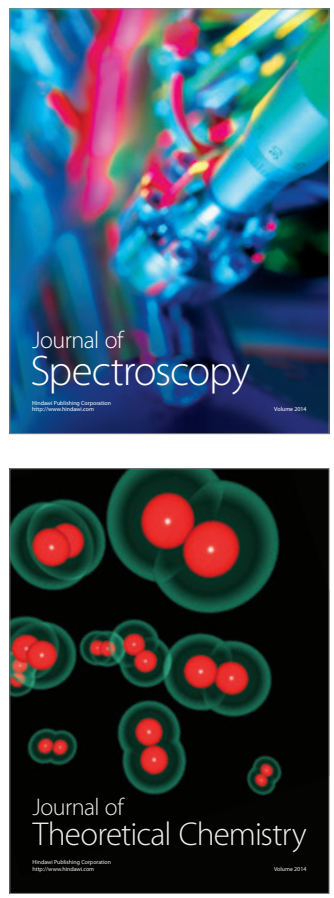
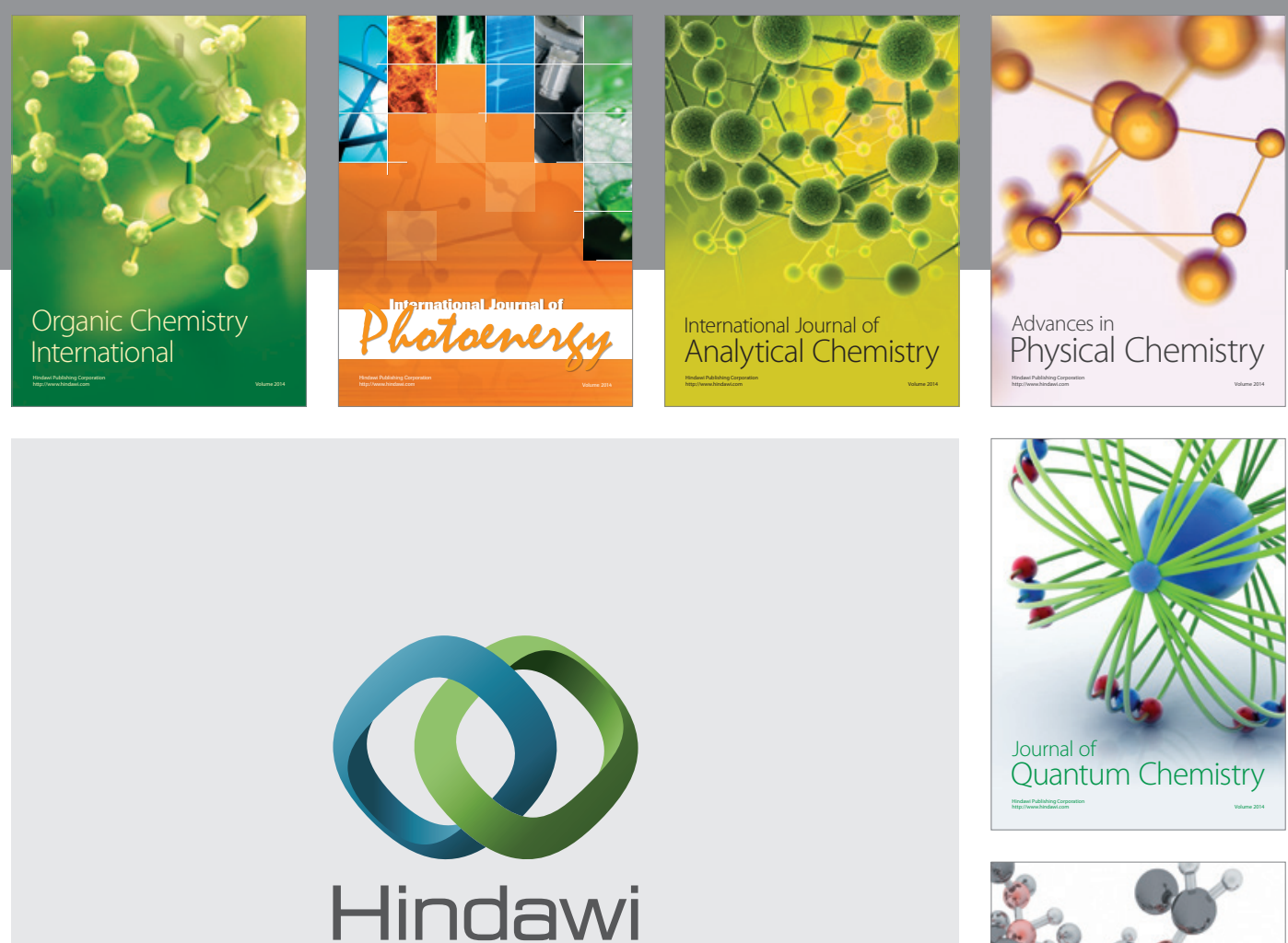

Submit your manuscripts at

http://www.hindawi.com

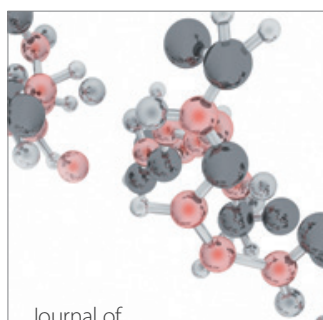

Analytical Methods

in Chemistry

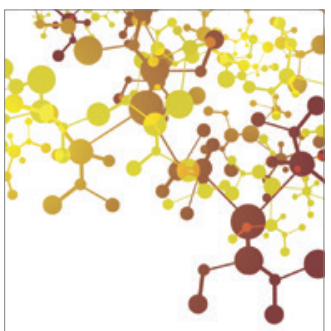

Journal of

Applied Chemistry

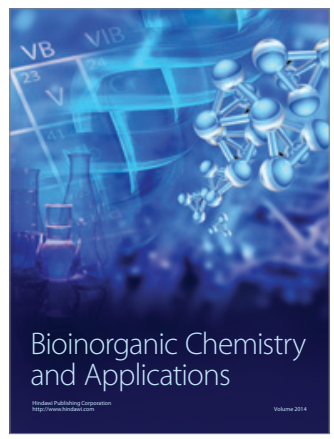

Inorganic Chemistry
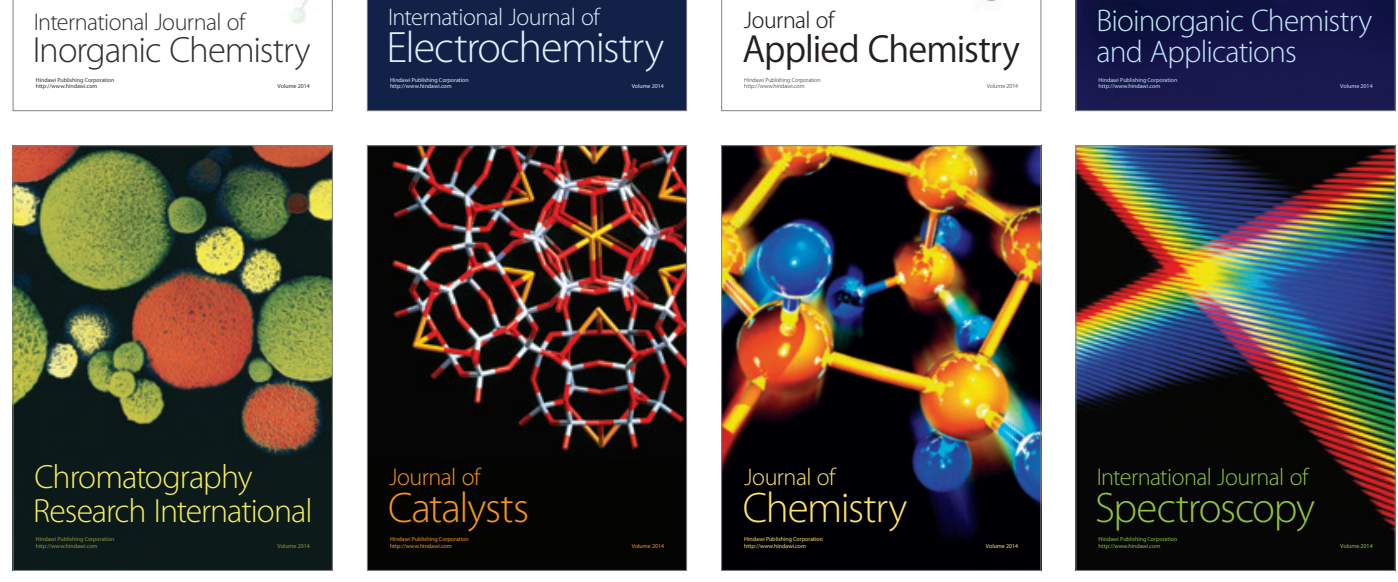